University of Tennessee Health Science Center

UTHSC Digital Commons

\title{
A Survey of Treatment Characteristics in a University-based Graduate Orthodontic Program
}

\author{
A. Brian Anderson \\ University of Tennessee Health Science Center
}

Follow this and additional works at: https://dc.uthsc.edu/dissertations

Part of the Orthodontics and Orthodontology Commons

\section{Recommended Citation}

Anderson, A. Brian , "A Survey of Treatment Characteristics in a University-based Graduate Orthodontic Program" (2010). Theses and Dissertations (ETD). Paper 15. http://dx.doi.org/10.21007/ etd.cghs.2010.0014.

This Thesis is brought to you for free and open access by the College of Graduate Health Sciences at UTHSC Digital Commons. It has been accepted for inclusion in Theses and Dissertations (ETD) by an authorized administrator of UTHSC Digital Commons. For more information, please contact jwelch30@uthsc.edu. 


\title{
A Survey of Treatment Characteristics in a University-based Graduate Orthodontic Program
}

\begin{abstract}
While there are a few national surveys on malocclusion in the U.S., few reports characterize actual orthodontic patients and their treatments. The purpose of this study was to describe the patients and their treatment at a university based orthodontic department, namely the University of Tennessee Health Science Center, Memphis. The goals of this study are: (1) to research patient demographics, dental and skeletal relationships and treatment variables; (2) to test for temporal trends in these patients and their treatment across a 26 year interval from 1980 to 2005; and (3) to assess the correlations among patient demographics, dental and skeletal relationships, and treatment variables. Data were collected from 1,500 patient records chosen at random from all cases. Girls represent $60 \%$ of the overall sample, a percentage that did not change over time. This preponderance of females is driven by greater perception of need, not more prevalent or more severe malocclusions. Non-White races have increased in the patient population, suggesting slow improvement of their chronic under-representation. Patients treated with orthognathic surgery account for $2 \%$ of overall cases, but this percentage decreased over the time interval. The mean starting age of child and adolescent patients was 13.4 years. Over time, the average patient age increased, reflecting more adult patients. Extraction cases of all types decreased over time from above $70 \%$ down to below $50 \%$ of cases. Over this same time, treatment duration has decreased, and more Angle Class I patients are being treated compared to Class II cases. Causes are multifactorial, but people with simpler malocclusions seeking treatment seem to be one factor. Non-extraction treatment was only found to be of shorter duration when compared to extraction of (4-4/4-4), (4-4/5-5), and (4-4/0-0); no other extraction pattern involving premolars was found to be of longer duration than non-extraction, and treatment duration difference between all extraction patterns were not significant. This survey provides a unique insight into the patient population and treatment and how these have changed over time and not only adds to the orthodontic literature, but serves a useful "audit" of treatment at The University of Tennessee Graduate Orthodontic Clinic.
\end{abstract}

\section{Document Type}

Thesis

\section{Degree Name}

Master of Dental Science (MDS)

\section{Program}

Orthodontics

\section{Research Advisor}

Edward F. Harris, Ph.D.

\section{Keywords}

Orthodontics

\section{Subject Categories}

Dentistry | Orthodontics and Orthodontology 


\title{
A SURVEY OF TREATMENT CHARACTERISTICS IN A UNIVERSITY- BASED GRADUATE ORTHODONTIC PROGRAM
}

\author{
A Thesis \\ Presented for \\ The Graduate Studies Council \\ The University of Tennessee \\ Health Science Center
}

\begin{abstract}
In Partial Fulfillment
Of the Requirements for the Degree

Master of Dental Science

From the University of Tennessee
\end{abstract}

By

A. Brian Anderson

May 2010 
Copyright $(\subseteq 2010$ by A. Brian Anderson All rights reserved 


\section{DEDICATION}

I would like to dedicate this thesis to my parents, who have provided continued love and support throughout my life. They have taught me that with hard work and perseverance you can accomplish anything. Thank you, Mom and Dad, for everything. 


\section{ACKNOWLEDGEMENTS}

I would like to thank my thesis committee chairman, Dr. Edward F. Harris, for his help, support, and true patience with me in working on this project. Without his guidance this experience would not have been possible. I would also like to thank Dr. Richard A. Williams, and Dr. Jere L. Yates, the other committee members for their valuable input and guidance during this process. 


\begin{abstract}
While there are a few national surveys on malocclusion in the U.S., few reports characterize actual orthodontic patients and their treatments. The purpose of this study was to describe the patients and their treatment at a university based orthodontic department, namely the University of Tennessee Health Science Center, Memphis. The goals of this study are: (1) to research patient demographics, dental and skeletal relationships and treatment variables; (2) to test for temporal trends in these patients and their treatment across a 26 year interval from 1980 to 2005; and (3) to assess the correlations among patient demographics, dental and skeletal relationships, and treatment variables. Data were collected from 1,500 patient records chosen at random from all cases. Girls represent $60 \%$ of the overall sample, a percentage that did not change over time. This preponderance of females is driven by greater perception of need, not more prevalent or more severe malocclusions. Non-White races have increased in the patient population, suggesting slow improvement of their chronic underrepresentation. Patients treated with orthognathic surgery account for $2 \%$ of overall cases, but this percentage decreased over the time interval. The mean starting age of child and adolescent patients was 13.4 years. Over time, the average patient age increased, reflecting more adult patients. Extraction cases of all types decreased over time from above $70 \%$ down to below $50 \%$ of cases. Over this same time, treatment duration has decreased, and more Angle Class I patients are being treated compared to Class II cases. Causes are multifactorial, but people with simpler malocclusions seeking treatment seem to be one factor. Non-extraction treatment was only found to be of shorter duration when compared to extraction of (4-4/4-4), (4-4/5-5), and (4-4/0-0); no other extraction pattern involving premolars was found to be of longer duration than nonextraction, and treatment duration difference between all extraction patterns were not significant. This survey provides a unique insight into the patient population and treatment and how these have changed over time and not only adds to the orthodontic literature, but serves a useful "audit" of treatment at The University of Tennessee Graduate Orthodontic Clinic.
\end{abstract}




\section{TABLE OF CONTENTS}

CHAPTER I: INTRODUCTION AND RATIONALE............................................... 1

CHAPTER II: REVIEW OF THE LITERATURE....................................................... 3

Reasons Patients Seek Orthodontic Treatment...................................................... 3

Sex Differences and Malocclusion .................................................................... 4

Sex Differences and Orthodontic Treatment and Need ........................................ 5

Racial Differences in Malocclusion and Treatment Need ...................................... 8

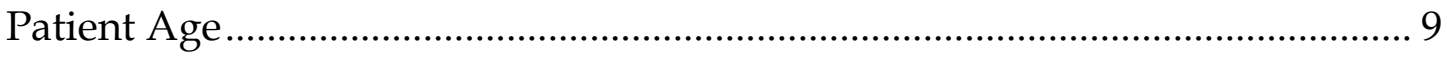

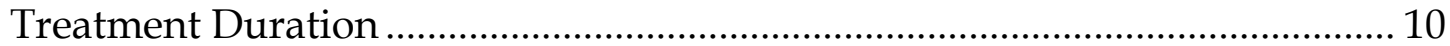

Extractions in Orthodontic Treatment ............................................................... 11

Angle's Molar Classification ............................................................................. 13

CHAPTER III: MATERIALS AND METHODS .................................................. 15

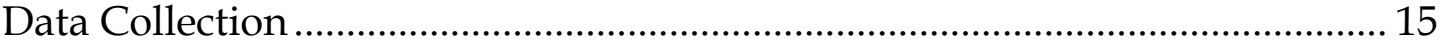

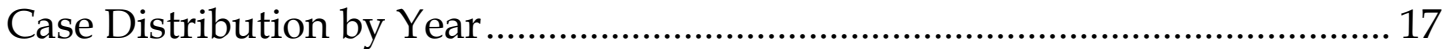

Statistical Analysis …………………………………….................................. 17

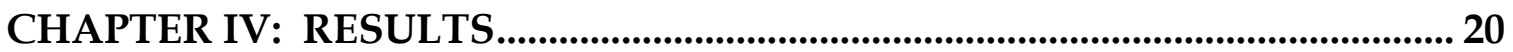

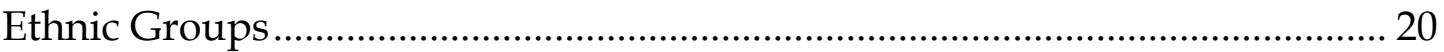

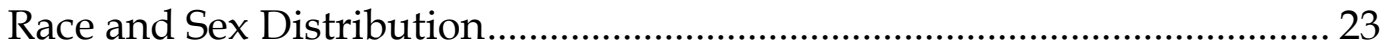

Race and Subsidized Treatment ................................................................. 23

Race and Orthognathic Surgery …………….............................................. 23

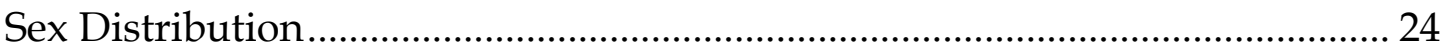

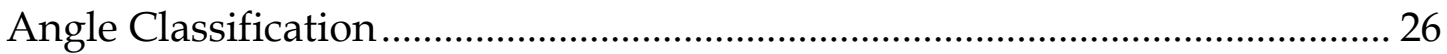

Angle Classification, Race, and Sex............................................................... 30

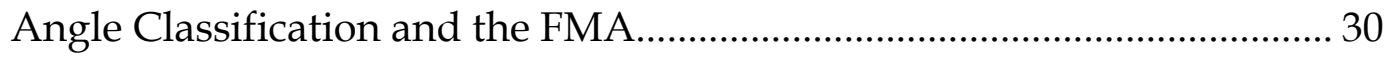

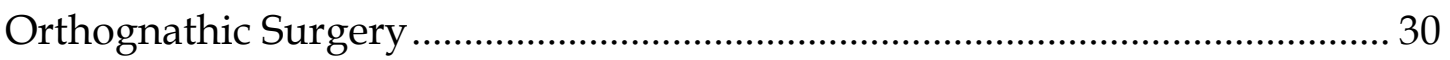

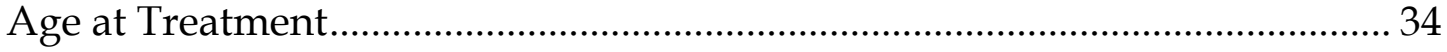

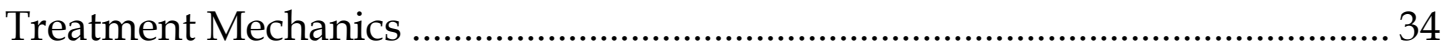

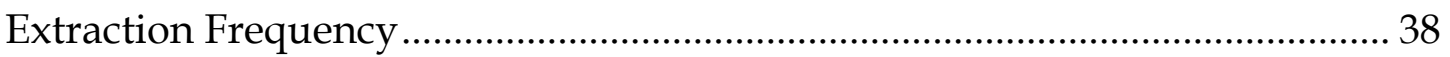

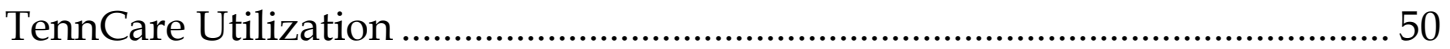

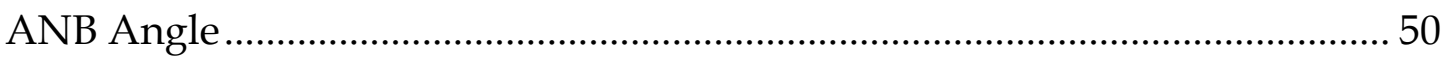

Frankfort Mandibular Plane Angle ................................................................ 56

Duration of Treatment................................................................................... 56

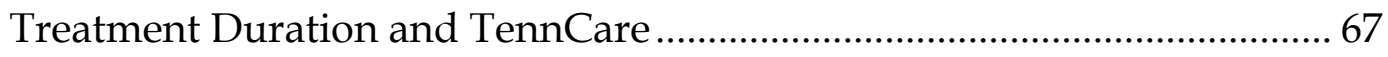

Treatment Duration, Angle Class and Extraction ............................................ 67

Treatment Duration and the FMA and ANB Angle ...................................... 69

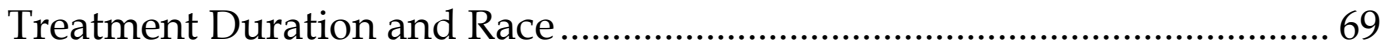


CHAPTER V: DISCUSSION …….......................................................................... 73

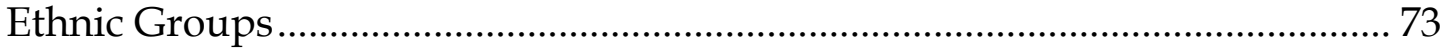

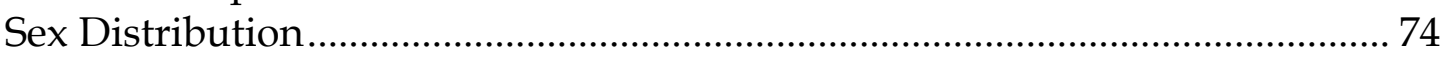

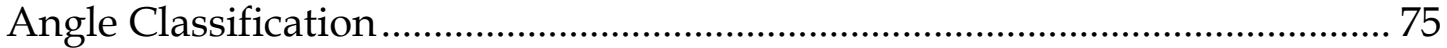

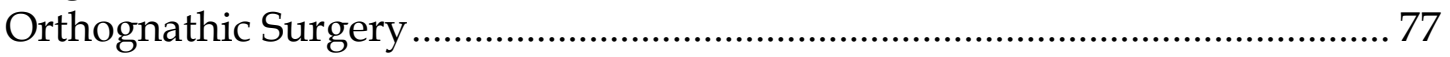

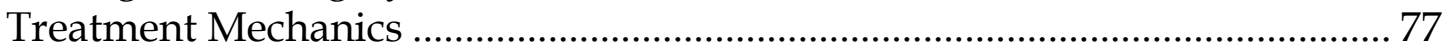

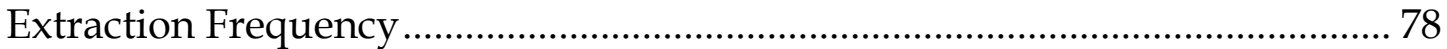

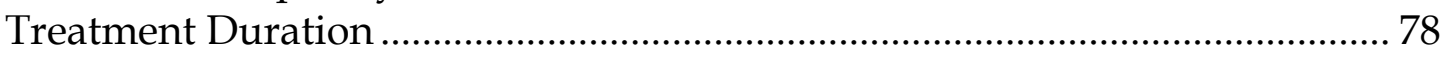

CHAPTER VI: SUMMARY AND CONCLUSIONS ............................................. 81

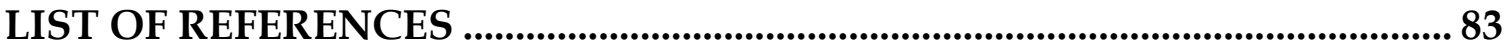

VITA 


\section{LIST OF TABLES}

Table 1. Proportions of the total sample by race or ethnic group $(n=1,612) \ldots . .20$

Table 2. Results of logistic regression testing for a significant change in proportions of Blacks and Whites between 1980 and 2005.

Table 3. Results of logistic regression testing for a significant change in proportions of other patients and Whites between 1980 and 2005........22

Table 4. Results of logistic regression testing for a significant change in proportions of boys and girls between 1980 and 2005

Table 5. Results of logistic regression testing for a significant change in proportions of Angle Class I and II patients between 1980 and 2005...27

Table 6. Results of logistic regression testing for a significant change in proportions of Angle Class I and III patients between 1980 and 2005

Table 7. Results of logistic regression testing for a significant change in proportions of Angle Class II and III patients between 1980 and 2005

Table 8. Results of logistic regression testing for a significant change in proportions of surgery and non-surgery patients between 1980 and 2005.

Table 9. Results of bivariate fit testing for a significant change in the start age over the quarter century surveyed.

Table 10. Results of logistic regression testing for a significant change in proportions of treatment mechanics for standard edgewise and straight-wire edgewise cases treated between 1980 and 2005

Table 11. Results of logistic regression testing for a significant change in proportions of treatment mechanics for Begg and standard edgewise cases treated between 1980 and 2005 .

Table 12. Results of logistic regression testing for a significant change in proportions of treatment mechanics for Begg and straight-wire edgewise cases treated between 1980 and 2005 .

Table 13. Results of logistic regression testing for a significant change in proportions of extraction and non-extraction for all cases treated between 1980 and 2005.

Table 14. Results of logistic regression testing for a significant change in proportions of extraction and non-extraction for Begg cases treated between 1980 and 2005

Table 15. Results of logistic regression testing for a significant change in proportions of extraction and non-extraction for standard edgewise cases treated between 1980 and 2005. 
Table 16. Results of logistic regression testing for a significant change in proportions of extraction and non-extraction for straight-wire edgewise cases treated between 1980 and 2005 ......

Table 17. Results of logistic regression testing for a significant change in proportions of four premolar extraction and non-extraction for all edgewise cases treated between 1980 and 2005.

Table 18. Results of logistic regression testing for a significant change in proportions of two premolar extraction and non-extraction for all edgewise cases treated between 1980 and 2005.

Table 19. Results of logistic regression testing for a significant change in proportions of four premolar extraction and two premolar extraction for all edgewise cases treated between 1980 and 2005.

Table 20. Results of logistic regression testing for a significant change in proportions of TennCare cases and non-TennCare cases treated between 1980 and 2005 .

Table 21. Results of logistic regression testing for a significant change in proportions of TennCare cases and non-TennCare cases treated between 2000 and 2005.

Table 22. Results of bivariate fit testing for a significant change in the ANB angle over the quarter century surveyed.

Table 23. Results of bivariate fit testing for a significant change in the FMA in all patients over the quarter century surveyed.

Table 24. Results of bivariate fit testing for a significant change in the FMA in White patients over the quarter century surveyed.

Table 25. Results of bivariate fit testing for a significant change in the FMA in Black patients over the quarter century surveyed.

Table 26. Results of bivariate fit testing for a significant change in the FMA in "other" patients over the quarter century surveyed.

Table 27. Results of bivariate fit testing for a significant change in time in treatment over the quarter century surveyed.

Table 28. Results of bivariate fit testing for a significant change in time in treatment for Begg cases over the quarter century surveyed.

Table 29. Results of bivariate fit testing for a significant change in time in treatment for standard edgewise cases over the quarter century surveyed.

Table 30. Results of bivariate fit testing for a significant change in time in treatment for straight-wire cases over the quarter century surveyed...66

Table 31. Results of bivariate fit testing for a significant change in time in treatment by ANB angle ...........................................................................

Table 32. Results of bivariate fit testing for a significant change in time in treatment by the FMA

Table 33. Proportions of the total sample by race compared with the respective proportions in the population of the city of Memphis .73 
Table 34. Proportions of Angle Class from various studies ....................................76 


\section{LIST OF FIGURES}

Figure 1. Counts of cases studied distributed by the year the case was started

Figure 2. Plot generated by a logistic fit of race (defined as Black or White) against the year the case was started

Figure 3. Plot generated by a logistic fit of race (defined as White or other) against the year the case was started .......................................................22

Figure 4. Frequency of boys compared to girls in all years, 1980 to 2005 ..........24

Figure 5. Plot generated by a logistic fit of sex against the year the case was

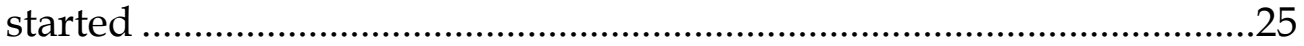

Figure 6. Frequency of molar classification (Angle) in all patients $(\mathrm{n}=$ $5,255)$ .26

Figure 7. Plot generated by a logistic fit of Angle Class I and II cases against the year the case was started

Figure 8. Plot generated by a logistic fit of Angle Class I and III cases against the year the case was started .28

Figure 9. Plot generated by a logistic fit of Angle Class II and III cases against the year the case was started

Figure 10. Mosaic chart showing percentage of Angle Class by race (as defined as Black or White).

Figure 11. Frequency of molar classification (Angle) in Black patients..................31

Figure 12. Frequency of molar classification (Angle) in White patients ................32

Figure 13. Plot of the frequency of surgical cases as a function of start dates......33

Figure 14. Plot of ages at the start of treatment (years) for all patients in the sample

Figure 15. Plot of ages at the start of treatment (years) for patients age 6 to 17 (sexes and races pooled)

Figure 16. Plot of ages at the start of treatment (years) for patients age 18 and older (sexes and races pooled)

Figure 17. Plot generated by bivariate fit between the year of case start against patient start age for all cases.

Figure 18. Histogram showing the number of cases treated with Begg, standard edgewise and straight-wire edgewise mechanics over the 26 years surveyed.....

Figure 19. Histogram showing the number of cases treated with standard edgewise and straight-wire edgewise mechanics only (excluding Begg) over the 26 years surveyed.

Figure 20. Plot generated by logistic analysis of treatment mechanics (standard edgewise, straight-wire) against the year the case was started 
Figure 21. Plot generated by logistic analysis of treatment mechanics (Begg, standard edgewise) against the year the case was started......

Figure 22. Plot generated by logistic analysis of treatment mechanics (Begg, straight-wire) against the year the case was started.

Figure 23. Plot generated by logistic analysis of extraction category against the year the case was started for all cases.

Figure 24. Plot generated by logistic analysis of extraction category against the year the case was started for Begg mechanics only.

Figure 25. Plot generated by logistic analysis of extraction category against the year the case was started for standard edgewise mechanics only.....

Figure 26. Plot generated by logistic analysis of extraction category against the year the case was started for straight-wire edgewise mechanics only.

Figure 27. Plot generated by logistic analysis of extraction category (Non-X, 4-Pre) against the year the case was started for standard edgewise and straight-wire edgewise mechanics.

Figure 28. Plot generated by logistic analysis of extraction category (Non-X, 2-Pre) against the year the case was started for standard edgewise and straight-wire edgewise mechanics.

Figure 29. Plot generated by logistic analysis of extraction category (4-Pre, 2-Pre) against the year the case was started for standard edgewise and straight-wire edgewise mechanics.

Figure 30. Mosaic plot showing frequency of extraction by Angle classification

Figure 31. Plot generated by logistic analysis of whether or not a patient had TennCare against the year the case was started for all years .52

Figure 32. Plot generated by logistic analysis of whether or not a patient had TennCare against the year the case was started for 2000 to 2005.

Figure 33. Histogram showing the distribution of ANB angles in the quarter-century surveyed.

Figure 34. Plot generated by bivariate fit of ANB angle by start year for all cases..

Figure 35. Histogram showing the distribution of the FMA in the quartercentury surveyed.

Figure 36. Plot generated by bivariate fit of FMA by start year for all cases........58

Figure 37. Plot generated by bivariate fit of FMA by start year for White patients only.

Figure 38. Plot generated by bivariate fit of FMA by start year for Black patients only

Figure 39. Plot generated by bivariate fit of FMA by start year for "other" patients only 
Figure 40. Plot of time in treatment by mechanics

Figure 41. Plot generated by bivariate fit between the year of case start against time in treatment for all cases.

Figure 42. Plot generated by bivariate fit of time in treatment by start year for Begg cases only....

Figure 43. Plot generated by bivariate fit of time in treatment by start year for standard edgewise cases only.

Figure 44. Plot generated by bivariate fit of time in treatment by start year for straight-wire cases only .66

Figure 45. Plot of time in treatment by whether or not the patient had TennCare .68

Figure 46. Mean treatment times for Begg, standard edgewise, and straightwire edgewise mechanics by Angle class.

Figure 47. Plot generated by bivariate fit of time in treatment by ANB angle.....70 Figure 48. Plot generated by bivariate fit of time in treatment by the FMA.........71

Figure 49. Plot of time in treatment by race. 


\section{CHAPTER I: INTRODUCTION AND RATIONALE}

Malocclusion is common in the United States and other developed countries, with most children in the U.S. population warranting orthodontic treatment (Kelly and Harvey 1977; Brunelle et al. 1996). Misaligned teeth negatively impact an individual's quality of life in areas such as mastication, speech, and probably most importantly one's appearance along with other psychological and social ramifications (Birkeland et al. 1996; Zhang et al. 2006). Not all people who could benefit from orthodontic treatment actually seek treatment, but more than $30 \%$ of White, $11 \%$ of Hispanics, and $8 \%$ of Black young Americans have reported having had some form of orthodontic treatment (Proffit et al. 1998).

There are few reports in the literature characterizing orthodontic patient samples and their treatments. While there have been three national surveys of the U.S. population (most recently Brunelle et al. 1996), these do not address the nature of the subpopulation of people actually treated orthodontically. There are in fact, few data on (A) the sex ratio of patients, (B) the age distribution of patients, (C) the classification of patients (Angle), or what percentage of the patient pool is treated in the mixed dentition versus the early permanent dentition versus adulthood. Virtually all claims of patient composition and of patient trends over time (e.g., an increase in adult patients) are anecdotal. The Journal of Clinical Orthodontics publishes surveys of Orthodontic practices (e.g., Keim 2005), but these queries address issues of practice management (e.g., income, brackets utilized, appliance type) rather than estimates of the patient composition.

As noted by Proffit (1994), a university-based orthodontic does not perfectly reflect treatment happening regionally or nationally. However, a large mix of faculty treating a large patient population roughly reflects patient populations and treatment techniques in private practice. Fundamental data are so sparse concerning who is receiving orthodontic treatment, that efforts in this direction are warranted.

The purpose of the present study is to describe the patient characteristics and their treatment at one university based graduate orthodontic teaching institution, namely The University of Tennessee Health Science Center, Memphis. Information from such a high volume "practice" with diagnosis and treatment from numerous faculty specialists provides a composite baseline that incorporates more treatment perspectives than seen in any given private practice. Of course, there are some inherent differences, such as an urban setting, lower fees (and longer appointment times), and selection for "good teaching cases" (i.e., 
more complex malocclusions), but these would seem to be offset by the opportunity to sample the large mix of specialists' treatment protocols.

The goals of this study were: (1) to research patient demographics, dental and skeletal relationships, and treatment variables; (2) to test for temporal trends in these patients and their treatment over a 26 year time period from 1980 to 2005; and (3) to determine if any correlations exist between patient demographics, dental or skeletal relationships, or treatment variables. 


\section{CHAPTER II: REVIEW OF THE LITERATURE}

\section{$\underline{\text { Reasons Patients Seek Orthodontic Treatment }}$}

Patients, and their parents, seek orthodontic treatment for a variety of reasons, and ultimately, a combination of factors determines whether treatment will be pursued. Dental health appears to be less of a priority to patients than esthetic concerns when deciding on orthodontic care, even if a significant disability exists (Jenny 1975). Patients seeking treatment do so for primarily esthetic reasons, with demand often based on psychological rather than functional factors (Prahl-Andersen 1978; Albino 1984). Patients have rated improved appearance as the "number one" benefit of treatment with dental health rated as second, and they actually would rather have straight teeth than healthy teeth (Shaw 1991).

Socio-cultural norms of esthetics often determine whether an individual will seek care. Children and their parents want to be perceived as "normal" (Jenny 1975), and orthodontic treatment is seen as a way to enhance an individual's social acceptance and self esteem (Shaw 1981). Peer relationships and first impressions are often based on one's physical appearance (Albino 1984), and attractive children are rated as more nice and more intelligent than their non-attractive counterparts. Among college students, appearance was found to be the only other factor besides "short acquaintanceships" to be consistently related to popularity (Prahl-Andersen 1978). Children who are taunted by others about their teeth reported higher dissatisfaction with their dental appearance and expressed a greater need for orthodontic treatment than those who did not report such harassment (Shaw 1981).

A higher percentage of girls receive orthodontic treatment than boys due to social and psychological differences between the sexes. In one report, girls had a higher dissatisfaction with their dental appearance than boys, with $68 \%$ of girls reporting dissatisfaction compared to $32 \%$ of boys (Shaw 1981). Also of interest, $75 \%$ of girls in a study by Cavior rated themselves as the least attractive in their class (Shaw 1981). In a British population of 11 to 14 year olds, girls had higher Child Perception Questionnaire scores than boys; they report a higher impact of malocclusion on emotional well being; and they expressed a greater desire for orthodontic treatment ( $\mathrm{O}^{\prime}$ Brien et al. 2006). Latvian girls answering a questionnaire reported that they had a need for orthodontics and were dissatisfied with their dental appearance more than Latvian boys did, even though the orthodontic need between the two groups was not different (Liepa et al. 2003). Shaw (1991) stated that the reason more girls than boys receive orthodontic care is due to sex role stereotyping, where society places a greater 
importance on female physical attractiveness compared to that of males.

Prahl-Andersen (1978) noted that attractive females used in commercial advertising have contributed to the norms for beauty, and these models are the best sales promotions available to the orthodontist due to their promotion of beauty as the norm. An antiquated, but still possibly highly pervasive cultural thought, is that while an attractive man can seek out an attractive wife, an unattractive man can find an attractive wife given certain compensations such as money. An unattractive woman may not have such options when finding a husband (Prahl-Andersen 1978). Some parents may believe this to be true and be more inclined to provide orthodontic treatment for daughters rather than sons.

\section{Sex Differences and Malocclusion}

Research on the occlusion of young people in the United States ages 12 to 17 from the National Health Examination Survey Cycle III (NHES III, 1966-1970) evaluated the incidence and severity of malocclusion using the Treatment Priority Index (Grainger 1967) and five specific components of malocclusion. Vertical overbite, overjet, posterior crossbite, tooth displacement and buccal segment relation were analyzed. The sample size of the study consisted of 7,500 youths who were selected to represent the youth of the continental United States as a whole. There was no statistical difference between males and females in any of the specific components of malocclusion. So too, there was no sex difference in the overall score of the malocclusion using the Treatment Priority Index (Kelly and Harvey 1977).

More recently, research on occlusion was conducted using the data from the Third National Health and Nutrition Examination Survey (NHANES III) collected in 1988 to 1991 on 7,000 people ages 8 to 50 years (Brunelle et al. 1996). This research did not look at an overall score of malocclusion (such had been done in the NHES III with the TPI) but, rather, at five individual components, namely incisor alignment, midline diastema, posterior crossbite, overjet, and overbite. The authors described these components as "disassociated" measures of malocclusion. Significant sex differences were not found in the categories of posterior crossbite, overjet, or overbite, but did exist in categories of anterior alignment and midline diastema, with males having a greater degree of malocclusion in these categories. Mean alignment scores show males having more crowding in the mandibular arch with males mean of $2.9 \mathrm{~mm}$ and females having a mean of $2.6 \mathrm{~mm}$. The prevalence of a midline diastema $\geq 2 \mathrm{~mm}$ was present in $7.7 \%$ of males and in $5.3 \%$ of females (Brunelle et al. 1996). More females than males had received orthodontic treatment in this study, which would at least partly explain these small sex differences in the prevalence of 
malocclusion because adolescents in treatment (or having completed treatment) were omitted from the analysis.

In a sample of 810 Italian school children (ages 11 to 14 years), the individual components of malocclusion of overjet, overbite, openbite, anterior and posterior crossbites, crowding, coincidence of the upper and lower midlines and diastema were measured (Ciufflo et al. 2005). Boys had an increased prevalence and increased mean value of overbite compared to girls, while the other measured components were the same between the sexes (Ciufflo et al. 2005).

Massler and Frankel (1951) looked at the occlusions of 2,758 U.S. high school students (ages 14 to 18 years) and measured variations of individual teeth from their ideal or normal relationships. Boys were affected slightly more often than girls by malocclusion at all age levels, with $4.4 \%$ more boys affected than girls. Boys also had a slightly higher number of maloccluded teeth than girls, with 10.96 per boy compared to 10.22 per girl. Of note, however, Sex differences in this study were not significant statistically (Massler and Frankel 1951).

Other studies on sex differences and malocclusion exist but almost none have samples as large as the ones just mentioned. Research has shown that, although males do have larger mesiodistal tooth sizes and arch dimensions than females, there is no sex difference in the risk or severity of malocclusion (Arya et al. 1974) because their arch and palate dimensions also are larger.

\section{$\underline{\text { Sex Differences and Orthodontic Treatment and Need }}$}

The NHES III data extrapolated to 2.4 million Americans ages 12 to 17 years show that significantly more females than males had received orthodontic treatment; $11.8 \%$ of girls and $9.6 \%$ of boys reported receiving orthodontic treatment of some kind. Parents of the surveyed adolescents who had not received orthodontic treatment were asked whether their child needed orthodontic treatment. Fewer parents of White male children reported that their sons needed treatment $(9.6 \%)$ than the parents of daughters $(13.3 \%)$. This sex difference also existed, in Blacks but to a lesser degree than in Whites.

The TPI scores of the children who were reported by their parents as having a need for orthodontics were different between boys and girls. The mean TPI score of Whites whose parents said they needed treatment was 7.6 for girls, but 8.9 for boys. Parents of untreated White girls who had been told by their dentist of their child's need for orthodontic treatment had an average TPI score of 7.8, while the boys who were told that they needed to see the orthodontist had 
an average TPI score of 9.5. In contrast, there was no significant difference between the TPI scores of untreated Black boys and girls whose parents said that they needed orthodontic treatment or were told by a dentist that they needed treatment. Parents and dentists of White youths perceive a different level of malocclusion at which they see the need for treatment, with dentists having an even greater difference between the sexes than the parents. There was no sex difference in the self-perceived need for orthodontics in the children of NHES III. The percentage of children who said that they needed orthodontic treatment was 18\%, with girls and boys responding about equally (Kelly and Harvey 1977).

In the data from NHANES III, a greater percentage of girls than boys had received orthodontic treatment: $20.5 \%$ of girls and $16.4 \%$ of boys had received treatment in the 8 to 17 age group and $22.7 \%$ of women and $14.2 \%$ of men in the 18 to 50 age interval. A lower percentage of males received orthodontic treatment compared to females in both age groups, but the difference may be declining. More boys and fewer girls in the younger age group are receiving treatment when compared to the older age group (Brunelle et al. 1996). This declining difference suggests changing attitudes in regards to sex differences in the perceived need for orthodontic treatment.

In a study of third and fourth grade school children in Florida $(n=3,696)$, $9.5 \%$ of the girls were receiving orthodontic treatment compared to $6.8 \%$ of the boys (Wheeler et al. 1994). Using the Index of Orthodontic Treatment and Need (IOTN), Wheeler and coworkers showed that more boys needed orthodontic treatment than girls, with boys having a $44.2 \%$ need and girls having a $41.8 \%$ need. With the definition of demand used in their study (i.e., those currently in orthodontic treatment) this would make sense because more girls are currently in treatment and therefore would not be included in the "need" group.

Based on a review of 5,350 orthodontic cases treated in the Department of Orthodontics at The University of Tennessee Health Science Center, $40 \%$ of the patients are boys and $60 \%$ are girls, which, statistically, is a hugely biased sex ratio (Harris, unpublished data). In other words, girls are 1.5 times as likely as boys to be treated in this university setting. Of note, minor malocclusions are omitted from this graduate clinic population since prospective patients are screened for "good teaching cases" that would benefit from comprehensive rather than limited treatment. Other studies also found a 6 to 4 ratio of girls to boys. In a survey of 1,000 consecutively treated patients in Britain, and almost 1,500 patients in Belgium, this same ratio was reported (Rose 1974; Willems et al. 2001).

The United States is not alone in the disparity among males and females receiving orthodontic treatment. In a British study of 162 patients referred for 
orthodontic treatment $54 \%$ were female and $46 \%$ were male (O'Brien et al. 1996). Of those patients referred to an orthodontist by a general dentist or other health care professional, $54 \%$ were accepted for treatment. Acceptance criteria were based on whether the orthodontist felt that there was sufficient treatment need. Of the patients who were accepted for treatment, $62 \%$ were female and $38 \%$ were male. Using the IOTN to compare malocclusions of all of the children, the study showed that, when a need for orthodontic treatment was present, a girl was three times more likely to be accepted for orthodontic treatment than a boy. Furthermore, the child's sex was predictive of patient acceptance of treatment: boys were less likely than girls to undergo treatment once accepted for free treatment in the British healthcare system. O'Brien and coworkers (1996) attributed these differences to sex role stereotyping, explaining that society considers the physical appearance of girls to be more important than that of boys.

A study of 920 randomly selected orthodontic patients from the Netherlands revealed that 400 were males and that 520 were females (Al Yami et al. 1998). The IOTN was performed on the pretreatment casts and the results showed that $83 \%$ of the patients fell into the definite-need category of the combined dental health component (DHC) and aesthetic component (AC) of the IOTN. Males and females did show small but significant differences both on the DHC and the AC. Males had a greater need for treatment than females in the aesthetic component, with scores of 8.0 and 7.8, respectively. Males also showed a greater need in the dental health component with scores of 4.1 compared to 3.9. Al Yami and coworkers claimed that these differences are small and not clinically significant, but significance occurs in the fact that, although males have only a slightly greater treatment need, they are outnumbered in the orthodontic sample by a 5.2 to 4.0 ratio of females to males.

In a study group of 359 eleven-year-old Norwegian school children scored with the IOTN, $53.2 \%$ of children had a moderate to very great need of treatment using the DHC while $29.4 \%$ had the same need according to the AC. No significant difference was found between girls and boys for need of orthodontic treatment using either of the two parts of the IOTN (Birkeland et al. 1996).

In a French study of 531 orthodontically untreated school children ages 9 to 12 years, there was no significant difference in orthodontic treatment need between girls and boys using either the DHC or the AC components of the IOTN. About $21 \%$ of the children warranted orthodontic treatment using the IOTN grades of need (Souames et al. 2006).

In a sample of 223 randomly selected first-year university students in Hong Kong, males and females had no significant difference in orthodontic 
treatment need using two different indices, namely the IOTN and the Occlusal Index (Tang and So 1994).

Latvian school children $(n=504)$ were assessed using the Index of Complexity, Outcome, and Need (ICON), and no difference of treatment need was found between the sexes (Liepa et al. 2003). About 35\% of the children in the study were found to have a need for orthodontic treatment (Liepa et al. 2003).

\section{$\underline{\text { Racial Differences in Malocclusion and Treatment Need }}$}

Date from the NHES III reveal that consistent differences in the average TPI scores of youths ages 12 to 17 are not associated with race; that is to say that there is not an overall greater need for treatment in any one racial group (Kelly and Harvey 1977). In this sample $(n=7,500)$, significantly more Blacks $(8.2 \%)$ than Whites $(5.0 \%)$ have TPI scores $\geq 10$ indicating a severe need for orthodontic treatment, but significantly more Blacks $(14.7 \%)$ than Whites $(10.5 \%)$ also have a TPI score of zero, indicating no need for treatment (Kelly and Harvey 1977). However, Whites who had been or where being treated were not included in the counts, so any race difference is minor. In terms of certain individual components of malocclusion racial differences were noted. Blacks are more likely than Whites to have a Class I (62\% compared to 52\%) or a Class III (19\% compared to $13 \%$ ) molar relationship, while Whites are more likely to be Class II molar (34\% compared to $18 \%$ ). White children are more likely to have a deep bite, while Black children are more likely to have an open bite. Whites were also more likely to have higher tooth displacement scores indicating more crowding (Kelly and Harvey 1977). Even though these racial differences do exist, overall there is no difference between Blacks and Whites in treatment need. Data from the NHANES III also looked at Mexican-American children. Mexican-Americans were nearly twice as likely as Blacks or Whites to have extreme crowding in the anterior segment and tended to have more extreme Class II malocclusions than Whites and more extreme Class III malocclusions than Blacks. However, they were much less likely than either Whites or Blacks to have vertical deviations from the ideal (Proffit et al. 1998). As assessed by the Index of Orthodontic Treatment and Need (IOTN), Blacks, Mexican-Americans, and Whites were found to have very similar total treatment need with about $55 \%$ of the sample having some degree of treatment need. However, Blacks were found to have a significantly higher severe need than Mexican-Americans and Whites. This is attributed to the fact that this is a mixed sample of treated and untreated subjects and that fewer Blacks who had a severe need of treatment actually received that treatment (Proffit et al. 1998). 
While different racial groups have the same overall need for orthodontic treatment, there are substantial racial disparities in the number of orthodontic visits reported by Black and Hispanic children (Okunseri et al. 2007). Data from 1996 to 2004 indicate that of respondents age 9 to 18 with at least one orthodontic office visit in the previous year, $85 \%$ were White, $4.5 \%$ were Black, $6.7 \%$ were Hispanic, 2.5\% were Asian, and the rest were "other" (Okunseri et al. 2007). When covariates such as income and health insurance were removed these disparities still existed in all years for Black children compared to White children, and in three of the nine years for Hispanic children compared to White children. Okunseri et al., conclude that these differences in orthodontic office visits are not only socioeconomic, but also cultural (2007).

Date from the NHANES III reveal that Whites were significantly more likely than non-Hispanic Blacks and Mexican-Americans to have had orthodontic treatment. In the 8 to 17 age range $22.9 \%$ of Whites, $6.1 \%$ of Blacks and $8.3 \%$ of Mexican-Americans had received orthodontic treatment. In the 18 to 50 age range, $22.2 \%$ of Whites, $5.0 \%$ of Blacks, and $6.1 \%$ of Mexican-Americans had received treatment.

Manski et al. found that, overall, non-Whites were less likely to visit an orthodontist, but that from 1987 to 1996 the percentage of non-Whites visiting an orthodontist significantly increased from $1.5 \%$ to $2.1 \%$. During this time the percentage of Whites visiting an orthodontist increased slightly, but not significantly, from $3.5 \%$ to $3.6 \%$ (Manski et al. 2000).

In a sample of third and fourth grade children $(n=3,696)$, demand was found to be higher in White children than in Black children with $11.8 \%$ of White children's parents wanting treatment compared to $1.2 \%$ of Black children's parents. In this sample, however, White children had a greater need for treatment $(47.2 \%)$ than Black children (35.3\%) (Wheeler et al. 1994).

\section{Patient Age}

As recently as the late 1960 s to the early 1970 s, around $95 \%$ of all orthodontic patients were children or adolescents. By 1990, the percentage of adult patients had increased five-fold, to $25 \%$, but has since declined to around $15-20 \%$ in the late 1990s (Buttke and Proffit 1999; Proffit 2007). This drop seen in

adult patients was only a drop in percentage, as the absolute number of adults in treatment had not appreciably changed while the number of adolescents and seeking treatment has increased (Proffit 2007). Data from 1996 indicate that of all orthodontic patients, children under 12 represent $20.3 \%$ of the total, children 12 to 18 represent $54.4 \%$, and adults 19 years and older compromised 25.3\% (Guay 
et al. 2008). It is clear that the composition of patients treated for orthodontics is changes across time, although not as drastically now as it once did.

In a sample of 65,000 U.S. adults, $1 \%$ has had an orthodontic office visit in the past year, with $65 \%$ of these patients being women and $35 \%$ being men (Whitesides et al. 2008). Whites, Blacks, and Hispanics in this adult sample were proportionally represented in comparison to the national population (Whitesides et al. 2008).

In reviewing orthodontic insurance claims in the state of Washington, Huang et al., found a patient age range of two to eighty-nine years old and found that $86 \%$ of the patients were less than twenty years of age (Huang et al. 2004). In a study of 1,000 consecutively treated British patients, the mean age of the first orthodontic consult was 10.7 years, while the mean age of start is 11.6 years. Two-thirds (69\%) of the cases treated began between the ages of 10 and 13 (Rose 1974).

\section{$\underline{\text { Treatment Duration }}$}

Orthodontic treatment duration is highly variable and depends on many factors of treatment need, treatment modality, and patient cooperation.

Depending on the research cited, average reported treatment can range from 22 to 31 months (Vig et al. 1990; Fink and Smith 1992; Alger 1998). Factors that may affect treatment duration include case difficulty, number of phases of treatment, number of broken appointments, broken appliances, poor oral hygiene, poor headgear wear, poor elastic wear, ANB angle, and mandibular plane angle (Vig et al. 1990; Fink and Smith 1992; Beckwith et al. 1999)

Interestingly, the literature does not agree on whether extractions as part of treatment affect treatment duration. Beckwith et al. found that extraction cases took 1.4 months longer to treat than non-extraction cases, but this difference was not significant (1999). Fink and Smith (1992) report that premolar extraction is the most important variable explaining differences in duration of treatment. They found that each extracted premolar increases treatment time by 0.9 months and that four premolar extraction increases treatment time by 3.6 months, a significant difference. Alger reported that extraction cases average 4.6 months longer than non-extraction cases (1998). Vig et al. (1990) found that when the patients of multiple practices were pooled, that there was no difference in treatment time for extraction and non-extraction patients. However, when each of the five private practices from which they gathered their cases were considered individually, each of the five had a significant difference between the treatment times of extraction and non-extraction cases. 
Patient characteristics reported to affect treatment time are Salzmann score, ANB angle, and the mandibular plane angle. Fink and Smith (1992) found that treatment time increases as the ANB angle and Salzmann score increase, but, to their surprise, they also found that treatment time decreases 0.3 months per degree increase of the mandibular plane angle.

\section{Extractions in Orthodontic Treatment}

The great premolar extraction debate has been going on throughout the history of orthodontics with strong emotion and enthusiasm. In the early twentieth century, Edward H. Angle and his followers were strict nonextractionists, but by the 1950s extraction in orthodontics became more common with the introduction of Charles H. Tweed's modifications of Angle's edgewise appliance and P. Raymond Begg's introduction of his light-wire appliance. Tweed championed extractions in order to upright mandibular incisors over basal bone in hopes of maximizing the stability of the post-orthodontic dentition and to enhance facial esthetics. Tweed estimated that four-premolar-extraction was necessary in approximately $50 \%$ of all cases (Tweed 1945). Begg favored premolar extraction based on the fact that the soft diet of modern man did not allow for the considerable interproximal attrition observed in the stone-age man and that four premolar extraction could simulate this attrition and alleviate malocclusion (Begg 1954). As Tweed and Begg's perspectives and appliances became popular, extraction treatment became very common in the U.S. (Proffit 1994).

The frequencies of extractions are perceived to have varied appreciably over time and with regard to individual practitioners. However, there are relatively few reports in the literature on actual extraction frequencies and extraction patterns.

Peck and Peck (1979) examined the records of 537 of their own patients and documented an overall extraction rate of $42.1 \%$. A third (36\%) of their patients received extractions in both arches, while $5 \%$ had extractions in the maxillary arch alone, and $1 \%$ had extractions in the mandibular arch alone. Interestingly, they also found that females were more likely to have extractions, with $44.3 \%$ of females receiving extraction compared to $39.0 \%$ of males; it is not reported whether or not this difference is significant (Peck and Peck 1979). Peck and Peck also compared their extraction rates with other reports, and they gave a range of extraction frequency reported in the literature from 6.5\% (Case in 1913) to $83.5 \%$ (Hooper in England in 1967). Other reported extraction percentages in 
the United States were 80\% reported by Tweed in 1966 and 33\% reported by Ricketts in 1976 (Peck and Peck 1979).

In a telephone survey of Michigan orthodontists $(n=264)$ conducted from 1986 to 1987 , the average extraction frequency was determined to be $39 \%$ of patients with reported ranges from $5 \%$ to $85 \%$ (Weintraub 1989). The most frequent extraction percentages reported were $25 \%$ and $50 \%$, with $34 \%$ of participants each reporting these percentages. Orthodontist's self-estimations of extraction percentages were determined to be inaccurate when the researchers looked at the practices of those orthodontists in the extreme ranges of extraction frequency. Actual extraction rates ranged from a $20 \%$ overestimate of extractions to a $15 \%$ underestimate. In one practice, only $6.5 \%$ of patients were treated nonextraction, while in others, only $5.2 \%$ and $11.5 \%$ were treated with premolar extractions (Weintraub 1989). Most (70\%) of the extraction cases studied had four premolars extracted, and the average extraction rate per patient was found to be 3.5 teeth (Weintraub 1989).

Results from a questionnaire mailed to orthodontists in the United States showed that extraction rates declined 22\% between 1984 and 1989, from a frequency of $38 \%$ in 1984 to $29 \%$ in 1989 . Over $50 \%$ of the responding orthodontists reported a decrease in extraction frequency, while $3 \%$ reported an increase in extraction frequency (Brian and O'Connor 1993). Reported reasons for the decrease in extraction rates were a desire for improved facial esthetics, TMJ concerns, and medicolegal concerns (Brian and O'Connor 1993).

Proffit (1994) reviewed 400 orthodontic cases treated over a 40 year period from 1953 to 1993 at The University of North Carolina. In 1953, extractions were part of treatment in $30 \%$ of the patients, but, by 1963, the extraction frequency had more than doubled to $73 \%$, and it eventually rose to its peak of $76 \%$ in 1968 . Since 1968, however, the extraction frequency slowly and steadily declined to $28 \%$ in 1993, only slightly below its 1953 level (Proffit 1994). Four first-premolars were extracted in $10 \%$ of the reviewed cases in 1953. This percentage jumped to $50 \%$ in just ten years and, by 1993, it had fallen to just below 1953 levels. Class II camouflage treatment (extraction of upper first premolars or upper first premolars and lower second premolars) did not show a statistically significant change over time. The prevalence of camouflage treatment peaked in 1968 and 1973 at $16 \%$ of cases and fell to $8 \%$ in 1993, which was the same frequency as four first-premolar extractions. One of every six extraction patients had an extraction category of "other" which included uneven premolar extractions, mandibular incisor extractions, and extractions of impacted teeth (Proffit 1994).

Factors affecting the decision of whether to extract teeth are variable and have changed over time. Personal preferences of the orthodontist, features of the 
malocclusion, treatment objectives, and treatment techniques are some major factors in the extraction decision (Weintraub 1989). Weintraub found no association between either the orthodontic program attended or year of graduation and the frequency of extraction (1989). Brian and O'Connor (1993) found that orthodontists who had been in practice fewer than 5 years reported an extraction rate of $26 \%$ compared to an extraction rate of $31 \%$ of those who had been practicing more than 20 years. These data suggest that more recent graduates are more likely to treat cases non-extraction. Proffit noted that at the University of North Carolina there were very few changes in faculty during any given time period in which large changes in extraction patterns occurred (1994). This suggests that personal attitudes regarding extraction, and not changes in the faculty per se were the cause for changes in extraction frequencies.

Reasons for the decline in extraction as part of treatment are numerous. Normal ideals for facial esthetics have changed, and the literature reveals that long-term stability is not improved by extraction (Proffit 1994). Increased utilization of functional appliances and of palatal expansion has decreased the need to extract teeth in some cases involving molar correction and crowding (Weintraub 1989). In the 1980s many orthodontists began bonding brackets rather than using fully-banded fixed appliances. This allowed for more space for the teeth and thus less need for extraction in borderline cases (Proffit 1994). Concerns over premolar extraction and the development of temporomandibular disorder, although unwarranted, also caused orthodontists to be less likely to extract teeth (Proffit 1994).

\section{$\underline{\text { Angle's Molar Classification }}$}

Edward H. Angle gathered data on "thousands of patients" with malocclusions and reported his findings in his famous Malocclusion of the Teeth ( $7^{\text {th }}$ edition) published in 1907. Angle found that $69.2 \%$ of his patients were Class I molar, $21.6 \%$ were some form of Class II molar, and $4.2 \%$ were Class III molar.

Data from the Evanston Dental Caries Study reveal Angle's Molar classification on over 25,000 untreated children. Two-thirds (69\%) of children in the 6 to 8 year old range were reported to be "normal," which is undefined, but presumably a Class I molar relationship with little or no other variables of malocclusion present. For children in the 12 to 14 year old age group, only $54 \%$ were classified as "normal." Of the younger group, $19 \%$ were considered to have a Class I malocclusion, $11 \%$ to have a Class II malocclusion, and $1 \%$ to have a Class III malocclusion. Of the older group, $30 \%$ were considered to have a Class I malocclusion, $14 \%$ to have a Class II malocclusion, and $1 \%$ to have a Class III 
malocclusion. Therefore, Class I malocclusion increased $11 \%$, Class II, 3\%, and Class III, did not increase at all from the younger group to the older group. Overall, the total was found to be a $14 \%$ increase in the prevalence of malocclusion (Emrich et al. 1965). Like previously mentioned studies, Blacks were found to be more likely to have a Class III molar relationship, and Whites to have a Class II relationship, although statistics were not performed to reveal these differences as significant (Emrich et al. 1965).

Data from the NHES III, collected on a mixed sample of treated and untreated children, reveal that $53 \%$ of children are Angle Class I molar, $32 \%$ are Class II, and 14\% are Class III (Kelly and Harvey 1977). Racial differences in Angle's classification found in the NHES III were mentioned in the previous section.

Data collected on almost 1,500 Belgian patients presenting for treatment between 1983 and 1997 showed that 31\% of the sample had a Class I molar, 62\% had a Class II molar and 6\% had a Class III molar (Willems 2001). It is importance to realize that although not all in this sample were treated, all patients did appear at university based orthodontic clinic and probably had more than mild malocclusions.

Massler and Frankel (1951) found that in a sample of Caucasian schoolchildren ( $\mathrm{n}=2758), 3 \%$ had an ideal occlusion, $18 \%$ had a "normal" occlusion, $50 \%$ had a Class I malocclusion, $19.4 \%$ had a Class II malocclusion, and $9 \%$ had a Class III malocclusion. Using the same techniques as Massler and Frankel, Altemus studied Black children $(\mathrm{n}=3,289)$. He found that $4 \%$ had an ideal occlusion, $13 \%$ had a "normal" occlusion, $66.4 \%$ had a Class I malocclusion, $12 \%$ had a Class II malocclusion, and 5\% had a Class III malocclusion (1957). Data from these two studies are inconsistent with other studies that show Blacks have a greater incidence of Class III malocclusions than Whites. 


\section{CHAPTER III: MATERIALS AND METHODS}

\section{$\underline{\text { Data Collection }}$}

Data were collected on 1,500 orthodontic patients treated at the graduate clinic of the Department of Orthodontics at the University of Tennessee, Memphis, representing approximately one-fourth of the patients treated at this clinic since 1980. The choice of starting at 1980 is due to an historical practicality. While the graduate orthodontic program has existed since 1942, archived patient records were disposed of (for lack of storage space) when the Department moved to its present location in the Dunn Dental Building in 1980. In that pre-computer era, disposal of the physical records removed all traces of the patients' files.

For the present study, Patient charts (consisting of progress notes, photographs, radiographs, and other documents) were examined from the University of Tennessee archives in alphabetical order with the intent of eliminating any selection bias. The only inclusion criteria were that a patient must have started orthodontic treatment after January 1, 1980, and finished before December 31, 2005. Patient charts were examined page by page. All documents in the chart were reviewed for relevant information. Data were collected on the following points.

A. Patient ID Number: Patient ID number was collected for identification and organization purposes only. No identifying information was collected.

B. Sex: Patient sex was determined primarily by visual identification from photographs and the Christian name. Otherwise, it was gathered from the health history or other paperwork in the chart.

C. Race: Racial category was determined by photographic identification, based primarily on skin color, nose, and hair form. We recognized seven categories of "race": Asian, Black, Hispanic, Indian, Islander, middle-eastern and White. The intent here merely was to document the commonly perceived increase in non-Caucasian patients and their distribution over time. We fully appreciate that "race" is a nebulous, complex issue (Montagu 1964; Edgar 2009).

D. Instructor: Instructor data were recorded by name of the attending faculty member. Using instructor data provided the type of fixed orthodontic appliance used in patient treatment of the cases. If name of the instructor was unavailable, appliance type was determined by photographs or treatment mechanic descriptions when available and was recorded as Tweed, Begg, Straight-wire, or "other."

E. TennCare: TennCare is Tennessee's Medicaid managed care program that provides services for low income children and adolescents. If it was indicated in the patient chart either in the initial progress notes or in other 
documentation, the patient was recorded as a TennCare (or other subsidized treatment) patient. If no documentation was found indicating that a patient has been subsidized by any social program it was assumed that the patient was not a TennCare patient.

F. Birth Date: Patient's birth date was recorded in order to determine patient age at the start and end of treatment as well as the duration of treatment. If the date of birth was unavailable, but a patient age is found in the record, a birth date of January 1, for the relevant year was recorded so that a close estimate of the patient age could be made.

G. Start Date: Patient start date was recorded to determine patient age at the start of treatment. Start date was determined by review of the progress notes and was defined by date of first cementation of orthodontic brackets, bands, or appliances used in any capacity other than space maintenance (i.e. a lower lingual arch or Nance appliance) or delivery of a removable functional appliance (i.e., a Bionator or a Fränkel appliance) or an active retainer. Start date was not based on the date of initial records.

H. Deband Date: Patient deband date was recorded to determine patient age at the end of treatment and treatment time duration.

I. Angle's Classification: Patient Angle's classification was obtained from information in the patient's chart.

J. FMA: Patient pretreatment Frankfort-mandibular-plane angles (Tweed 1946) was recorded from chart documentation. When this information was unavailable in the chart, FMA was measured directly from the pretreatment lateral cephalogram.

K. ANB: The ANB angle (Riedel 1952; Steiner 1953) was recorded from chart documentation. When this information was unavailable, the ANB angle was measured directly from a pretreatment lateral cephalogram.

L. Extraction Pattern: Extraction patterns were recorded using a numerical code as follows:

1. Non-extraction

2. Four first premolars $(4-4 / 4-4)$

3. Four second premolars (5-5/5-5)

4. Maxillary first premolars and mandibular second premolars (4-4/5-5)

5. Maxillary second premolars and mandibular first premolars (5-5/4-4)

6. First molars (6-6)

7. Second molars (7-7)

8. Maxillary first premolars only $(4-4 / 0-0)$

9. Mandibular first premolars only $(0-0 / 4-4)$

10. Maxillary second premolars only $(5-5 / 0-0)$

11. Mandibular second premolars only (0-0/5-5)

12. Other extraction patterns

13. Incisor extractions 
M. Orthognathic surgery: If the progress notes or other documentation indicated that a patient had completed orthognathic surgery, this category was recorded as "yes." Patients who were treatment planned for orthognathic surgery, but who did not follow through with this treatment were recorded as a "no."

N. Untreated: Patients who had records taken but who did not begin treatment were recorded as "no," so the number of cases on whom initial records were taken but treatment was not performed could be analyzed. These patients either were not approved by TennCare, or declined treatment after presentation of the treatment plan.

O. Incomplete Treatment: Patients who started treatment, but whose appliances where removed early for non-compliance or patients who moved away during active treatment were recorded as "yes."

P. Miscellaneous: Any extra information deemed interesting was recorded here. For example, if a patient had a cleft lip and palate, any syndrome, or special medical condition, it was noted here.

\section{Case Distribution by Year}

Cases were selected at random (based on patient code), and it was left to chance whether the sample distribution was uniform across the time interval of 1980 through 2005. In fact (Figure 1), the distribution is fairly proportional across the 26 years. Most counts were between 40 and 60 per year, with a minimum of 31 for 1989 and cases in excess of 80 for the three years 2002 to 2004.

\section{$\underline{\text { Statistical Analysis }}$}

The data collected are several sorts: nominal, ordinal, interval, and ratio. Broadly, chi-square analysis (contingency tables) was used for nominal and ordinal data, with the data presented as proportions and/or percentages. The higher level data were described with standard descriptive statistics (Sokal and Rohlf 1995), followed by inferential text, as appropriate.

One prime theme here is to test for temporal differences: whether demographic conditions in the patient pool and/or treatment characteristics have changed over the quarter-century of patient records sampled. The individual tests are described in the text, but the general plan was to use the year of the starting records as the independent variable and the patient's status (e.g., age, FMA) or a feature of treatment, such as extractions or orthognathic surgery, as the outcome. When the dependant variable is interval or ratio scale, 


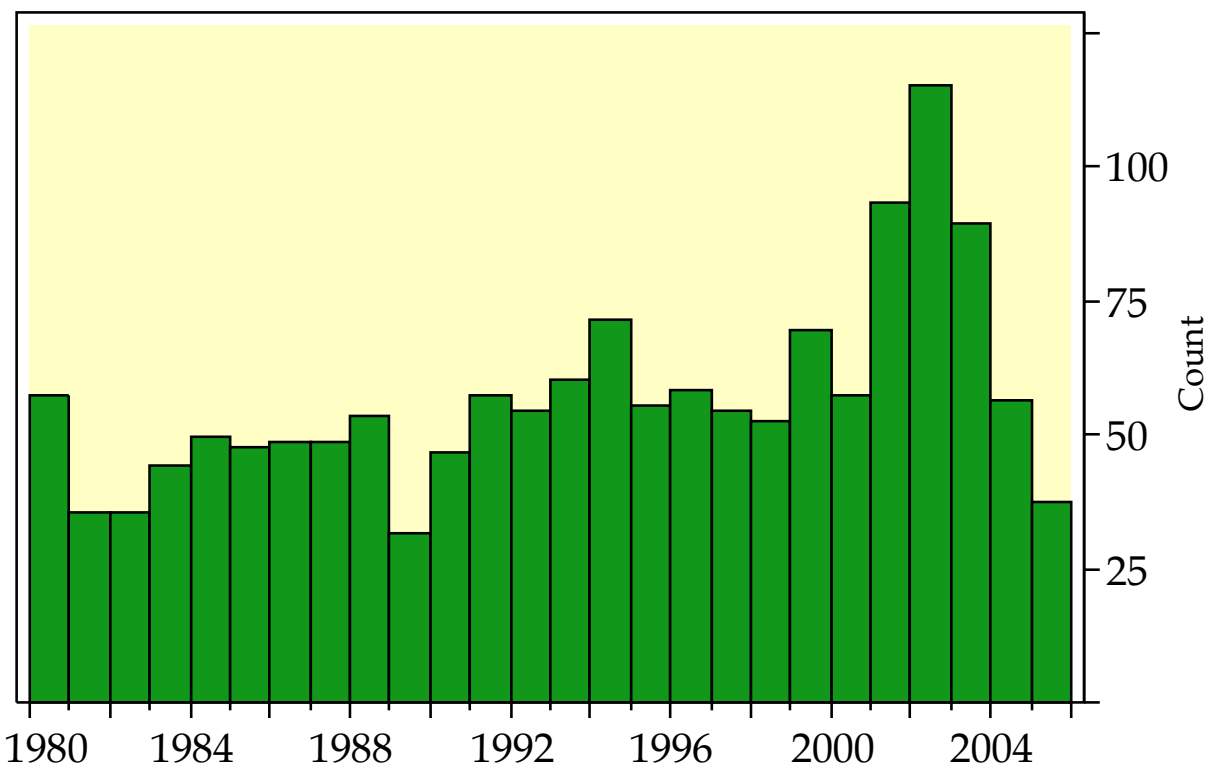

Figure 1. Counts of cases studied distributed by the year the case was started. Total sample is 1,470 . 
conventional regression models are suitable (e.g., Freund and Littell 1991). When the variable is nominal or ordinal, a nominal logistic model was used.

Unless noted, tests were evaluated as two-tail, and the conventional level of alpha $=0.05$ was used throughout, without any allowance for multiple comparisons. 


\section{CHAPTER IV: RESULTS}

\section{$\underline{\text { Ethnic Groups }}$}

"Race" is a very nebulous term (Montagu 1964; Edgar and Hunley 2009). The purpose here is simply to test the perception that non-Caucasian cases have achieved greater access to orthodontic care as time has advanced. Several studies show that non-Caucasians are underserved in health-care contexts. Race designation was available for a total of 1,612 individuals (Table 1). It is evident from this table that most of the patients are Whites (75\%), most of the others are Blacks $(21 \%)$, and other groups only compose $4 \%$ of the cases overall.

Our perception is that non-White races as orthodontic patients have become more common with time, both as racial proscriptions have diminished in the community and (concomitantly) more ethnic groups have moved into the greater Memphis community. Logistic regression was used to test for a trend comparing White and Black patients and White and other patients over the studied time interval. The frequencies of Black patients and of "other" patients have increased significantly with time when compared to White patients $(\mathrm{P}=$ 0.0005: Figure 2, Table 2; $\mathrm{P}=0.005$ : Figure 3, Table 3, respectively).

In the range of years studied, the proportions of Blacks and of other nonCaucasian ethnic groups have increased significantly. However, the census of the City of Memphis proper is 61\% Black, and the under-representation of Blacks among those attending this orthodontic clinic mirrors that seen nationally (e.g., Proffit 1998), where non-White groups in general, but American Blacks in particular are under-represented. There almost certainly are multiple causes for the under-representation, but differences in disposable income commonly are cited.

Table 1. Proportions of the total sample by race or ethnic group $(n=1,612)$.

\begin{tabular}{lrr}
\hline Race & Count & Percent \\
\hline Asian & 29 & 1.799 \\
Black & 342 & 21.216 \\
Hispanic & 7 & 0.434 \\
Indian & 11 & 0.682 \\
Islander & 1 & 0.062 \\
Mideast & 5 & 0.310 \\
White & 1217 & 75.496 \\
\hline
\end{tabular}




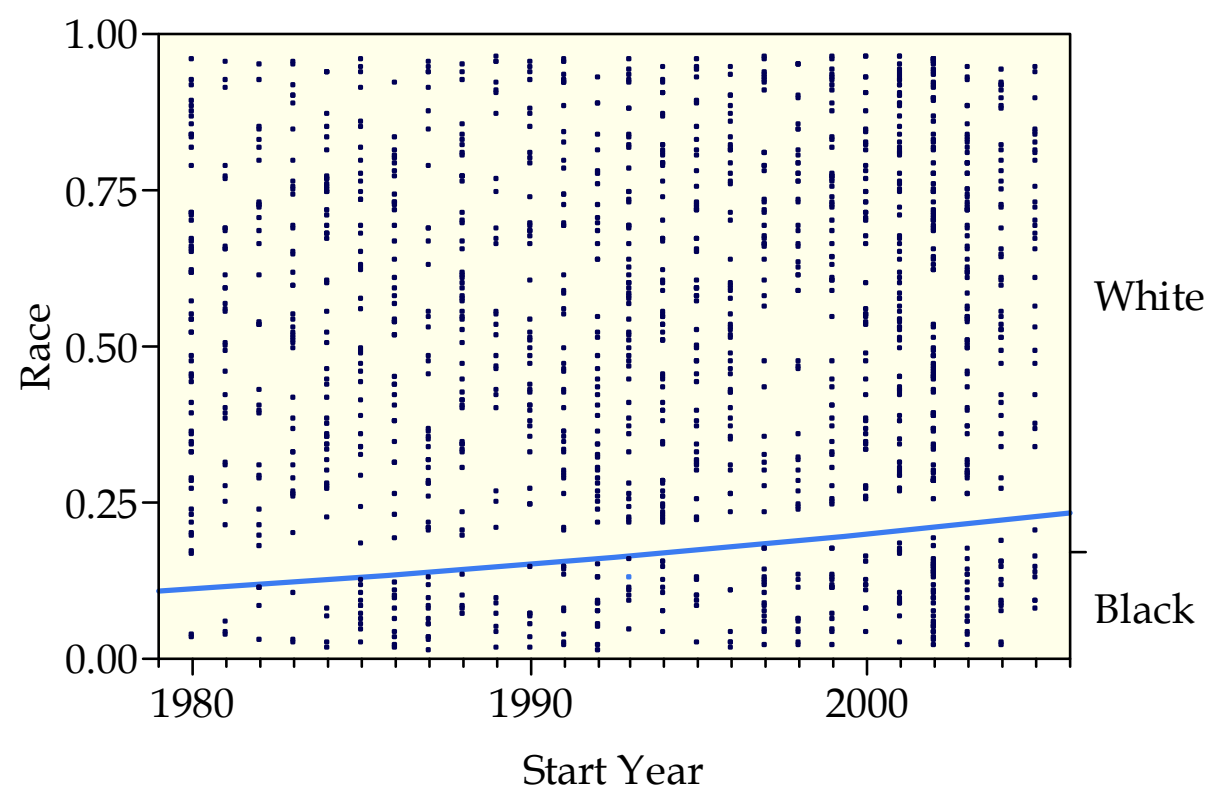

Figure 2. Plot generated by a logistic fit of race (defined as Black or White) against the year the case was started.

The frequency of Black patients as compared to White patients increased significantly through time in the quarter-century interval.

Table 2. Results of logistic regression testing for a significant change in proportions of Blacks and Whites between 1980 and 2005.

\begin{tabular}{lcccc}
\hline Term & Estimate & Sem & $\mathrm{X}^{2}$ & P-value \\
\hline Intercept & -68.799773 & 19.741288 & 12.15 & 0.0005 \\
Start Year & 0.03370783 & 0.0098956 & 11.60 & 0.0007 \\
\hline
\end{tabular}




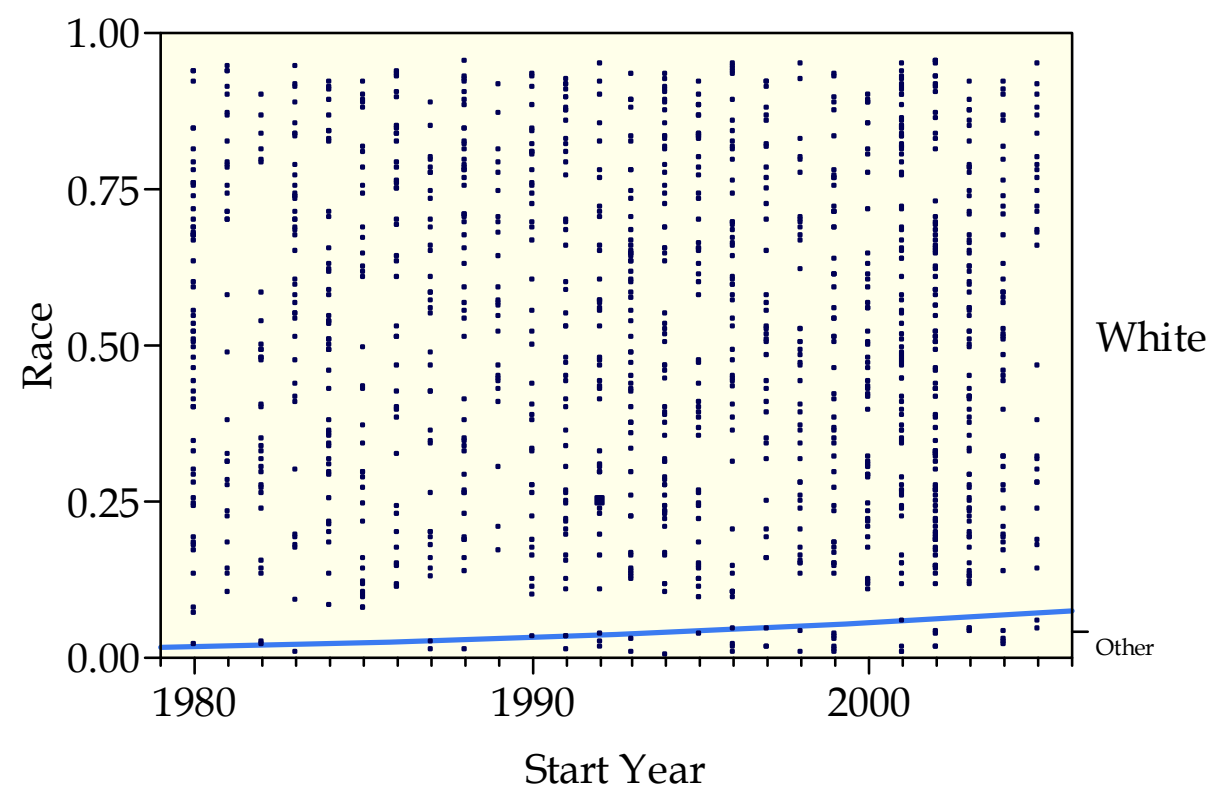

Figure 3. Plot generated by a logistic fit of race (defined as White or other) against the year the case was started.

The frequency of other patients as compared to White patients increased significantly through time in the quarter-century interval.

Table 3. Results of logistic regression testing for a significant change in proportions of other patients and Whites between 1980 and 2005.

\begin{tabular}{lcccc}
\hline Term & Estimate & Sem & $\mathrm{X}^{2}$ & P-value \\
\hline Intercept & -119.60276 & 42.473344 & 7.93 & 0.0049 \\
Start Year & 0.05837976 & 0.0212757 & 7.53 & 0.0061 \\
\hline
\end{tabular}


Glassell and Harris (2007) reported that the characteristic preponderance of girls seen in the White orthodontic patient population is not present in the Black patient population, where the two sexes are represented about equally. They found that the proportion of girls with lower treatment-needs who inflated the percentage of White female patients was absent in the Blacks. We are unaware of any study that has tested for Black-White differences in selfperceptions of malocclusion - which also may influence seeking treatment.

In this particular sample, the percentage of girls in the Black sample (61\%; $208 / 342)$ is not significantly different than in the White sample $(58 \% ; 711 / 1,217)$ as tested by chi-square analysis $\left(\mathrm{X}^{2}=0.6 ; \mathrm{P}=0.42\right)$. That is, there is an equivalent preponderance of girls compared to boys in both races.

\section{Race and Subsidized Treatment}

One measure of financial influences on utilization is whether the groups had different uptake of government subsidized treatment, notably TennCare. Overall, almost $5 \%$ of the cases in this study were financially supported by TennCare $(5 \% ; 72 / 1,496)$. However, the percentage of Blacks $(17 \%)$ is significantly higher than of Whites $(2 \%)$, with a chi-square of $97.9(\mathrm{df}=1 ; \mathrm{P}<$ 0.0001).

It was tested whether those Blacks whose treatment was financed by TennCare exhibited more-deviant malocclusions. Two skeletal measures were tested (FMA, ANB), but neither of these angles differed in the TennCare compared to the self-paid sample of Blacks. This suggests that the differences depend more on the extent of the tooth-based malocclusions than on differences in the supporting bony relationships.

\section{Race and Orthognathic Surgery}

We also tested whether orthognathic treatment differed by race. Blacks in our sample had a somewhat higher frequency of orthodontic-surgery treatments $(2.3 \% ; 6 / 257)$ compared to Whites $(1.8 \% ; 21 / 1,187)$, but the difference is not significant statistically $\left(\mathrm{X}^{2}=0.3 ; \mathrm{P}=0.55\right)$, primarily because the sample sizes are small. 


\section{$\underline{\text { Sex Distribution }}$}

There is a clear preponderance of girls over boys in the treated sample. The patient's sex was known for a total of 6,927 cases, and 59\% were female. By chi-square this deviates significantly from an expected split of 50:50 $\left(X^{2}=231.6 ; 1\right.$ df; P < 0.0001). In other words about 1.5 girls were treated for every boy. As discussed later, this predominance of girls probably stems from their greater (and their parents') greater esthetic concern compared to boys. This greater esthetic concern - and concern about lesser esthetic problems - is welldocumented in the dental literature (e.g., Shaw 1991). The sex ratio of patients, at about 60:40 (Figure 4), has been very stable throughout the quarter century of records reviewed here. By logistic regression (sex on year; Figure 5, Table 4) the preponderance of girls in the patient pool has been quite consistent throughout the surveyed time $\left(\mathrm{X}^{2}=0.12 ; \mathrm{P}=0.73\right)$.

The excess of girls - compared to boys - is the same in Blacks and Whites (other races are too uncommon for analysis). In Whites, 58\% are girls and $42 \%$ are boys (total $n=1,217$ ). By chi-square analysis, this ratio is the same as Blacks, where $61 \%$ are girls and $39 \%$ are boys (total $n=342$ ). The chi-square test $(1 \mathrm{df})$ is $0.6(\mathrm{P}=0.04261)$.

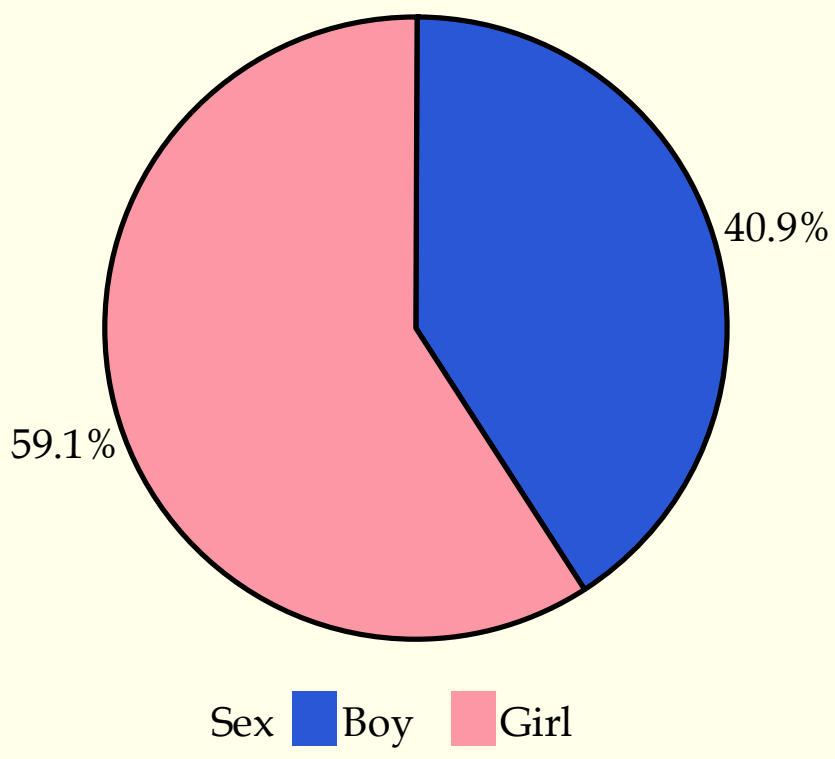

Figure 4. Frequency of boys compared to girls in all years, 1980 to 2005. 


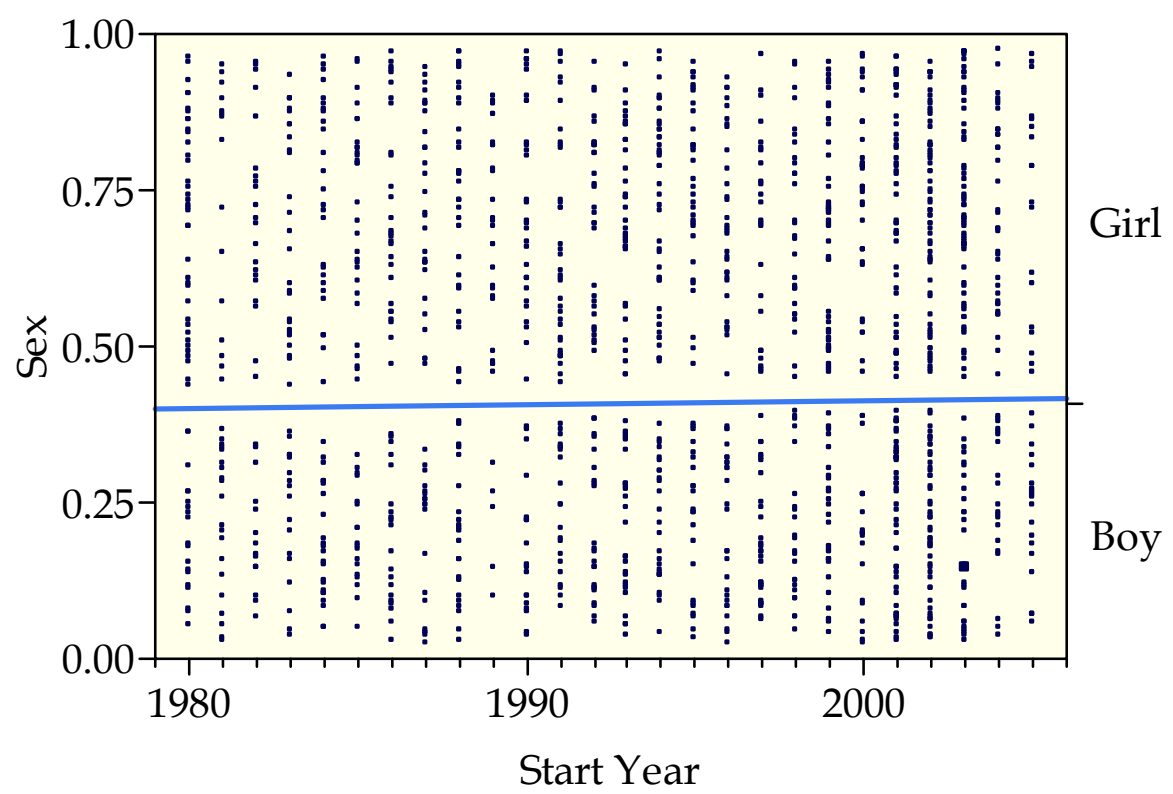

Figure 5. Plot generated by a logistic fit of sex against the year the case was started.

The frequencies of boys and girls have not changed significantly through time in the quarter-century interval.

Table 4. Results of logistic regression testing for a significant change in proportions of boys and girls between 1980 and 2005.

\begin{tabular}{lcccc}
\hline Term & Estimate & Sem & $\mathrm{X}^{2}$ & P-value \\
\hline Intercept & -5.3650655 & 14.313184 & 0.14 & 0.7078 \\
Start Year & 0.00250726 & 0.0071785 & 0.12 & 0.7269 \\
\hline
\end{tabular}




\section{$\underline{\text { Angle Classification }}$}

For all scored cases combined $(n=5,255)$, the frequency of Angle Class II cases was the most common molar relationship encountered (50\%), followed by Class I cases at $41 \%$ of the total (Figure 6). This leaves about $9 \%$ of all scored cases exhibiting a Class III relationship $(8.6 \% ; \mathrm{n}=454 ;)$. This is substantially different from proportions found in the general population where $53 \%$ of children are Angle Class I molar, 32\% are Class II, and 14\% are Class III (Kelly and Harvey 1977).

Over the 26 years surveyed, the ratio of patients' Angle classification has changed significantly. Comparatively, more Class I patients, as compared to Class II patients, are being treated over time $\left(X^{2}=52.7 ; P<0.0001\right.$ : Figure 7;

Table 5). However, this is not true when comparing Angle Class I and III patients where there is no significant change over time $\left(X^{2}=0.29 ; P=0.59\right.$ : Figure 8, Table 6). When Class IIs are compared to Class IIIs there is a significant increase of the Class IIIs over the surveyed time $\left(\mathrm{X}^{2}=4.19 ; \mathrm{P}<0.04\right)$ as shown in Figure 9, Table 7.

Over the 26 years surveyed, the ratio of patients' Angle classification has changed significantly. Comparatively, more Class I patients, as compared to Class II patients, are being treated over time $\left(X^{2}=52.7 ; P<0.0001\right.$, Figure 7; Table 5). However, this is not true when comparing Angle Class I and III patients where there is no significant change over time $\left(X^{2}=0.29 ; P=0.59\right.$;

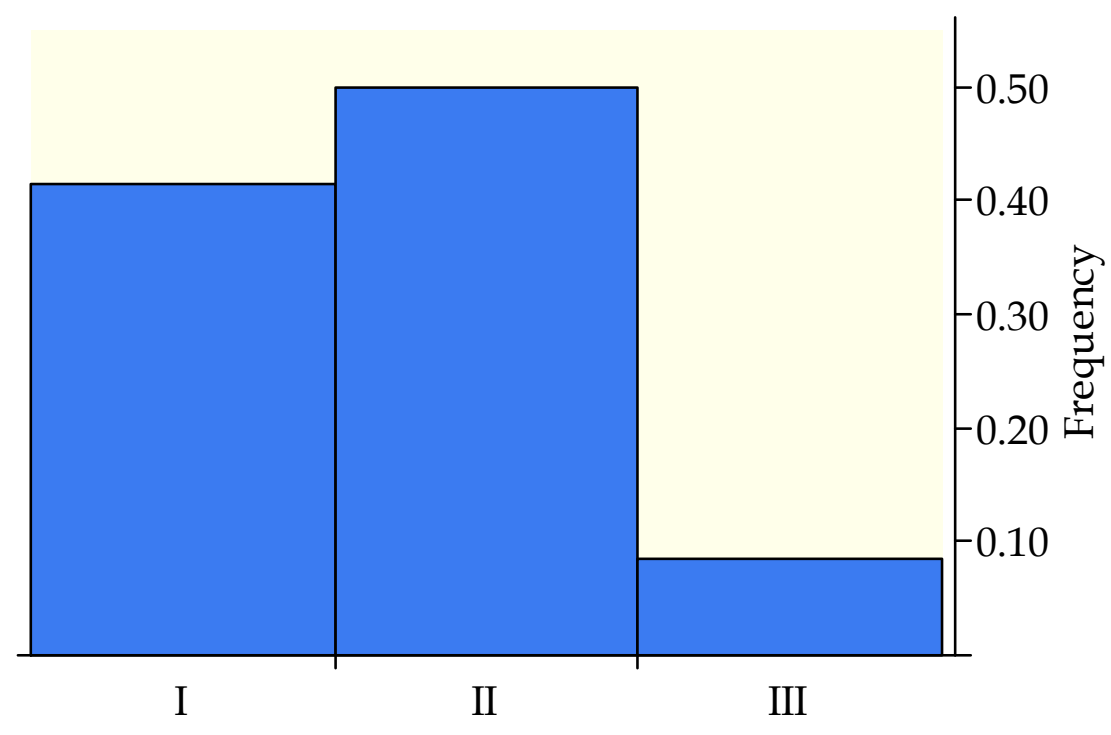

Figure 6. Frequency of molar classification (Angle) in all patients $(n=5,255)$. 


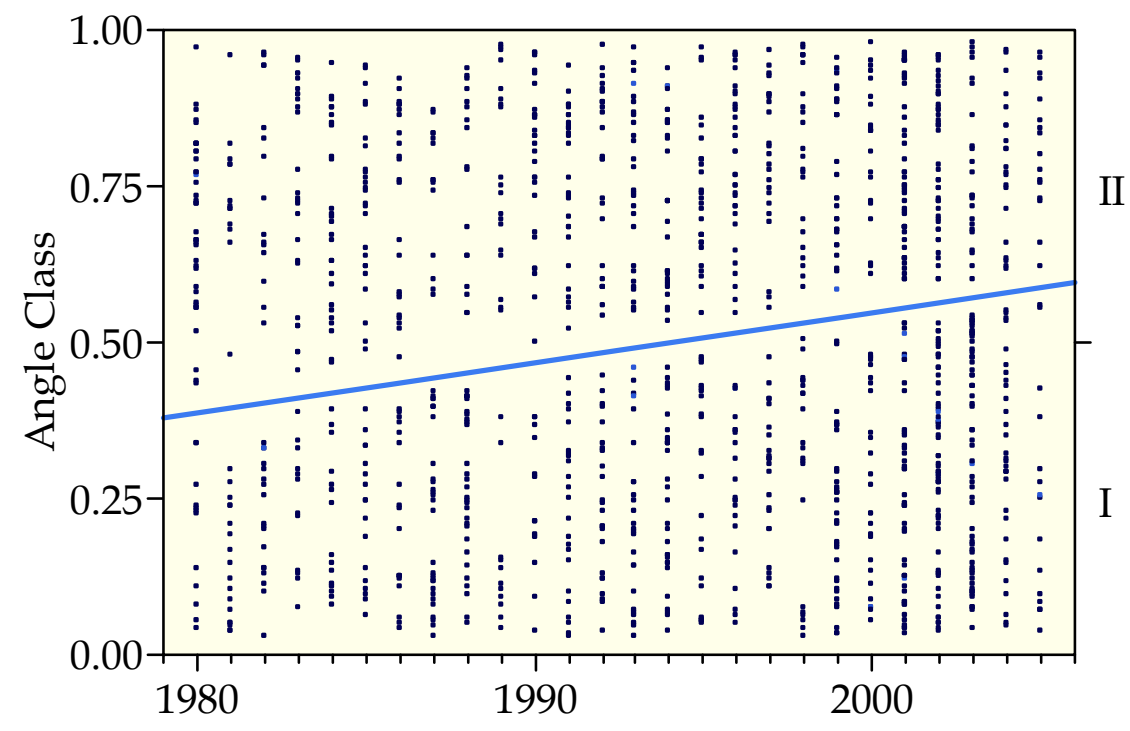

Start Year

Figure 7. Plot generated by a logistic fit of Angle Class I and II cases against the year the case was started.

The frequencies of Class I cases compared to Class II cases increased significantly through time in the quarter-century interval.

Table 5. Results of logistic regression testing for a significant change in proportions of Angle Class I and II patients between 1980 and 2005.

\begin{tabular}{lcccc}
\hline Term & Estimate & Sem & $\mathrm{X}^{2}$ & P-value \\
\hline Intercept & 64.636173 & 15.106201 & 18.31 & $<0.0001$ \\
Start Year & 0.03241414 & 0.0075759 & 18.31 & $<0.0001$ \\
\hline
\end{tabular}




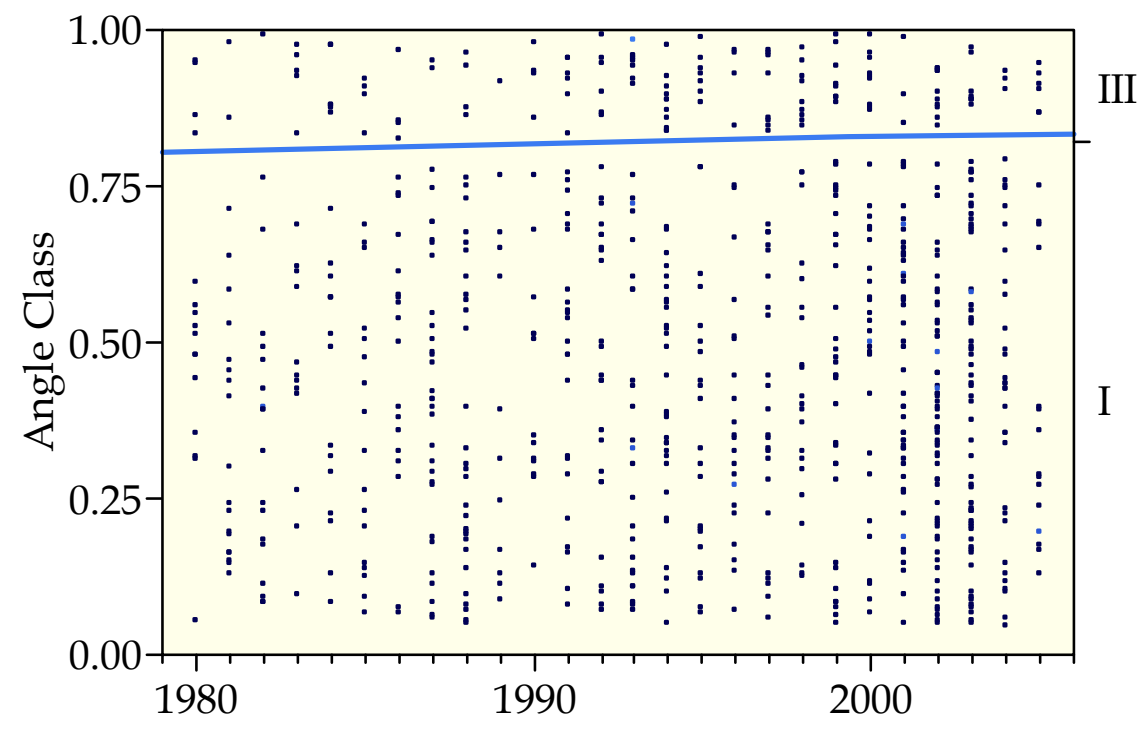

Start Year

Figure 8. Plot generated by a logistic fit of Angle Class I and III cases against the year the case was started.

The frequencies of Class I cases compared to Class III cases has not significantly changed through time in the quarter-century interval.

Table 6. Results of logistic regression testing for a significant change in proportions of Angle Class I and III patients between 1980 and 2005.

\begin{tabular}{lcccc}
\hline Term & Estimate & Sem & $\mathrm{X}^{2}$ & P-value \\
\hline Intercept & -13.84127 & 25.521185 & 0.29 & 0.5876 \\
Start Year & 0.00770709 & 0.0127959 & 0.36 & 0.5470 \\
\hline
\end{tabular}




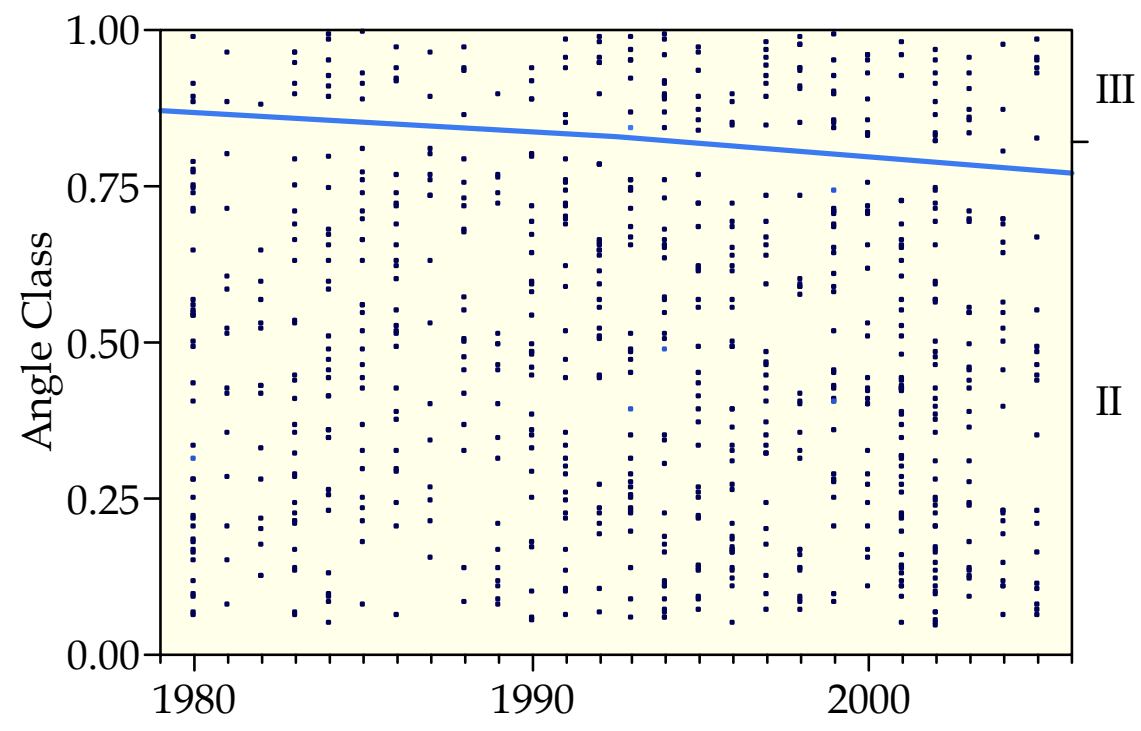

Start Year

Figure 9. Plot generated by a logistic fit of Angle Class II and III cases against the year the case was started.

The frequencies of Class III cases compared to Class II cases increased significantly through time in the quarter-century interval.

Table 7. Results of logistic regression testing for a significant change in proportions of Angle Class II and III patients between 1980 and 2005.

\begin{tabular}{lcccc}
\hline Term & Estimate & Sem & $\mathrm{X}^{2}$ & P-value \\
\hline Intercept & 52.8988828 & 25.857154 & 4.19 & 0.0408 \\
Start Year & -0.0257623 & 0.0129663 & 3.95 & 0.0469 \\
\hline
\end{tabular}


Figure 8; Table 6). When Class IIs are compared to Class IIIs there is a significant increase of the Class IIIs over the surveyed time $\left(\mathrm{X}^{2}=4.19 ; \mathrm{P}<0.04\right)$ as shown in Figure 9, Table 7.

Angle Classification, Race, and Sex

Studies of non-orthodontic samples of Americans report higher frequencies of Class III molar relationships among Blacks (Kelly and Harvey 1977). This race difference is also mirrored here. The Black-White differences in molar relation are highly significant statistically $\left(\mathrm{X}^{2}=52.7 ; \mathrm{df}=2 ; \mathrm{P}<0.0001\right)$, and Class III cases are more common in Blacks $(17 \% ; 57 / 330)$ than in Whites $(7 \%$; 90/1,196) as shown in Figures 10, 11, and 12. Conversely, Class II cases are more common in Whites $(51 \% ; 608 / 1,196)$ than in Blacks $(31 \% ; 103 / 330)$, which is also seen in Figures 10, 11, and 12. This leaves the Class I relationship more common in Blacks $(51 \% ; 170 / 330)$ than in Whites $(42 \% ; 498 / 1,196)$. For all cases combined, Class I patients represented $41 \%$ of the sample while Class II and III represented $50 \%$ and $9 \%$ respectively (Figure 6). In contrast, there was no suggestion of a sex difference by Angle's molar classification either in American Blacks or in American Whites.

\section{Angle Classification and the FMA}

It is interesting that the consequences of Angle's molar classification is different in American Blacks and Whites. When FMA was apprised as a function of Angle's classification, there is no dependence in Blacks ( $\mathrm{F}=1.2 ; \mathrm{P}=0.29)$, meaning that average FMA does not differ among Class I, II, and III. In Whites, however, the Class III sample had a significantly higher FMA than the other two categories $(\mathrm{F}=3.2 ; \mathrm{P}=0.04)$. Average FMA was about 25 degrees in Angle Class I and II, but about 27 degrees in the Class III sample.

\section{Orthognathic Surgery}

Only $2 \%$ of this sample $(30 / 1,499)$ was treated with an orthognathic procedure. Moreover, as shown in Figure 13 and Table 8, the frequency of surgical procedures has decreased through time $(\mathrm{P}=0.04)$.

Malocclusions treated with surgery were about equally divided between Class II (43\%) and Class III (47\%) cases, but, again, the total sample size $(\mathrm{n}=30)$ is small. Sex of the patient was not an identifiable risk factor for surgery in this small sample, with a male-female split of 14:16. Predictably, the age of the 


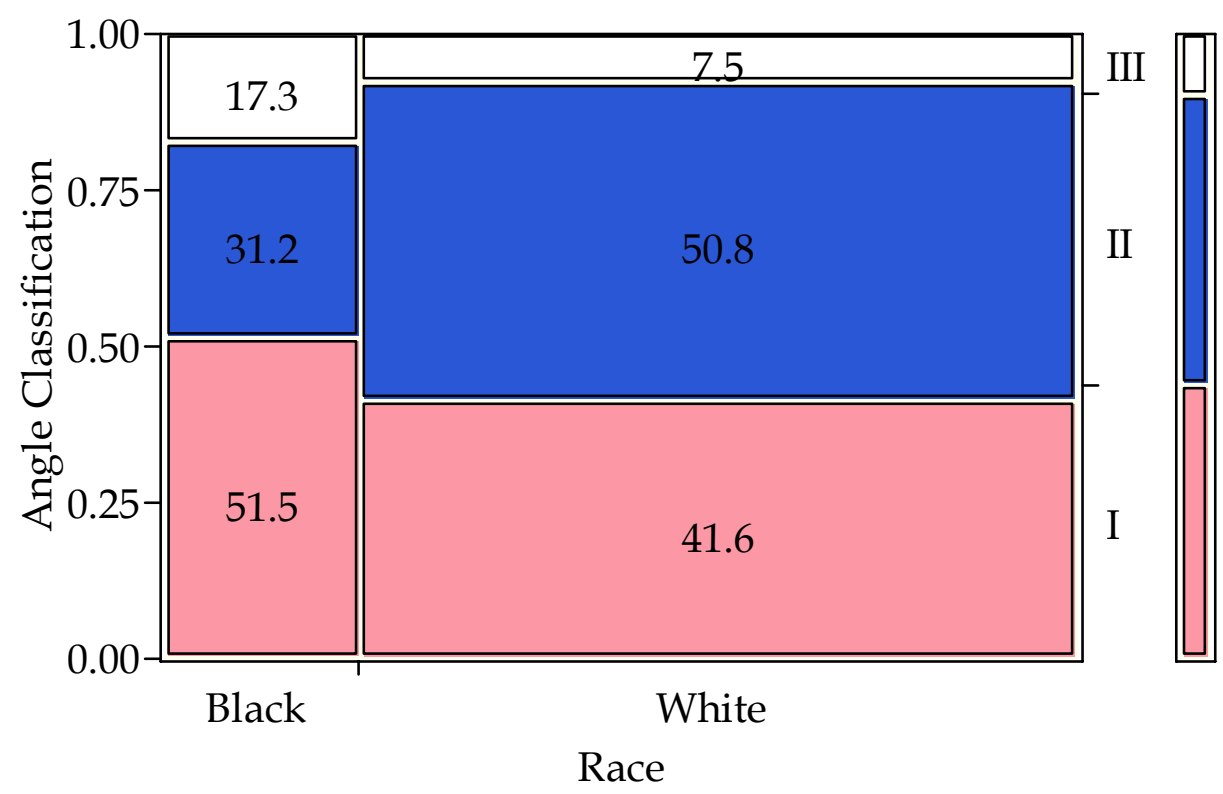

Figure 10. Mosaic chart showing percentage of Angle Class by race (as defined as Black or White).

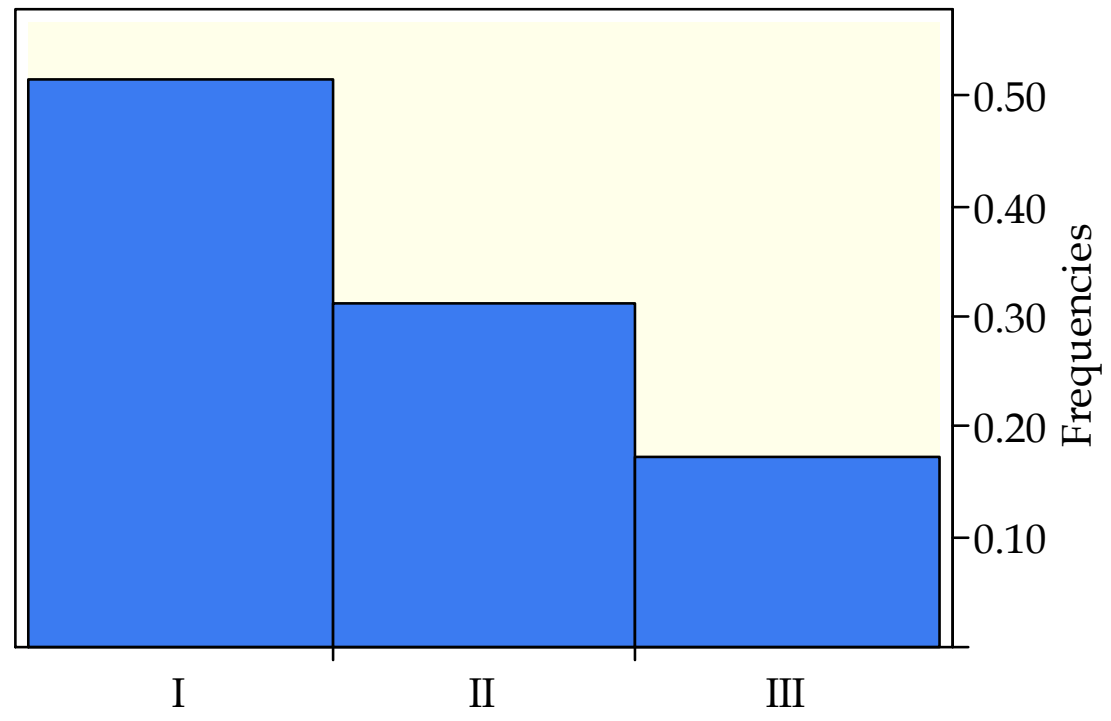

Figure 11. Frequency of molar classification (Angle) in Black patients. 


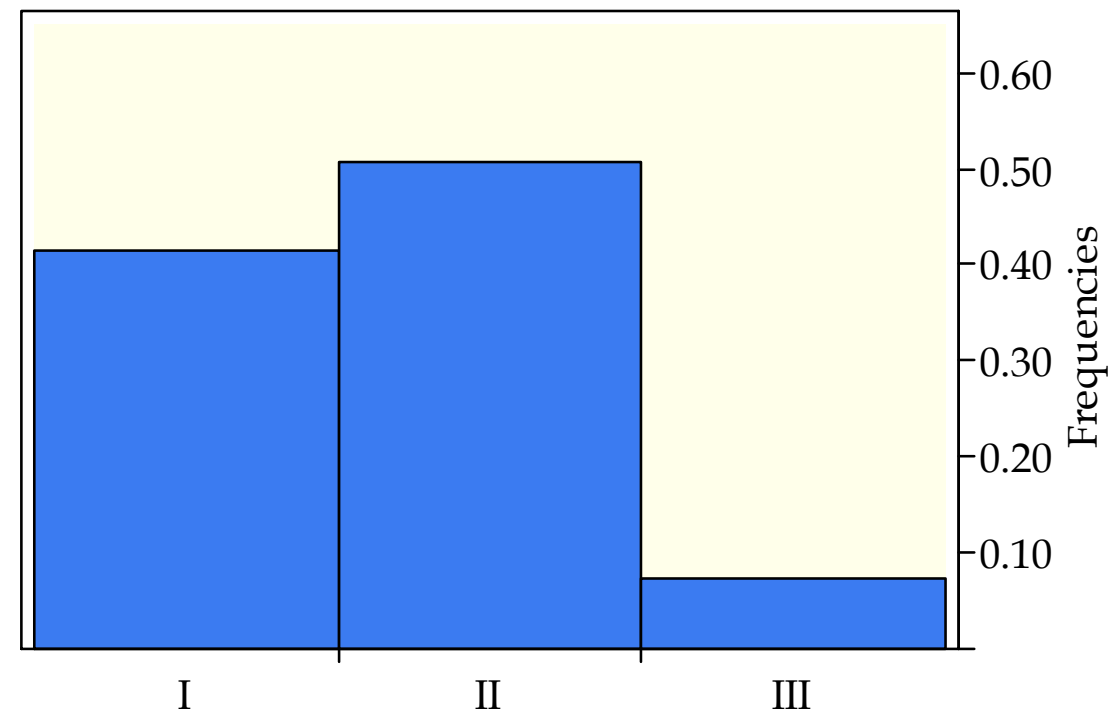

Figure 12. Frequency of molar classification (Angle) in White patients. 


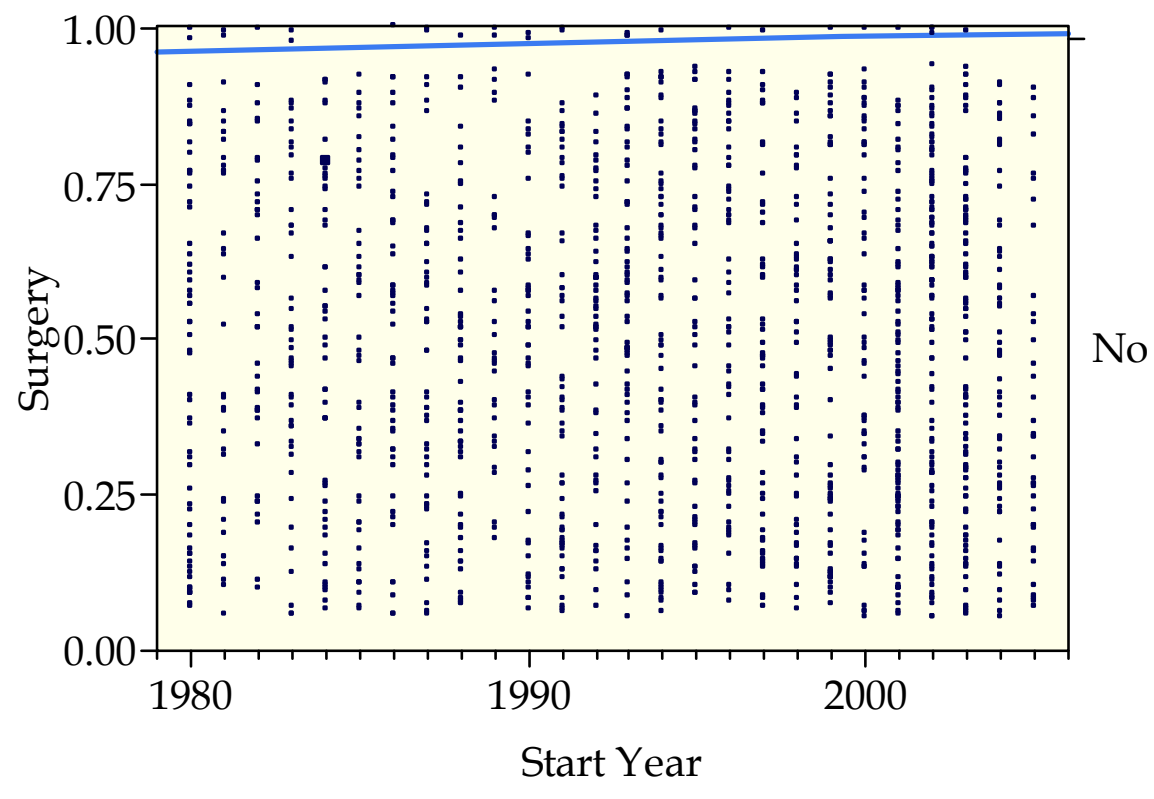

Figure 13. Plot of the frequency of surgical cases as a function of start dates. The frequency has decreased significantly over the 26 year interval recorded here.

Table 8. Results of logistic regression testing for a significant change in proportions of surgery and non-surgery patients between 1980 and 2005.

\begin{tabular}{lcccc}
\hline Term & Estimate & Sem & $\mathrm{X}^{2}$ & P-value \\
\hline Intercept & -94.229974 & 49.282127 & 3.66 & 0.0559 \\
Start Year & 0.0492315 & 0.0247503 & 3.96 & 0.0467 \\
\hline
\end{tabular}


surgical cases $(\bar{x}=20.2 \mathrm{yrs})$ significantly exceeded that of the other orthodontic patients $(\bar{x}=15.7 \mathrm{yrs})$, since the effective cessation of growth is generally a consideration $(\mathrm{F}=11.1 ; \mathrm{P}=0.0009)$.

\section{$\underline{\text { Age at Treatment }}$}

The backbone of most orthodontic practices is the young adolescent who has recently achieved a full permanent dentition, and that is the case here (Figure 14). The mean age at the start of treatment for the total sample is 15.8 years with a large standard deviation ( $\mathrm{sd}=7.4$ years). Younger cases consist of children with facial clefts or with craniofacial syndromes in whom treatment began soon after birth. The preadolescent segment consists of children receiving early treatment in the mixed dentition. The age distribution also is decidedly positively skewed, which reflects the older segment of the adult population now seeking orthodontic treatment.

The mean age of child and adolescent patients seeking treatment (patients age 6 to 17) is 13.4 years with a standard deviation of 1.9 years. The distribution of these patients is shown in Figure 15. Although there are younger patients, 6 years old was chosen as the lower end of the child and adolescent group because it is likely that these children are being treated orthodontically, with early treatment. The youngest children were excluded here because they are likely to be treated for cleft palate or branchial arch syndromes.

Adult patients, those 18 years old and older, had a mean age of 30.1 years with a standard deviation of 9.4. The oldest patient treated was 66 years old and the distribution of these patients is shown in Figure 16.

Over the time interval there was a significant increase in the age of patients at the start of treatment $(\mathrm{P}=0.0003$; Figure 17, Table 9). This trend reflects the fact that more adults are seeking orthodontic treatment as time goes forward.

\section{$\underline{\text { Treatment Mechanics }}$}

Treatment mechanics at the University consist of three categories: Begg mechanics, standard edgewise mechanics, and straight-wire edgewise mechanics. Begg treatment was discontinued in 1999, whereas both standard edgewise mechanics and straight-wire edgewise mechanics were used in the clinic throughout the quarter-century surveyed. Information about mechanics was available for 1,454 patients. Overall, the patients were treated with Begg 


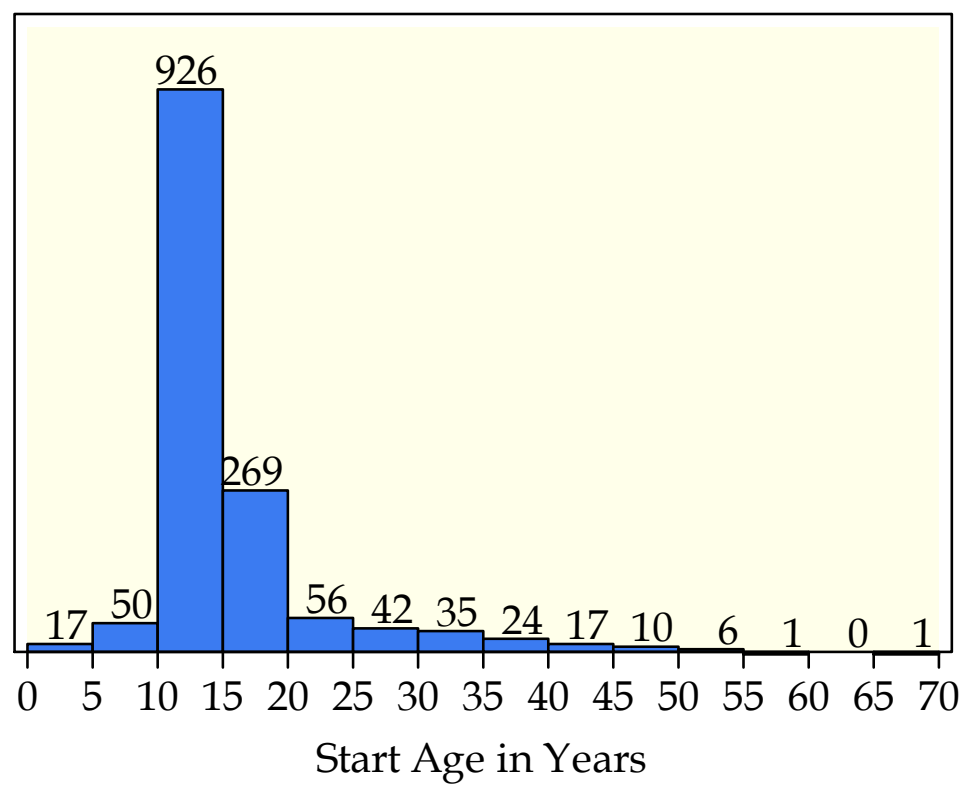

Figure 14. Plot of ages at the start of treatment (years) for all patients in the sample.

The vertical axis is counts of the cases (sexes and races pooled).

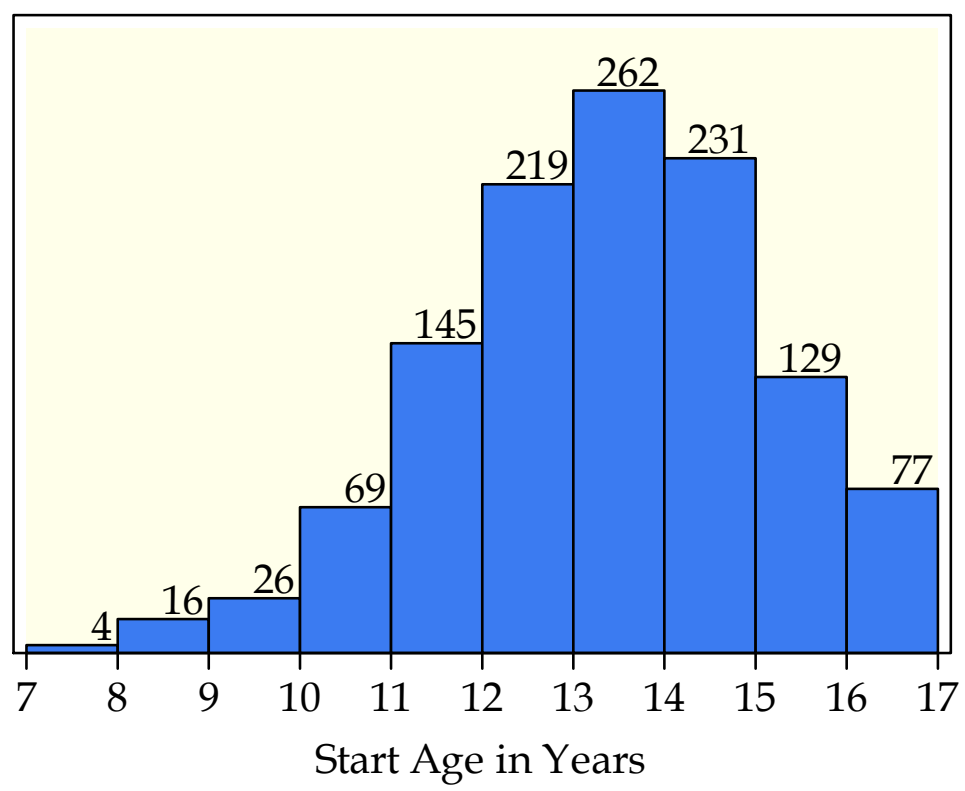

Figure 15. Plot of ages at the start of treatment (years) for patients age 6 to 17 (sexes and races pooled). 


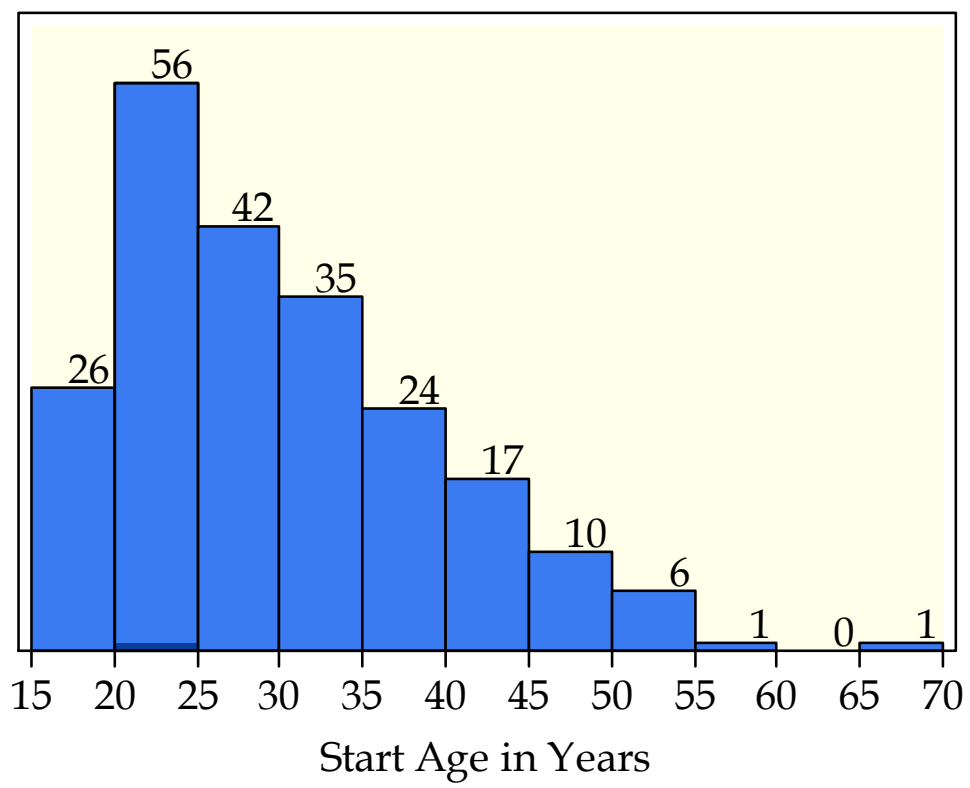

Figure 16. Plot of ages at the start of treatment (years) for patients age 18 and older (sexes and races pooled). 


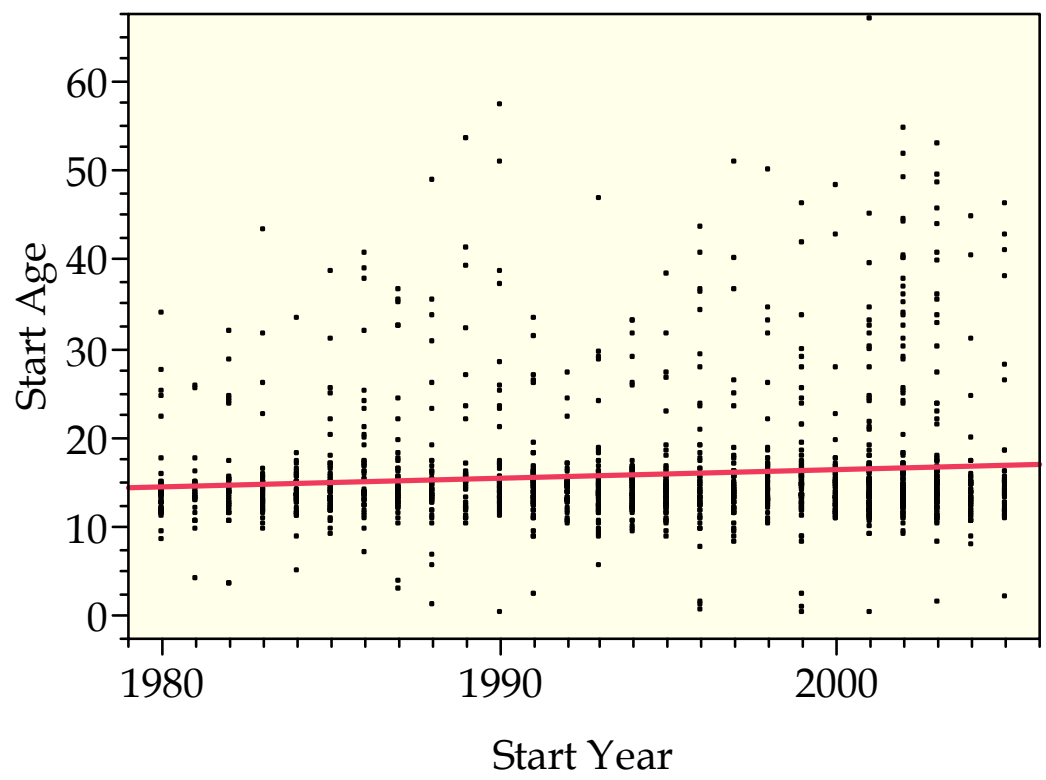

Figure 17. Plot generated by bivariate fit between the year of case start against patient start age for all cases.

Average patient start age has significantly increased over the interval studied, reflecting the increase in adult patients seeking treatment: Start Age $=-174.85+$ 0.10 (Start Year).

Table 9. Results of bivariate fit testing for a significant change in the start age over the quarter century surveyed.

\begin{tabular}{lcccc}
\hline Term & Estimate & Std Error & t-test & P-value \\
\hline Intercept & -174.8498 & 52.21472 & -3.35 & 0.0008 \\
Start Year & 0.0956165 & 0.026186 & 3.65 & 0.0003 \\
\hline
\end{tabular}


mechanics in $18 \%$ of cases, with standard edgewise in $38 \%$ of cases, and with straight-wire edgewise in $44 \%$ of cases (Figure 18).

As expected with a cessation of a treatment modality, the ratio of cases treated by type of mechanics changed. The frequency of Begg mechanics declined from being the most common type of treatment mechanics in the early eighties to eventually dying out in the late nineties. Over this time period the percentage of straight-wire edgewise and standard edgewise each increased to roughly $50 \%$ of the cases treated. Excluding the Begg cases from analysis, the overall distribution of cases is 53\% straight-wire edgewise mechanics and $47 \%$ standard edgewise mechanics (Figure 19).

Using logistic regression, the ratio of standard edgewise mechanics to straight-wire edgewise mechanics did not significantly change over time $\left(\mathrm{X}^{2}=\right.$ 0.02; $\mathrm{P}=0.90$ ), as seen in Figure 20, Table 10. However, as Begg mechanics declined, there was a proportionate increase in the practice of standard edgewise and straight-wire edgewise in the University clinic (Figure 21, Table 11, and Figure 22, Table 12, respectively).

\section{Extraction Frequency}

Extraction data were available for 1,439 patients treated from 1980 to 2005. Of these, $55 \%$ were treated with extractions while $45 \%$ were treated nonextraction. As shown in Figure 23, Table 13, the overall frequency of extraction treatment for all mechanics has significantly decreased over time $\left(\mathrm{X}^{2}=42.0 ; \mathrm{P}<\right.$ $0.0001)$.

Each type of treatment mechanics, when considered individually, also showed a decrease in frequency of extractions over time: $\operatorname{Begg}\left(\mathrm{X}^{2}=6.73 ; \mathrm{P}=\right.$ $<0.0095$; Figure 24, Table 14), standard edgewise $\left(X^{2}=19.95 ; P<0.0001\right.$; Figure 25, Table 15), and straight-wire edgewise $\left(X^{2}=7.23 ; P<0.0072\right.$; Figure 26, Table 16). The decrease in extraction frequency reflects a national trend, and there are several contributory causes towards non-extraction treatment.

As shown in Figure 27, Table 17, and in Figure 28, Table 18), when standard edgewise and straight-wire edgewise cases are compiled, both fourpremolar and two-premolar extraction cases significantly decrease over time compared to non-extraction cases $\left(\mathrm{X}^{2}=28.4 ; \mathrm{P}<0.0001 ; \mathrm{X}^{2}=20.9 ; \mathrm{P}<0.0001\right)$. When four-premolar and two-premolar extraction cases are compared over the 26 year interval, there are no significant differences found $\left(\mathrm{X}^{2}=1.19 ; \mathrm{P}<0.27\right.$;

Figure 29, Table 19). 


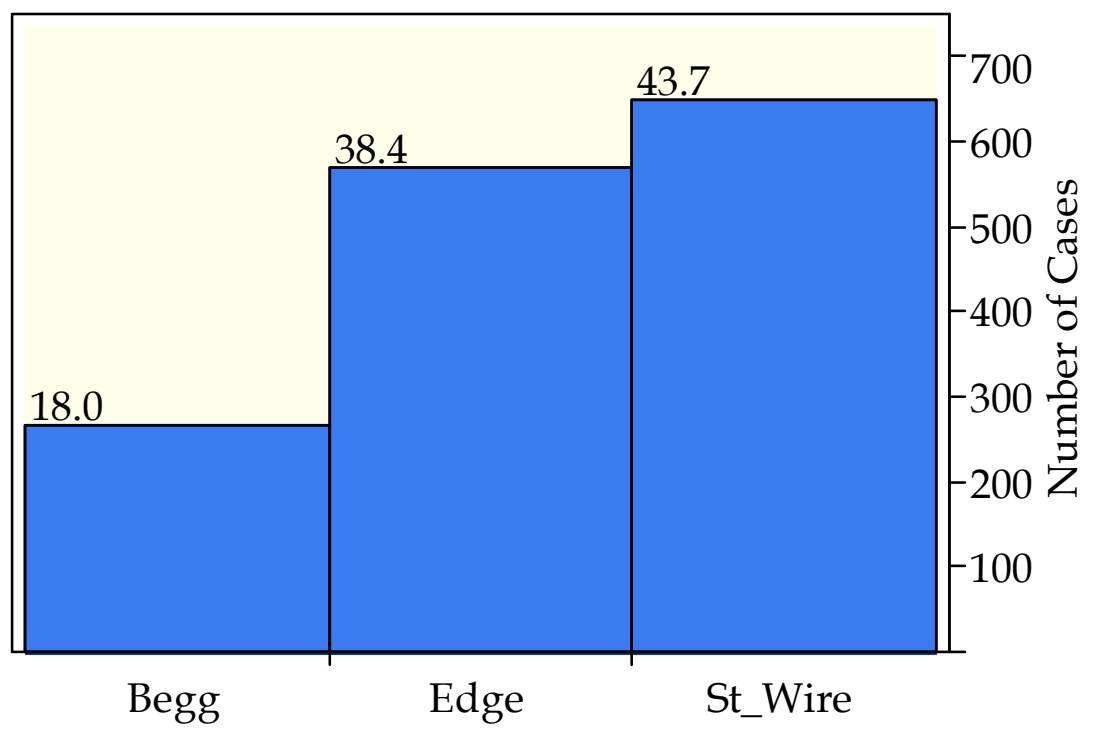

Figure 18. Histogram showing the number of cases treated with Begg, standard edgewise and straight-wire edgewise mechanics over the 26 years surveyed. Percentages are shown on top of the bars.

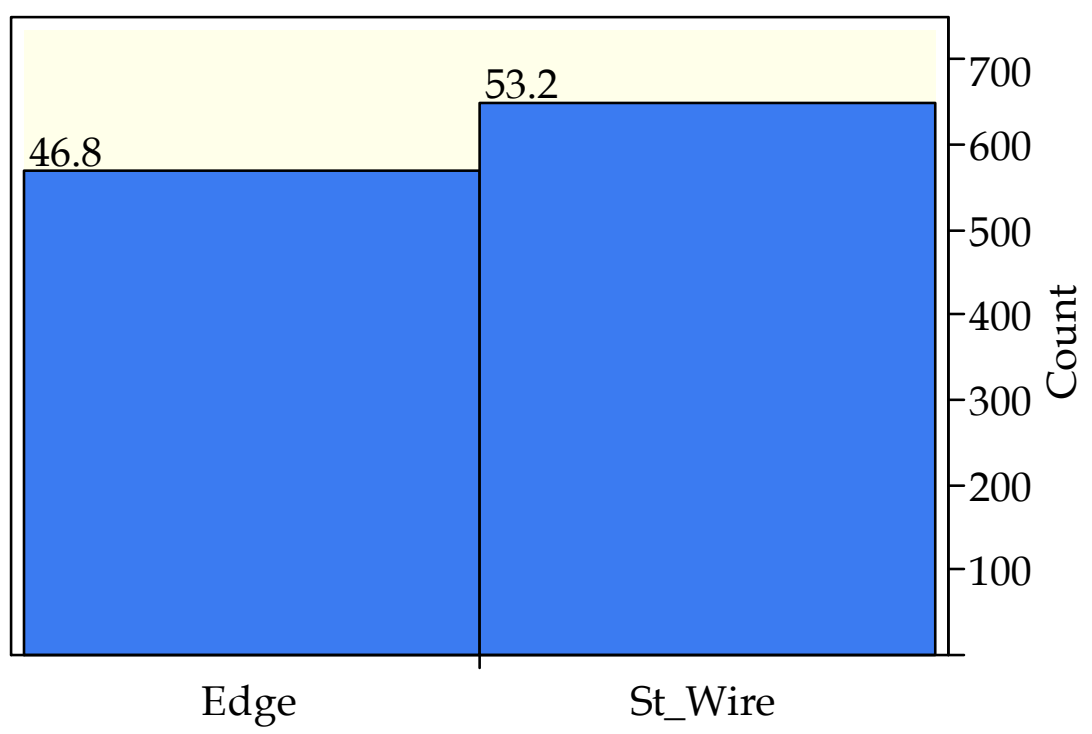

Figure 19. Histogram showing the number of cases treated with standard edgewise and straight-wire edgewise mechanics only (excluding Begg) over the 26 years surveyed.

Percentages are shown on top of the bars. 


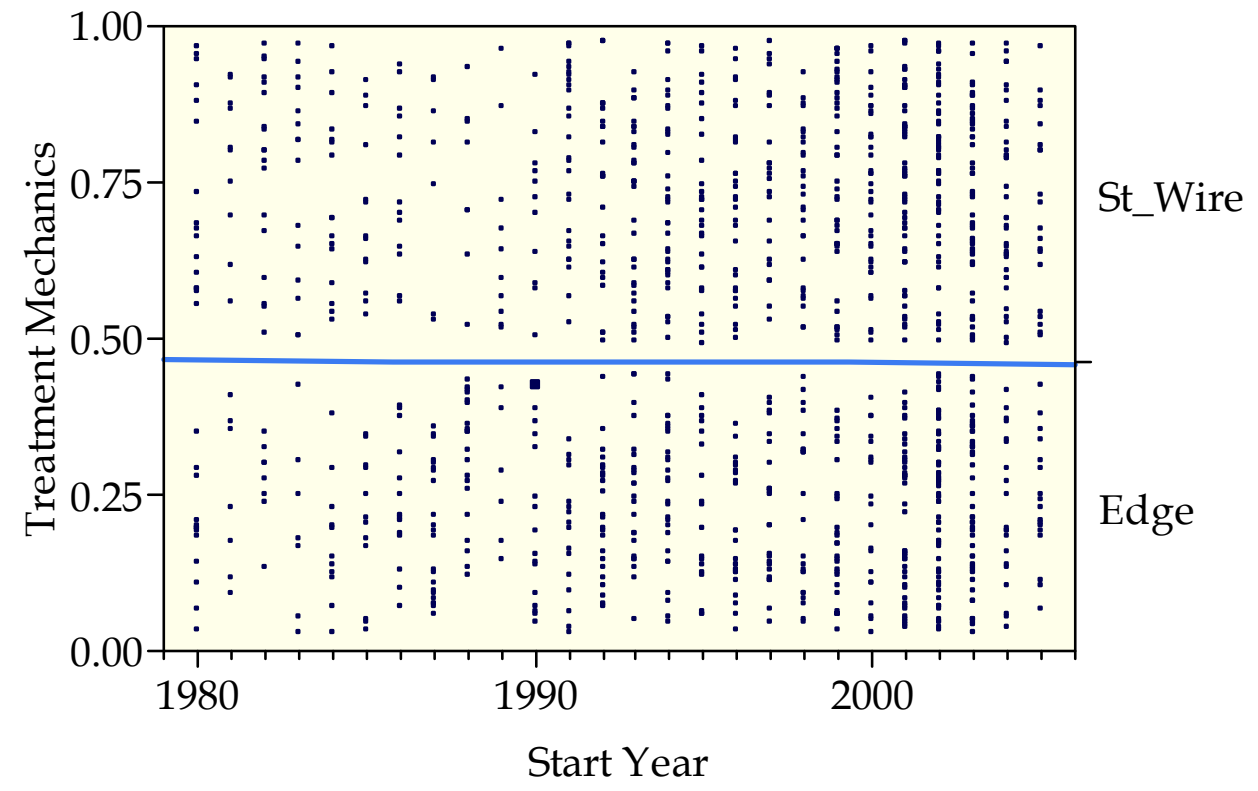

Figure 20. Plot generated by logistic analysis of treatment mechanics (standard edgewise, straight-wire) against the year the case was started. Excluding Begg mechanics, the ratio of treatment mechanics has not significantly changed through time in the quarter-century interval.

Table 10. Results of logistic regression testing for a significant change in proportions of treatment mechanics for standard edgewise and straight-wire edgewise cases treated between 1980 and 2005.

\begin{tabular}{lcccc}
\hline Term & Estimate & sem & $\mathrm{X}^{2}$ & P-value \\
\hline Intercept & 1.9688136 & 16.758991 & 0.01 & 0.9065 \\
Start Year & -0.0010636 & 0.0083983 & 0.02 & 0.8992 \\
\hline
\end{tabular}




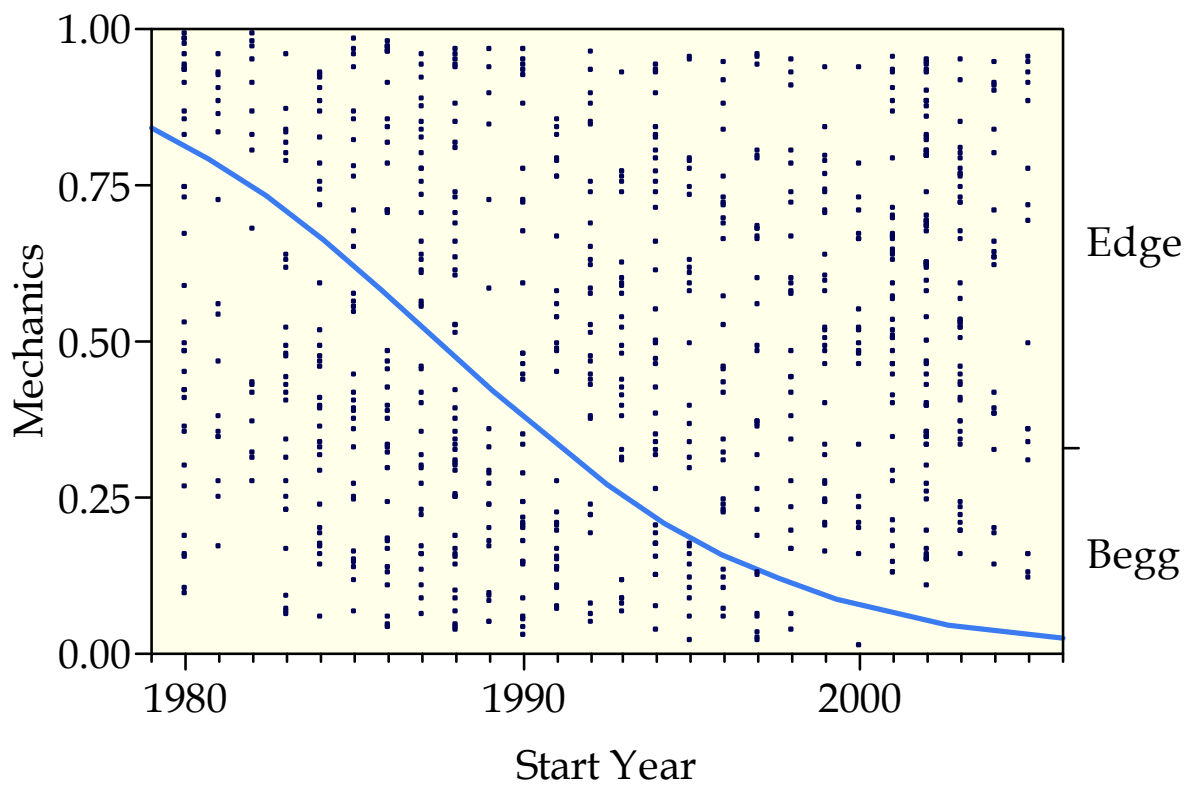

Figure 21. Plot generated by logistic analysis of treatment mechanics (Begg, standard edgewise) against the year the case was started.

The frequencies of treatment mechanics have significantly changed through time in the quarter-century interval.

Table 11. Results of logistic regression testing for a significant change in proportions of treatment mechanics for Begg and standard edgewise cases treated between 1980 and 2005.

\begin{tabular}{lcccc}
\hline Term & Estimate & Sem & $\mathrm{X}^{2}$ & P-value \\
\hline Intercept & 393.67 & 29.930274 & 173.00 & $<0.0001$ \\
Start Year & -0.20 & 0.0150421 & 173.40 & $<0.0001$ \\
\hline
\end{tabular}




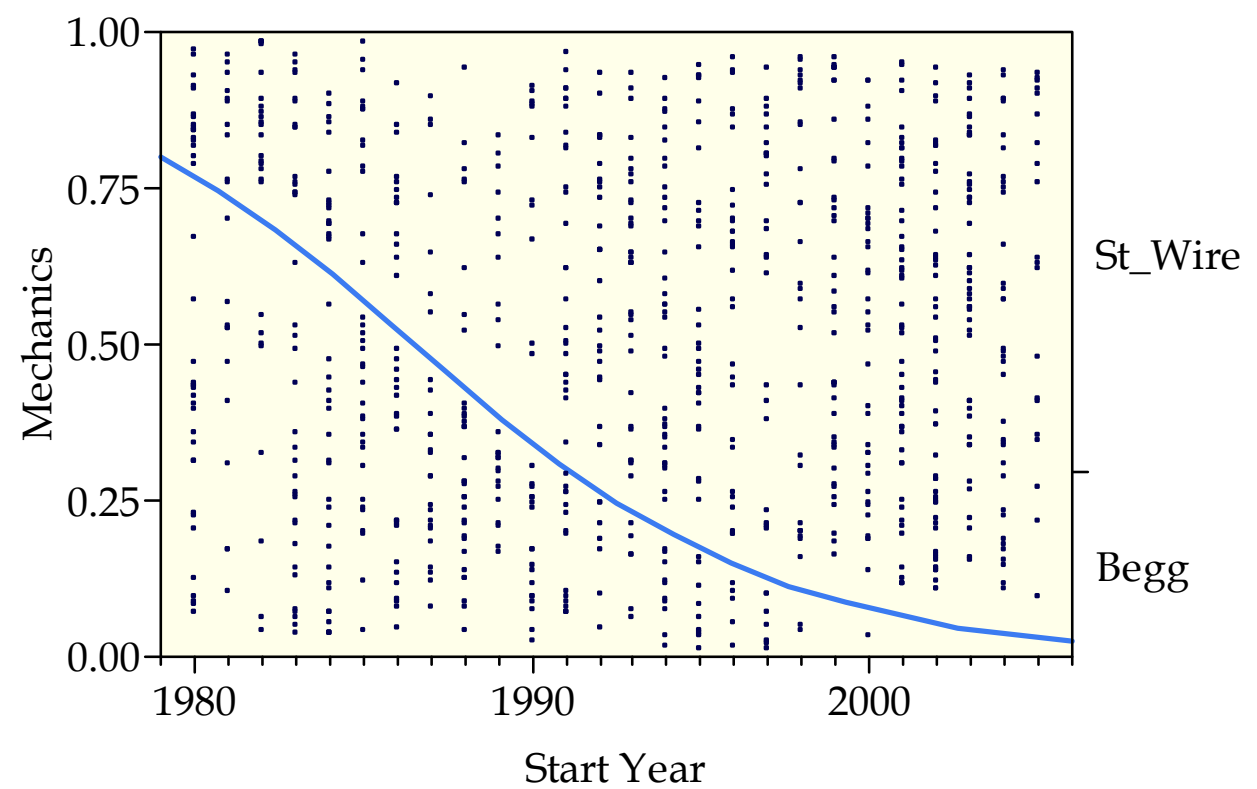

Figure 22. Plot generated by logistic analysis of treatment mechanics (Begg, straight-wire) against the year the case was started.

The frequencies of treatment mechanics have significantly changed through time in the quarter-century interval.

Table 12. Results of logistic regression testing for a significant change in proportions of treatment mechanics for Begg and straight-wire edgewise cases treated between 1980 and 2005.

\begin{tabular}{lcccc}
\hline Term & Estimate & Sem & $\mathrm{X}^{2}$ & P-value \\
\hline Intercept & 368.760545 & 27.24806 & 183.15 & $<0.0001$ \\
Start Year & -0.1856322 & 0.0136945 & 183.74 & $<0.0001$ \\
\hline
\end{tabular}




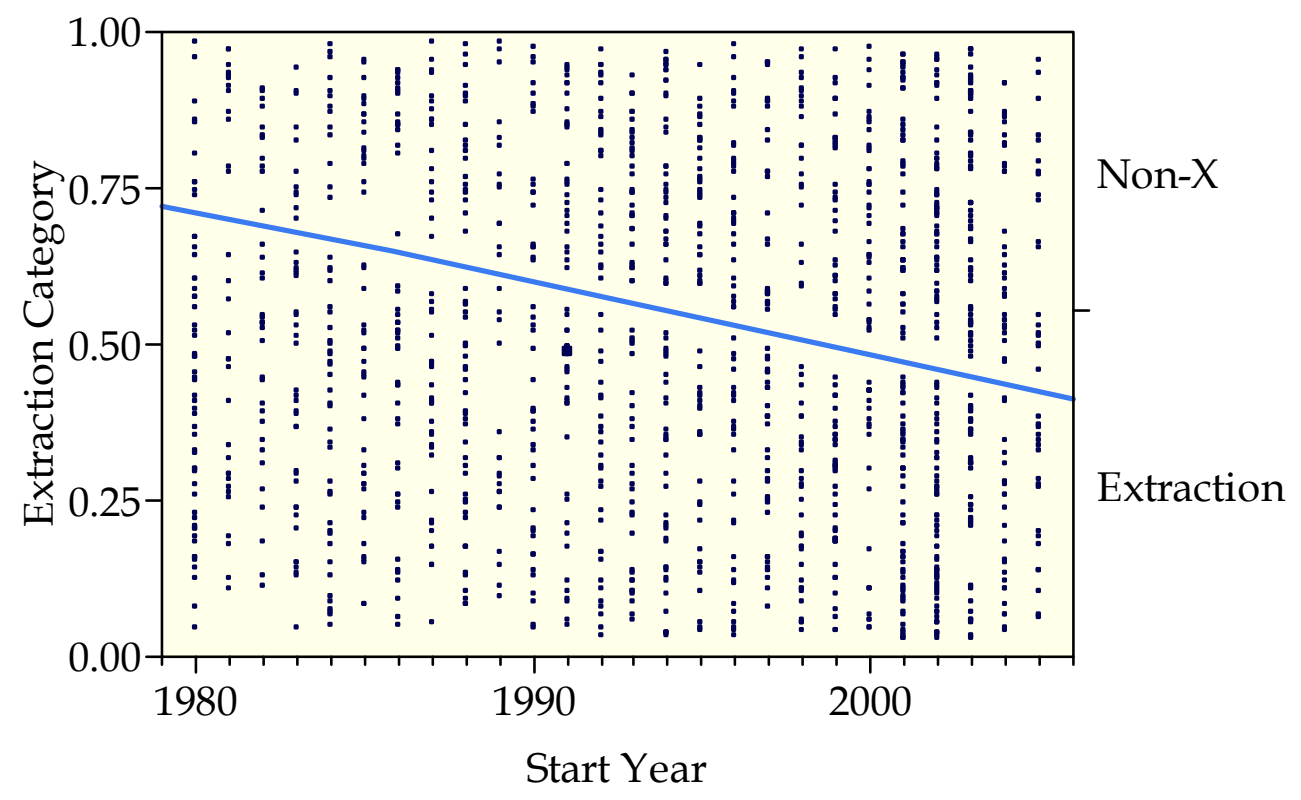

Figure 23. Plot generated by logistic analysis of extraction category against the year the case was started for all cases.

The frequency of extraction cases has significantly decreased over time in the quarter-century interval.

Table 13. Results of logistic regression testing for a significant change in proportions of extraction and non-extraction for all cases treated between 1980 and 2005.

\begin{tabular}{lcccc}
\hline Term & Estimate & Sem & $\mathrm{X}^{2}$ & P-value \\
\hline Intercept & 96.170574 & 14.807837 & 42.18 & $<0.0001$ \\
Start Year & -0.0481198 & 0.0074252 & 42.00 & $<0.0001$ \\
\hline
\end{tabular}




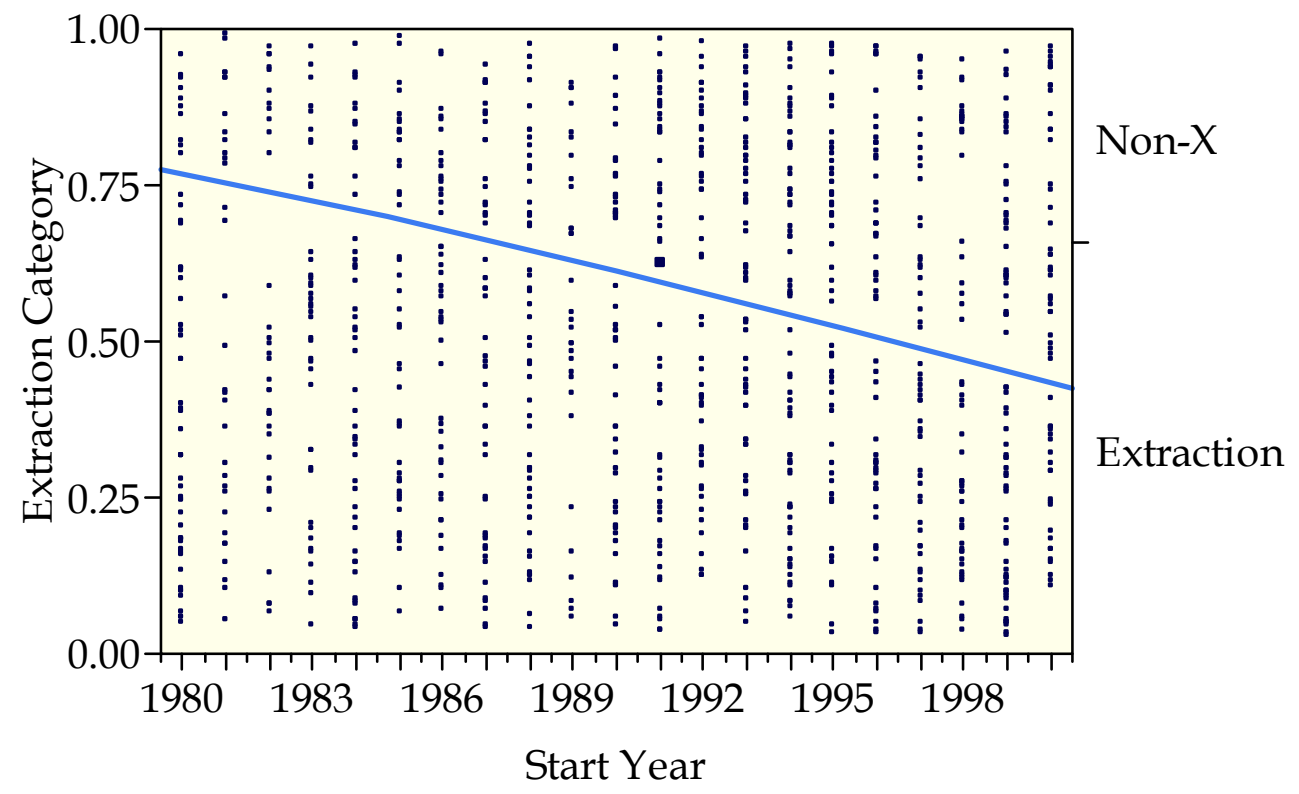

Figure 24. Plot generated by logistic analysis of extraction category against the year the case was started for Begg mechanics only.

The frequency of extraction cases has significantly decreased over time in the quarter-century interval.

Table 14. Results of logistic regression testing for a significant change in proportions of extraction and non-extraction for Begg cases treated between 1980 and 2005.

\begin{tabular}{lcccc}
\hline Term & Estimate & Sem & $\mathrm{X}^{2}$ & P-value \\
\hline Intercept & 146.963311 & 56.38589 & 6.79 & 0.0092 \\
Start Year & -0.0736175 & 0.0283669 & 6.73 & 0.0095 \\
\hline
\end{tabular}




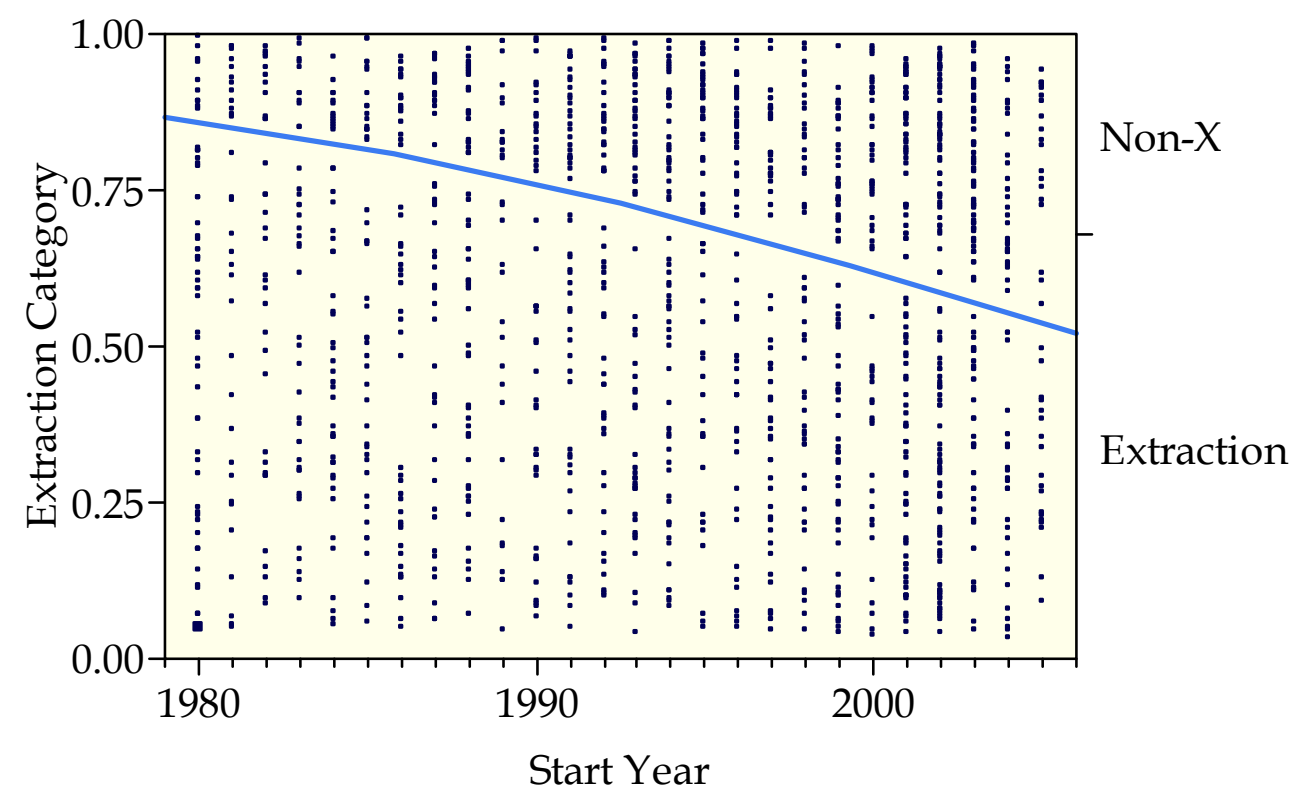

Figure 25. Plot generated by logistic analysis of extraction category against the year the case was started for standard edgewise mechanics only.

The frequency of extraction cases has significantly decreased over time in the quarter-century interval.

Table 15. Results of logistic regression testing for a significant change in proportions of extraction and non-extraction for standard edgewise cases treated between 1980 and 2005.

\begin{tabular}{lcccc}
\hline Term & Estimate & Sem & $\mathrm{X}^{2}$ & P-value \\
\hline Intercept & 133.46827 & 29.725589 & 20.16 & $<0.0001$ \\
Start Year & -0.0664906 & 0.0148873 & 19.95 & $<0.0001$ \\
\hline
\end{tabular}




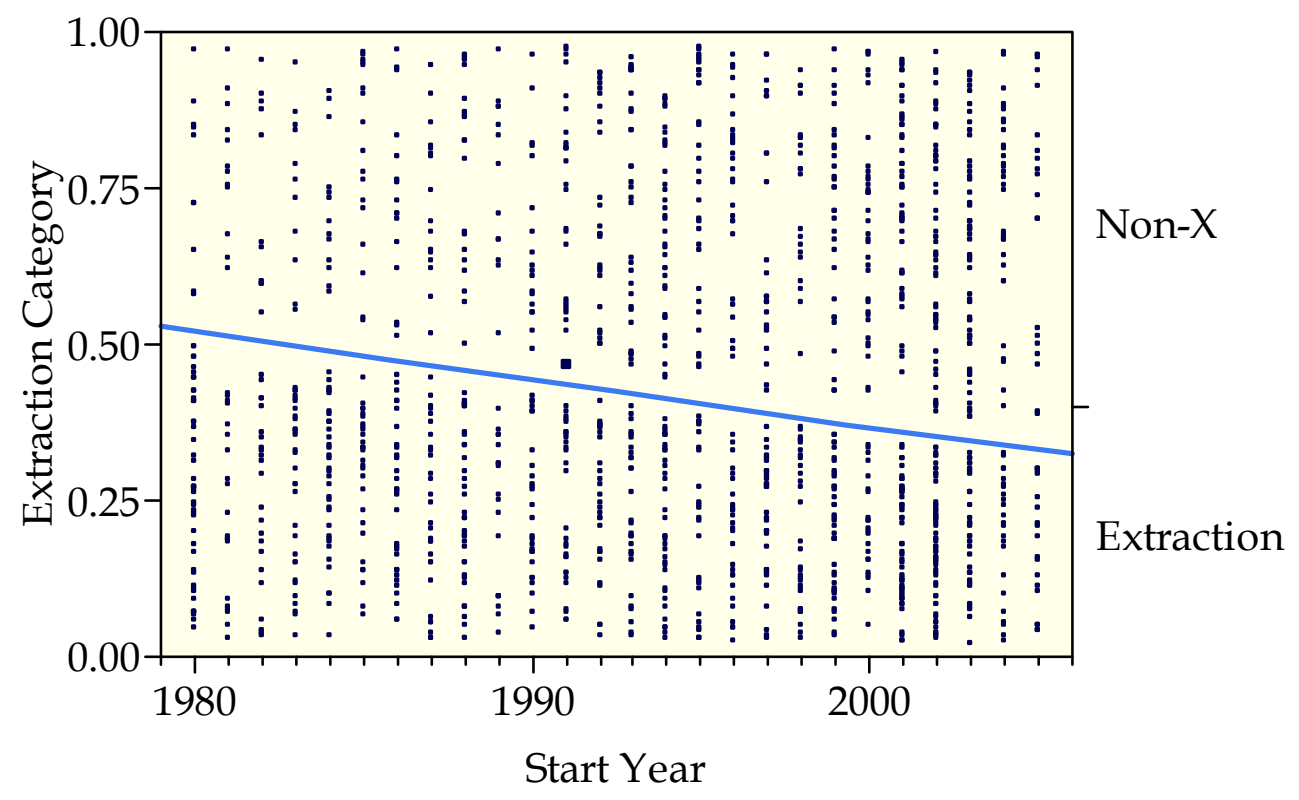

Figure 26. Plot generated by logistic analysis of extraction category against the year the case was started for straight-wire edgewise mechanics only.

The frequency of extraction cases has significantly decreased over time in the quarter-century interval.

Table 16. Results of logistic regression testing for a significant change in proportions of extraction and non-extraction for straight-wire edgewise cases treated between 1980 and 2005.

\begin{tabular}{lcccc}
\hline Term & Estimate & Sem & $\mathrm{X}^{2}$ & P-value \\
\hline Intercept & 62.1492066 & 23.268033 & 7.13 & 0.0076 \\
Start Year & -0.0313465 & 0.0116611 & 7.23 & 0.0072 \\
\hline
\end{tabular}




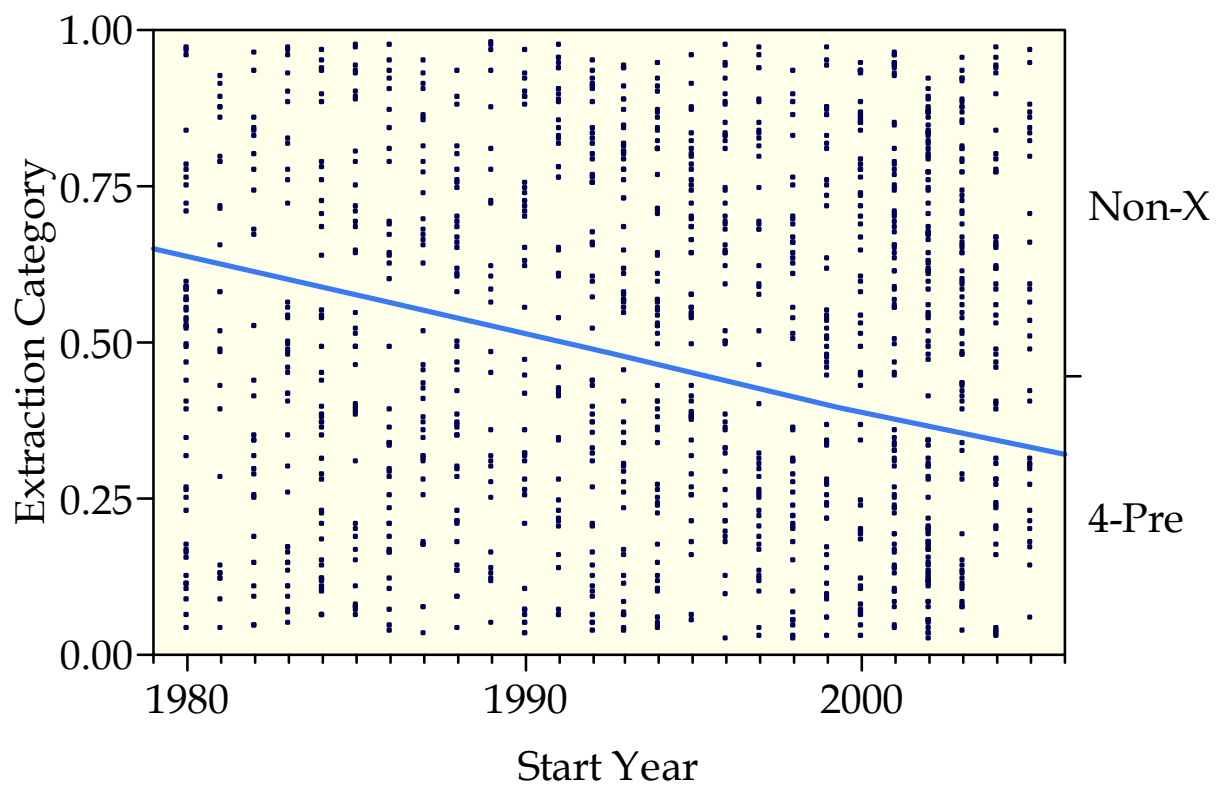

Figure 27. Plot generated by logistic analysis of extraction category (Non-X, 4Pre) against the year the case was started for standard edgewise and straightwire edgewise mechanics.

The frequency of 4 premolar extraction cases has significantly decreased compared to non extraction cases over time in the quarter-century interval.

Table 17. Results of logistic regression testing for a significant change in proportions of four premolar extraction and non-extraction for all edgewise cases treated between 1980 and 2005.

\begin{tabular}{lcccc}
\hline Term & Estimate & Sem & $\mathrm{X}^{2}$ & P-value \\
\hline Intercept & 100.800518 & 18.917202 & 28.39 & $<0.0001$ \\
Start Year & -0.0506265 & 0.0094803 & 28.52 & $<0.0001$ \\
\hline
\end{tabular}




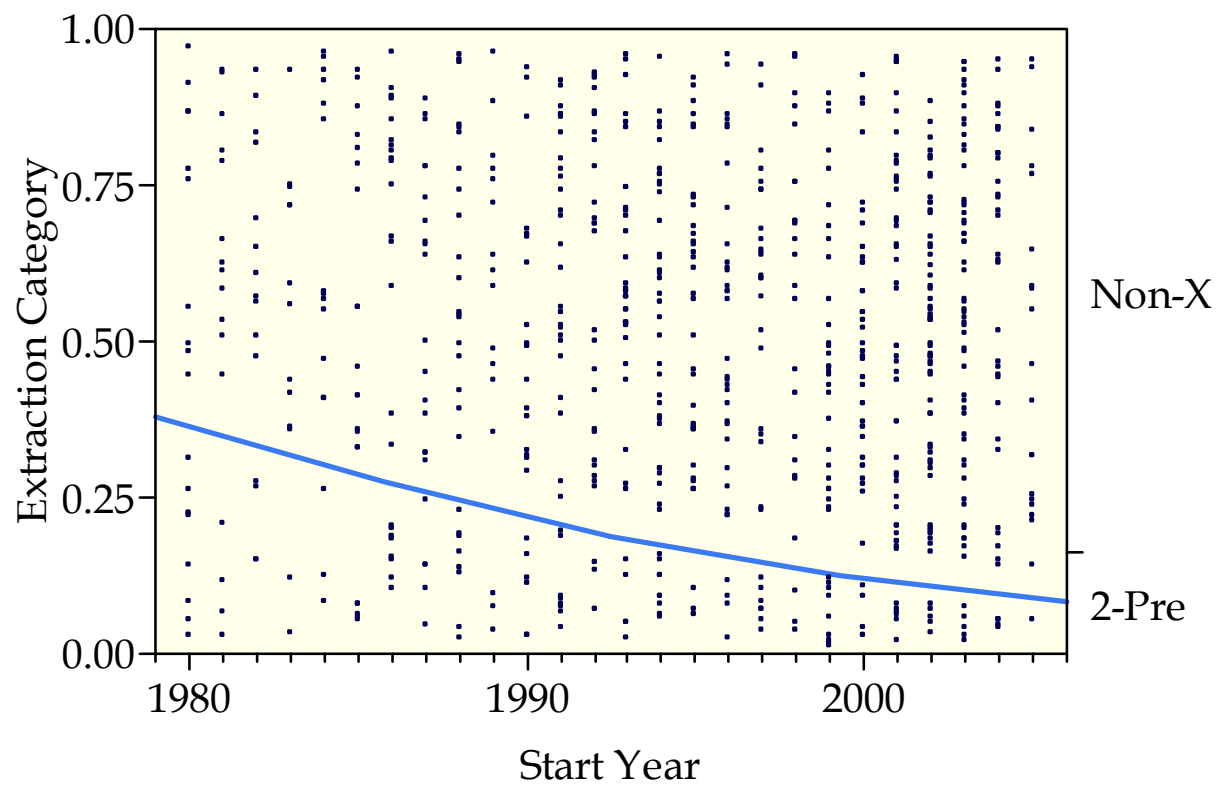

Figure 28. Plot generated by logistic analysis of extraction category (Non-X, 2Pre) against the year the case was started for standard edgewise and straightwire edgewise mechanics.

The frequency of 2 premolar extraction cases has significantly decreased compared to non-extraction cases over time in the quarter-century interval.

Table 18. Results of logistic regression testing for a significant change in proportions of two premolar extraction and non-extraction for all edgewise cases treated between 1980 and 2005.

\begin{tabular}{lcccc}
\hline Term & Estimate & Sem & $\mathrm{X}^{2}$ & P-value \\
\hline Intercept & 140.991814 & 30.83236 & 20.91 & $<0.0001$ \\
Start Year & -0.0714939 & 0.0154623 & 21.38 & $<0.0001$ \\
\hline
\end{tabular}




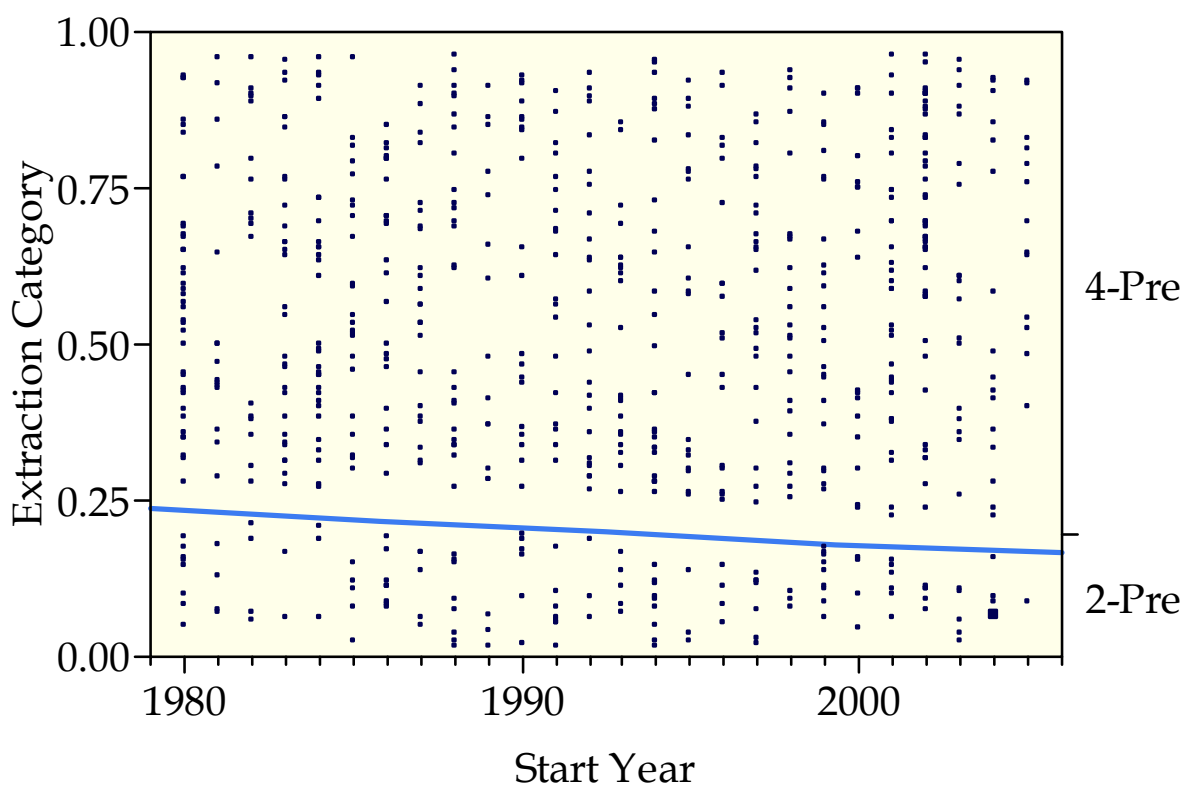

Figure 29. Plot generated by logistic analysis of extraction category (4-Pre, 2-Pre) against the year the case was started for standard edgewise and straight-wire edgewise mechanics.

The frequency of 4 premolar extraction cases has not significantly changed compared to 2 premolar extraction cases over time in the quarter-century interval.

Table 19. Results of logistic regression testing for a significant change in proportions of four premolar extraction and two premolar extraction for all edgewise cases treated between 1980 and 2005.

\begin{tabular}{lcccc}
\hline Term & Estimate & Sem & $\mathrm{X}^{2}$ & P-value \\
\hline Intercept & 31.7647817 & 29.139482 & 1.19 & 0.2757 \\
Start Year & -0.0166434 & 0.0146171 & 1.30 & 0.2549 \\
\hline
\end{tabular}


A significant difference in extraction rates exists for each Angle classification $\left(\mathrm{X}^{2}=14.8 ; 2 \mathrm{df} ; \mathrm{P}<0.0006\right)$. Over the surveyed time, $52 \%$ of Class I cases, $60 \%$ of Class II cases, and $46 \%$ of Class III cases were treated with extractions (Figure 30).

\section{$\underline{\text { TennCare Utilization }}$}

Data on TennCare utilization was available on 1,496 patients. Approximately $5 \%$ of all patients were subsidized for treatment by the State of Tennessee's Medicare program called TennCare. To qualify for subsidized treatment, patients have to be enrolled in the TennCare program, be under the age of 21 at the start of treatment, and score a 28 or higher on the Salzmann Handicapping Malocclusion Index (Salzmann 1968). According to the data, TennCare cases have significantly increased over the quarter century interval surveyed $\left(X^{2}=31.3 ; P<0.0001\right.$; Figure 31, Table 20). This probably is due to a combination of causes. Patient charts became much more informative and consistent in the late 1990s and documentation on TennCare patients increased dramatically. Furthermore, a faculty member in the department was added to the TennCare provider list in 1999, whereas, previously, a school administrator (a general dentist) had been on the provider list and referred patients at his discretion.

TennCare patients also significantly increased from 2000 to $2005\left(X^{2}=4.38\right.$; $\mathrm{P}<0.036$ ), and during that six year span, $9 \%$ of patients were subsidized by TennCare (Figure 32, Table 21). This increase in TennCare patients could be explained by word of mouth among TennCare families and an increase in referrals from TennCare dentists.

\section{$\underline{\text { ANB Angle }}$}

The average ANB angle over all cases measured $(n=1,483)$ is 3.6 degrees with a standard deviation of 3.0 and a range from -13 to 19 degrees. Figure 33 shows the distribution of all patients' ANB angles over the time surveyed.

Patients' ANB angles have not changed significantly over time, as a whole, or when divided into groups based on race (Figure 34, Table 22). 


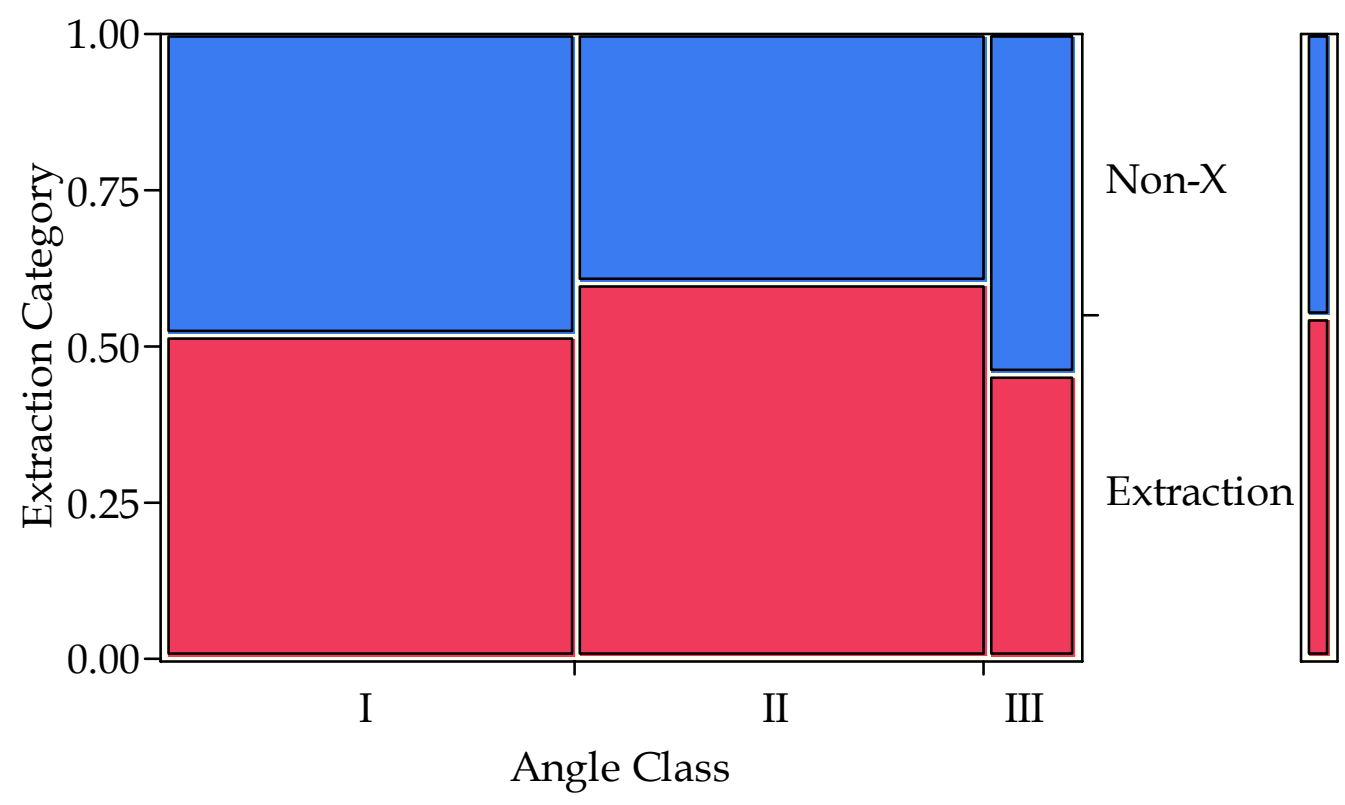

Figure 30. Mosaic plot showing frequency of extraction by Angle classification. A significant difference in extraction frequency exists for each Angle Class. 


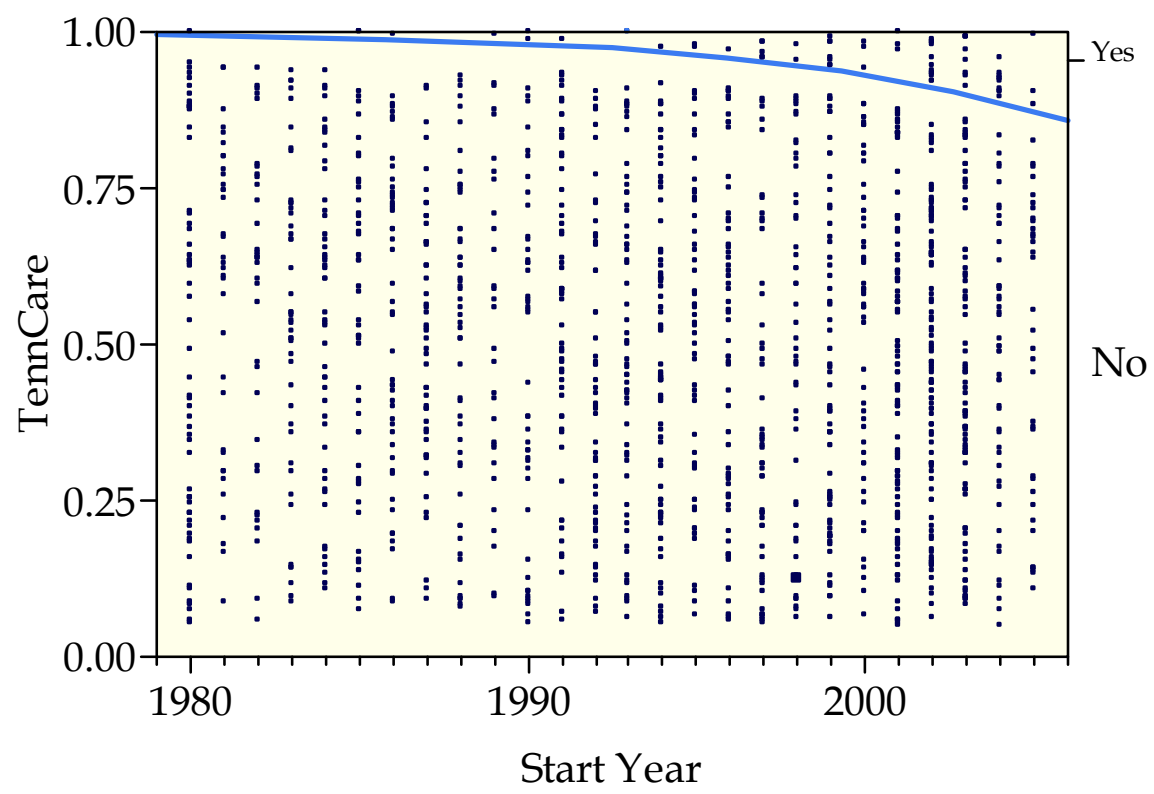

Figure 31. Plot generated by logistic analysis of whether or not a patient had TennCare against the year the case was started for all years.

The frequency of TennCare cases appears to have significantly increased over time, although whether or not more TennCare patients were actually treated is difficult to determine due to possible charting differences in the last 26 years.

Table 20. Results of logistic regression testing for a significant change in proportions of TennCare cases and non-TennCare cases treated between 1980 and 2005.

\begin{tabular}{lcccc}
\hline Term & Estimate & Sem & $\mathrm{X}^{2}$ & P-value \\
\hline Intercept & 268.508534 & 47.506829 & 31.95 & $<0.0001$ \\
Start Year & -0.1329609 & 0.0237658 & 31.30 & $<0.0001$ \\
\hline
\end{tabular}




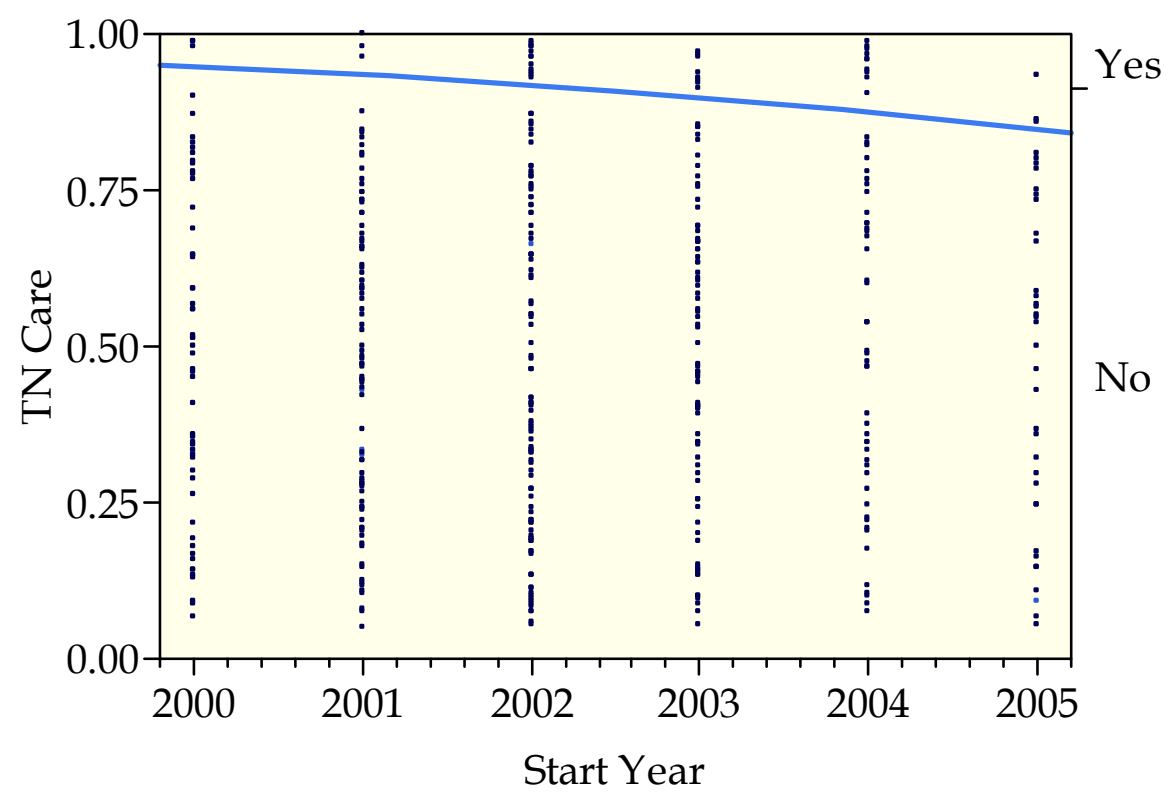

Figure 32. Plot generated by logistic analysis of whether or not a patient had TennCare against the year the case was started for 2000 to 2005.

The frequency of TennCare cases significantly increased over this time, perhaps because of better record keeping.

Table 21. Results of logistic regression testing for a significant change in proportions of TennCare cases and non-TennCare cases treated between 2000 and 2005.

\begin{tabular}{lcccc}
\hline Term & Estimate & Sem & $\mathrm{X}^{2}$ & P-value \\
\hline Intercept & 483.149649 & 229.87852 & 4.42 & 0.0356 \\
Start Year & -0.2401183 & 0.1147861 & 4.38 & 0.0364 \\
\hline
\end{tabular}




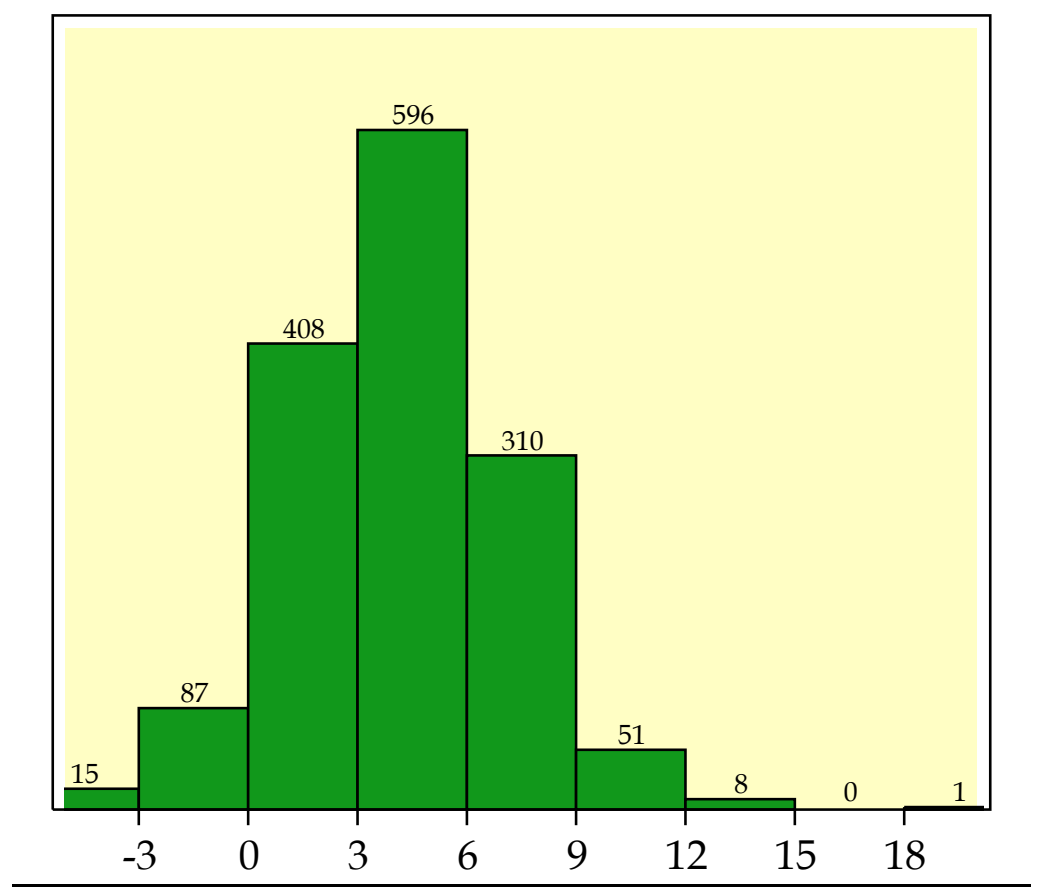

Figure 33. Histogram showing the distribution of ANB angles in the quartercentury surveyed.

ANB (angle) is shown along the horizontal axis, based on all cases scored ( $\mathrm{n}=$ $1,483)$. 


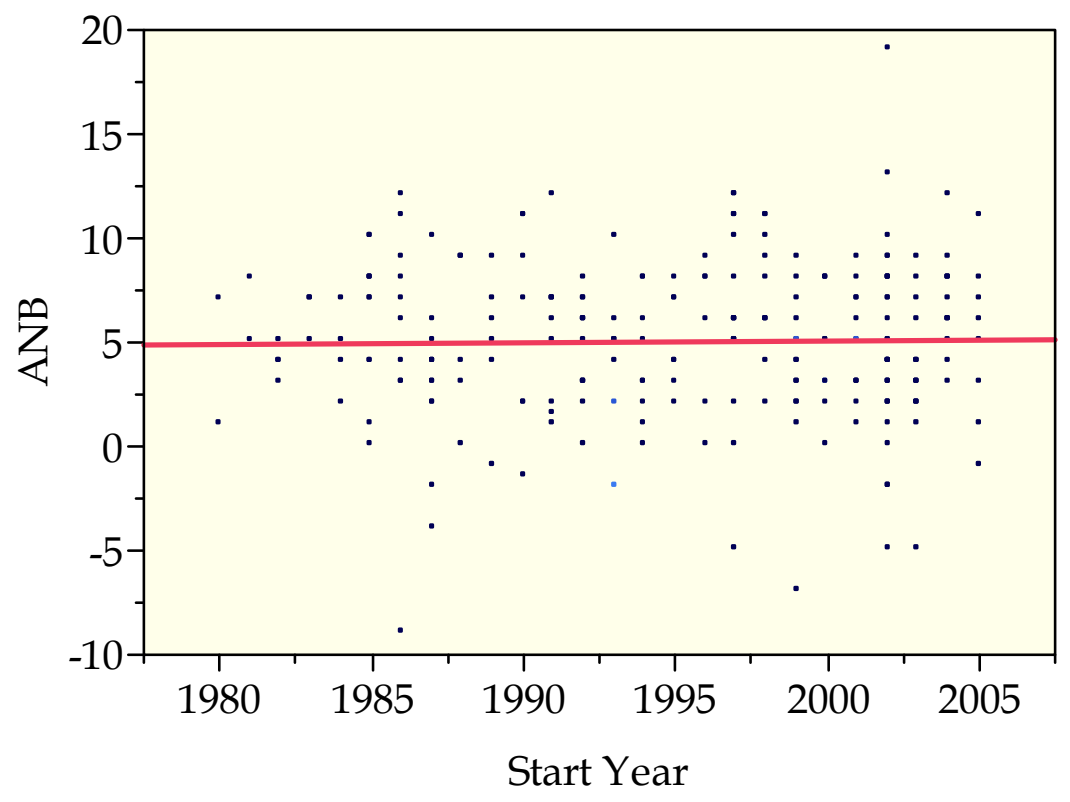

Figure 34. Plot generated by bivariate fit of ANB angle by start year for all cases. The average ANB angle has not significantly changed from 1980 to 2005.

Table 22. Results of bivariate fit testing for a significant change in the ANB angle over the quarter century surveyed.

\begin{tabular}{lrrrr}
\hline Term & Estimate & Std Error & t-test & P-value \\
\hline Intercept & 6.432219 & 21.30936 & 0.30 & 0.7628 \\
Start Year & -0.001447 & 0.01068 & -0.14 & 0.8923 \\
\hline
\end{tabular}




\section{Frankfort Mandibular Plane Angle}

The mean FMA is 25.9 degrees with a standard deviation of 6.1 degrees and a range of 6 degrees to 48 degrees. Figure 35 shows the distribution of the FMAs of all patients treated in the time surveyed.

When all patients are pooled, average FMA has significantly decreased over the surveyed interval (Figure 36, Table 23). When grouped into White, Black, and "other" groups, only the White patients show a significant change in FMA, which significantly decreased (Figure 37, Table 24; Figure 38, Table 25; and Figure 39, Table 26, respectively). The reason for this decrease in FMA over time is unknown, but may be due to changes in how Porion or other lateral cephalogram landmarks are traced.

\section{Duration of Treatment}

The average duration of treatment over the quarter-century surveyed is 2.5 years ( $\mathrm{sd}=1.2$ years) for all cases, 2.8 years $(\mathrm{sd}=1.3$ years) for Begg cases, 2.3 years ( $\mathrm{sd}=1.0$ years) for standard edgewise cases, and 2.5 years ( $\mathrm{sd}=1.2$ years) for straight-wire cases (Figure 40). Using one-way ANOVA and Tukey-Kramer HSD post-hoc analysis, it was found that these mean treatment times were significantly different from one another $(\mathrm{F}=15.4 ; \mathrm{P}<0.0001)$. That is, even though the means are similar, the sample sizes are so large that small differences are detected statistically. Edgewise treatment, with the shortest mean treatment time is significantly different from straight-wire with an intermediate time, and Begg treatment with the longest mean treatment time significantly exceeding mean treatment time for the straight-wire group. These treatment times involve many operators over several years, so the highly significant differences are somewhat surprising. On the other hand, results may be different in the private orthodontists' offices outside this teaching environment.

Treatment duration for all cases combined decreased over the 26 year period studied (Figure 41, Table 27). When Begg cases were looked at as an individual group, treatment time did not significantly change (Figure 42, Table 28), but when standard edgewise cases and straight-wire edgewise cases were looked at as separate groups (Figure 43, Table 29 and Figure 44, Table 30), treatment time decreased significantly. 


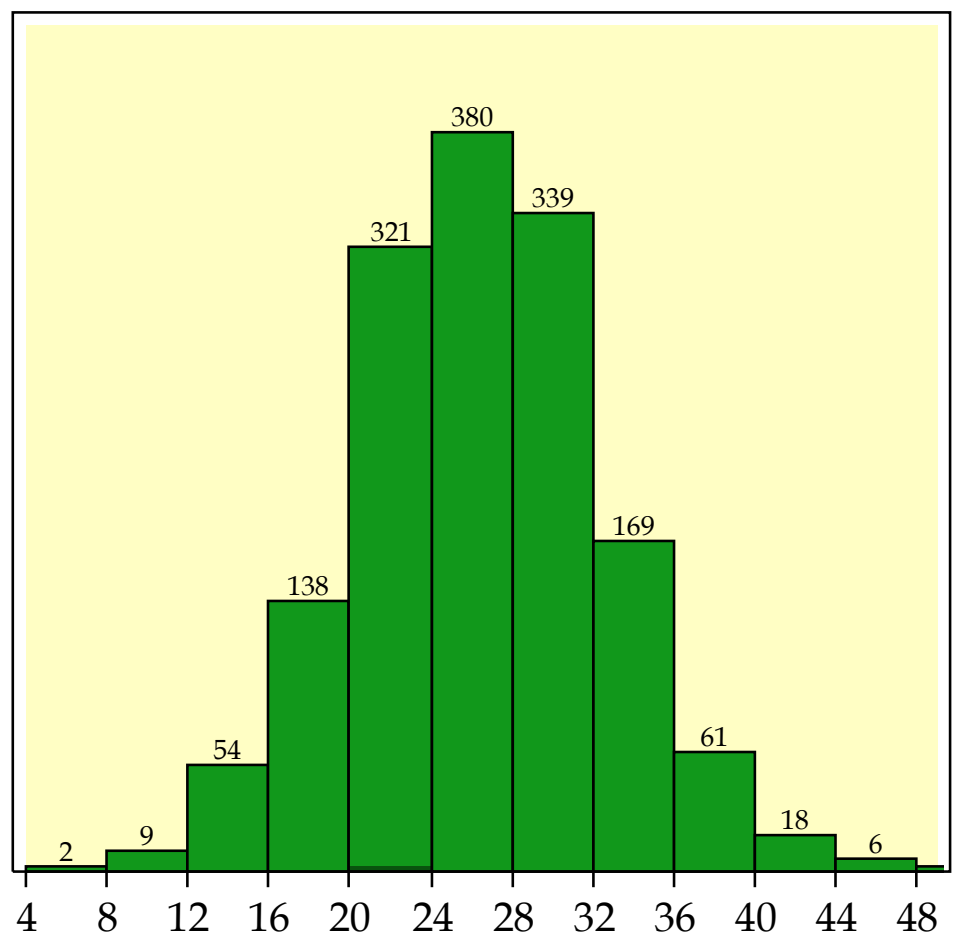

Figure 35. Histogram showing the distribution of the FMA in the quarter-century surveyed. 


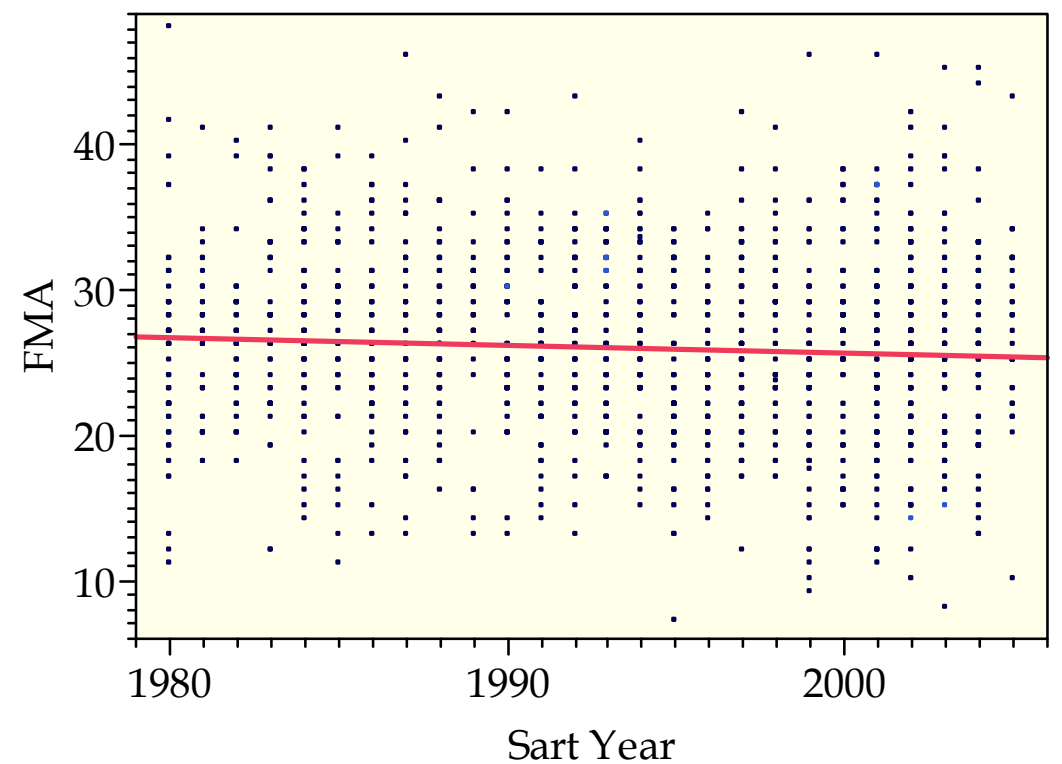

Figure 36. Plot generated by bivariate fit of FMA by start year for all cases. FMA significantly decreased from 1980 to 2005.

Table 23. Results of bivariate fit testing for a significant change in the FMA in all patients over the quarter century surveyed.

\begin{tabular}{lcccc}
\hline Term & Estimate & Std Error & t-test & P-value \\
\hline Intercept & 125.0589 & 43.11605 & 2.90 & 0.0038 \\
Start Year & -0.049701 & 0.021624 & -2.30 & 0.0217 \\
\hline
\end{tabular}




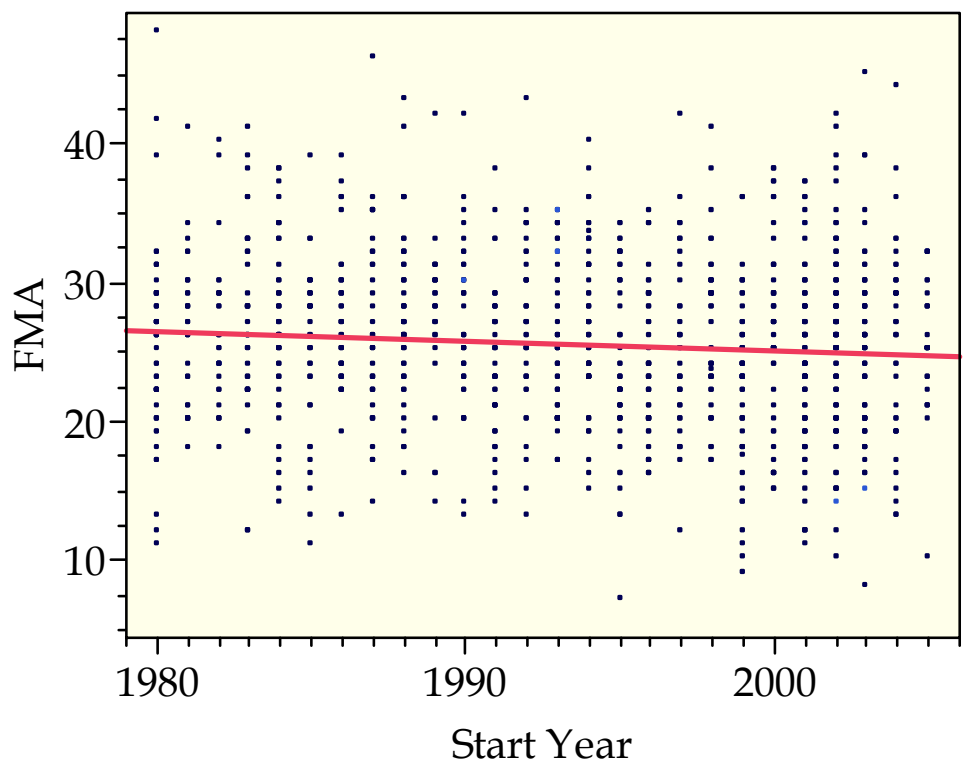

Figure 37. Plot generated by bivariate fit of FMA by start year for White patients only.

FMA significantly decreased from 1980 to 2005: FMA $=165.41-0.07$ (Start Year).

Table 24. Results of bivariate fit testing for a significant change in the FMA in White patients over the quarter century surveyed.

\begin{tabular}{lcccc}
\hline Term & Estimate & Std Error & t-test & P-value \\
\hline Intercept & 165.41877 & 47.33555 & 3.49 & 0.0005 \\
Start Year & -0.070177 & 0.023745 & -2.96 & 0.0032 \\
\hline
\end{tabular}




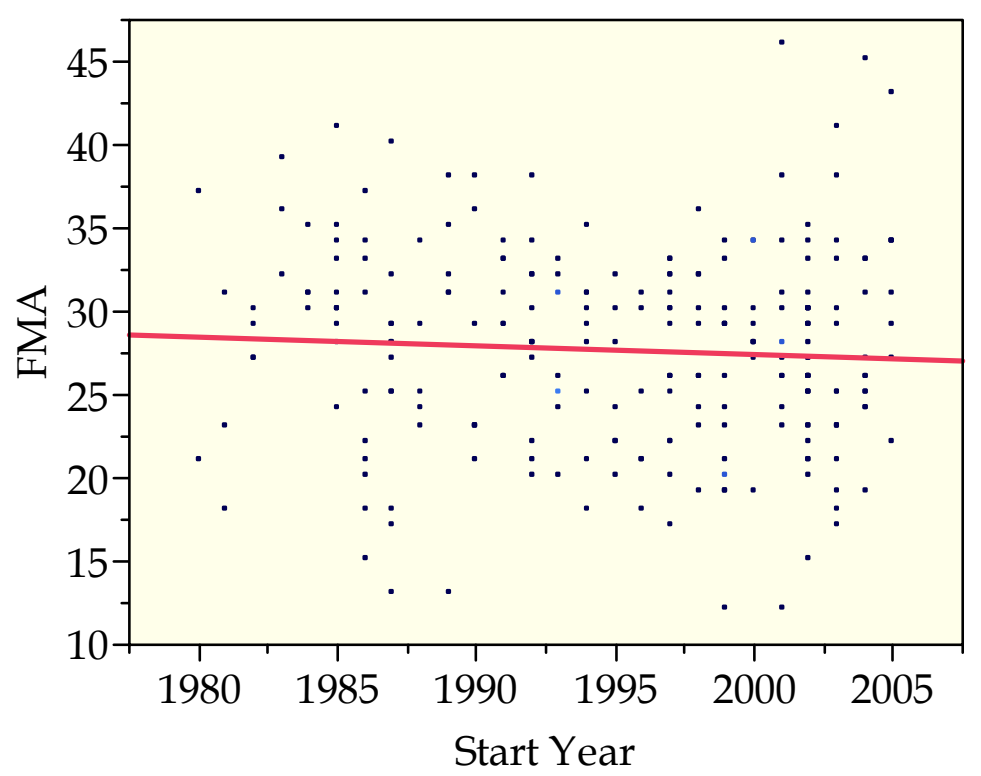

Figure 38. Plot generated by bivariate fit of FMA by start year for Black patients only.

FMA has not significantly changed from 1980 to 2005: FMA $=132.48-0.05$ (Start Year).

Table 25. Results of bivariate fit testing for a significant change in the FMA in Black patients over the quarter century surveyed.

\begin{tabular}{lccrc}
\hline Term & Estimate & Std Error & t-test & P-value \\
\hline Intercept & 132.48264 & 110.2289 & 1.20 & 0.2306 \\
Start Year & -0.052537 & 0.055246 & -0.95 & 0.3426 \\
\hline
\end{tabular}




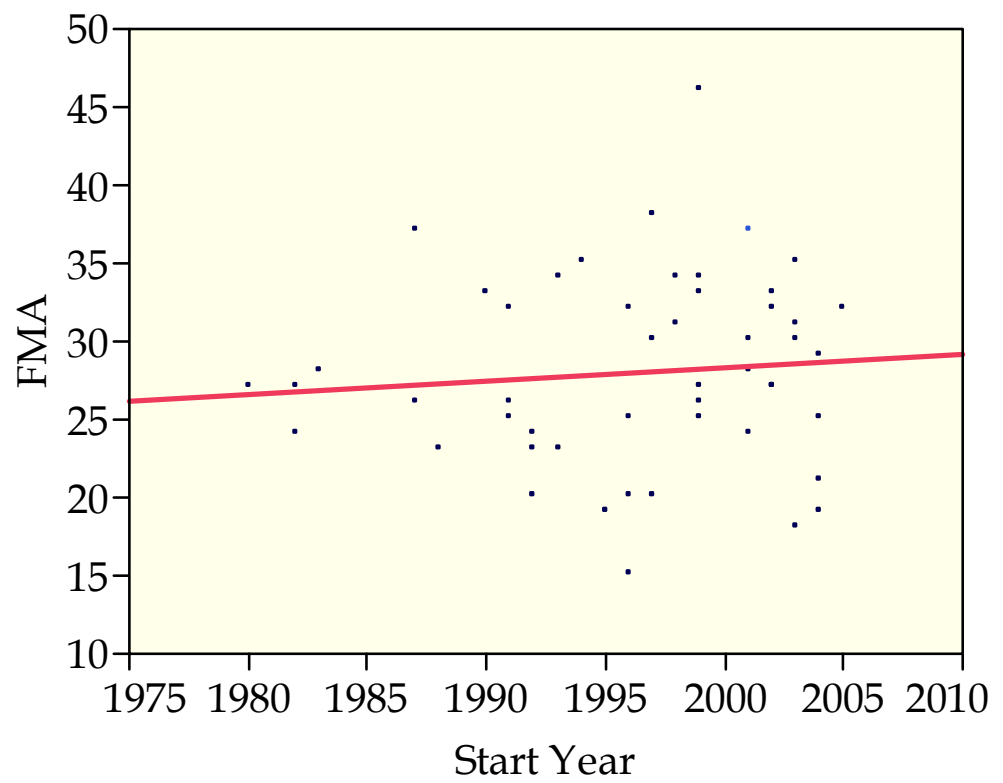

Figure 39. Plot generated by bivariate fit of FMA by start year for "other" patients only.

FMA has not significantly changed from 1980 to 2005: FMA $=-138.38+0.08$ (Start Year).

Table 26. Results of bivariate fit testing for a significant change in the FMA in "other" patients over the quarter century surveyed.

\begin{tabular}{lcccc}
\hline Term & Estimate & Std Error & t-test & P-value \\
\hline Intercept & -138.3856 & 268.7797 & -0.51 & 0.6090 \\
Start Year & 0.0833487 & 0.134641 & 0.62 & 0.5388 \\
\hline
\end{tabular}




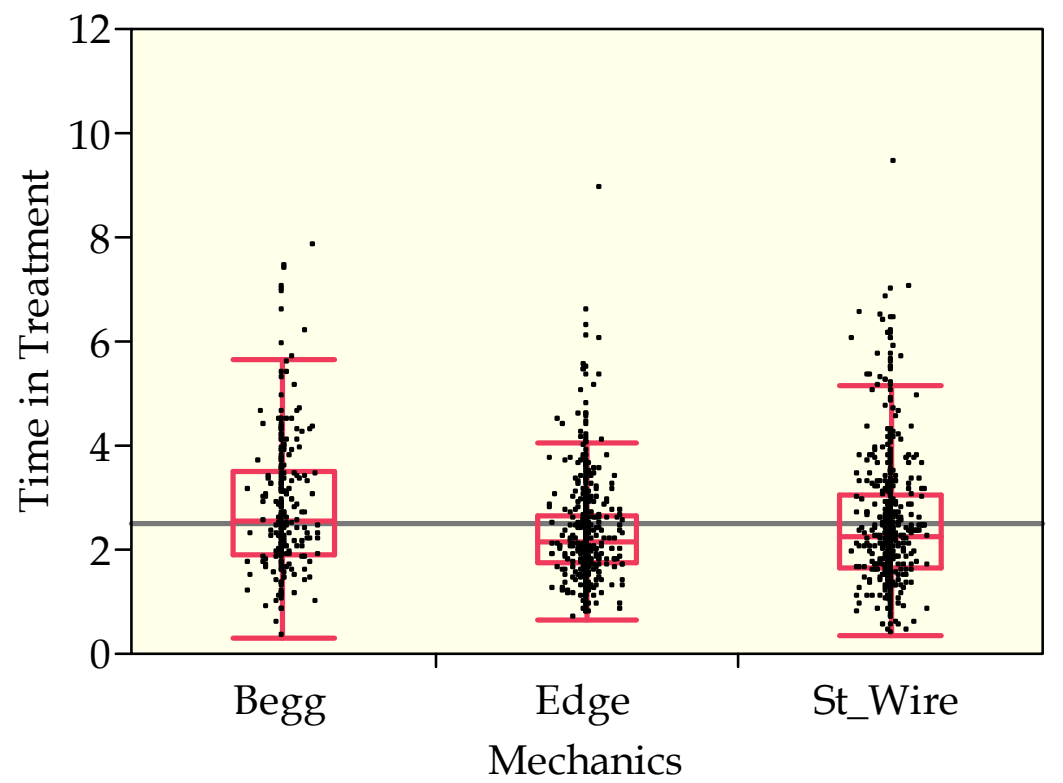

Figure 40. Plot of time in treatment by mechanics.

Begg treatment averaged 2.8 years, standard edgewise treatment averaged 2.3 years, and straight-wire edgewise averaged 2.5 years. Average treatment times were significantly different. 


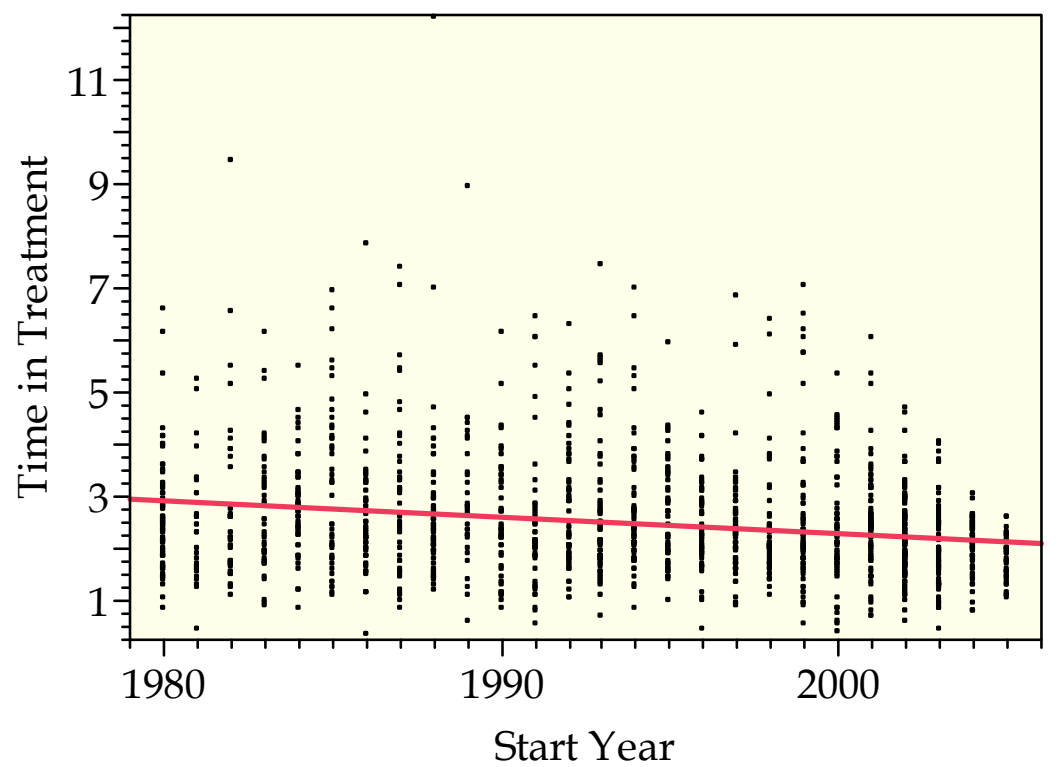

Figure 41. Plot generated by bivariate fit between the year of case start against time in treatment for all cases.

Time in treatment significantly decreased over the interval studied: Time in TX= 67.15 - 0.03(Start Year). Interpretation of this best-fit equation is that time in treatment diminished by 0.03 years per year, which is about $3 \frac{1}{2} 2$ months per decade.

Table 27. Results of bivariate fit testing for a significant change in time in treatment over the quarter century surveyed.

\begin{tabular}{lllcl}
\hline Term & Estimate & Std Error & t-test & P-value \\
\hline Intercept & 67.15206 & 8.376662 & 8.02 & $<0.0001$ \\
Start Year & -0.032436 & 0.004201 & -7.72 & $<0.0001$ \\
\hline
\end{tabular}




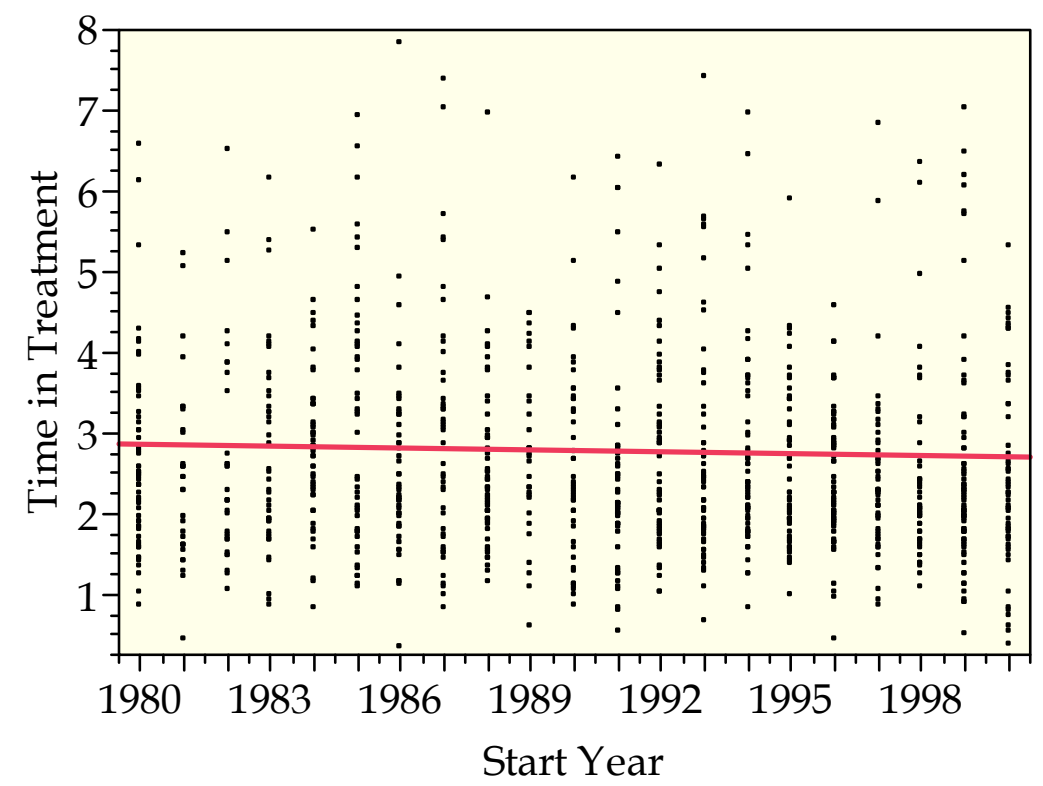

Figure 42. Plot generated by bivariate fit of time in treatment by start year for Begg cases only.

Time in treatment has not significantly decreased over the time studied for Begg mechanics: Time in TX $=18.58$ - 0.01(Start Year). Interpretation of this best-fit equation is that treatment time diminished by about 0.01 years per year, which is about one month per decade.

Table 28. Results of bivariate fit testing for a significant change in time in treatment for Begg cases over the quarter century surveyed.

\begin{tabular}{lcccc}
\hline Term & Estimate & Std Error & t-test & P-value \\
\hline Intercept & 18.582704 & 34.95218 & 0.53 & 0.5954 \\
Start Year & -0.007935 & 0.017589 & -0.45 & 0.6523 \\
\hline
\end{tabular}




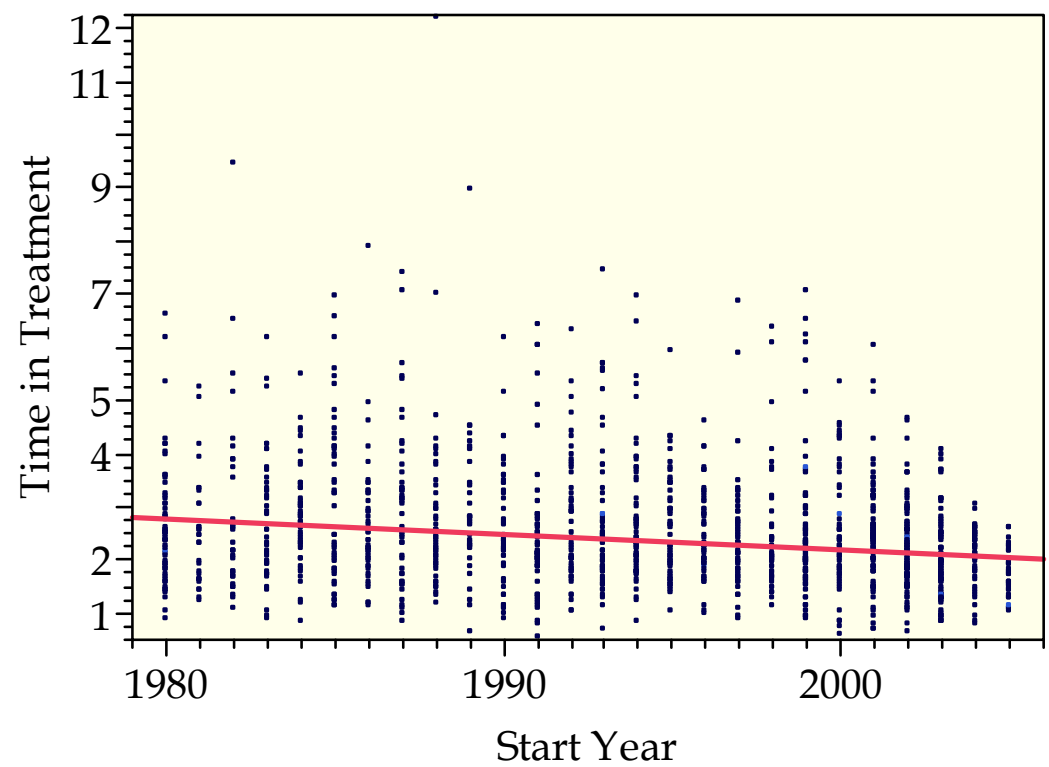

Figure 43. Plot generated by bivariate fit of time in treatment by start year for standard edgewise cases only.

Time in treatment has significantly decreased over the time studied for standard edgewise mechanics: Time in TX $=59.66-0.03$ (Start Year). This decrease translates to about 0.03 years per year, which is about $3 \frac{1}{2} 2$ months per decade (3.6 months).

Table 29. Results of bivariate fit testing for a significant change in time in treatment for standard edgewise cases over the quarter century surveyed.

\begin{tabular}{lcccc}
\hline Term & Estimate & Std Error & t-test & P-value \\
\hline Intercept & 59.658566 & 13.06305 & 4.57 & $<0.0001$ \\
Start Year & -0.028734 & 0.006546 & -4.39 & $<0.0001$ \\
\hline
\end{tabular}




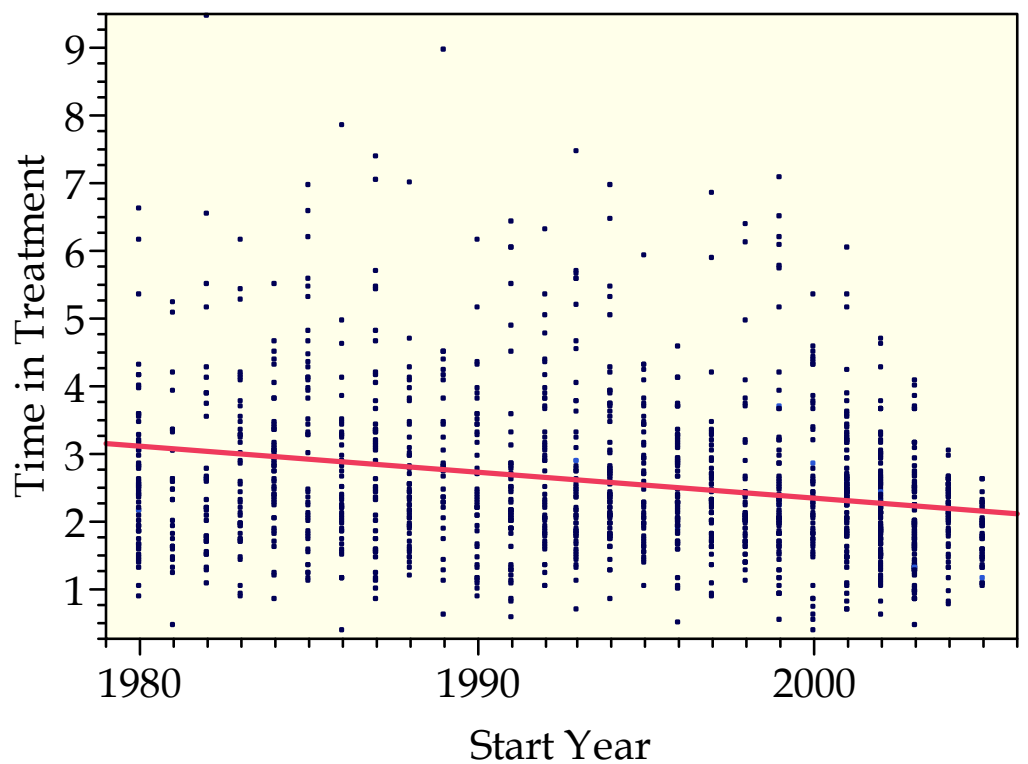

Figure 44. Plot generated by bivariate fit of time in treatment by start year for straight-wire cases only.

Time in treatment significantly decreased over the time studied for straight-wire mechanics: Time in TX $=80.06$ - 0.04(Start Year). This decrease is 0.04 years per year, which is about 4.7 months per decade. This is the largest of the changes observed.

Table 30. Results of bivariate fit testing for a significant change in time in treatment for straight-wire cases over the quarter century surveyed.

\begin{tabular}{lcccc}
\hline Term & Estimate & Std Error & t-test & P-value \\
\hline Intercept & 80.05632 & 13.95133 & 5.74 & $<0.0001$ \\
Start Year & -0.038869 & 0.006991 & -5.56 & $<0.0001$ \\
\hline
\end{tabular}


On average, TennCare patients spent slightly more time (2.64 years) in treatment than non-TennCare patients (2.47 years), although this difference was not significant $(\mathrm{F}=1.2 ; \mathrm{P}=0.28$; Figure 45).

\section{Treatment Duration, Angle Class and Extraction}

By two-way factorial ANOVA, both Angle classification ( $\mathrm{F}=19.9 ; \mathrm{P}<$ $0.0001)$ and whether or not extractions were part of treatment $(\mathrm{F}=37.5 ; \mathrm{P}<$ $0.0001)$ had a significant effect on treatment duration. When Angle class and extraction category were crossed (i.e., the interaction effect), $\mathrm{F}=3.2$ and $\mathrm{P}=$ 0.0117 . When controlling for extractions, the mean treatment time was 2.3 years for Class I patients, 2.6 years for Class II patients and 2.5 years for Class III patients. When controlling for Angle Class, the mean treatment time for nonextraction patients was 2.2 years and 2.7 years for extraction patients. Mean treatment times are graphed in Figure 46, and this shows the source of the significant interaction term. Begg treatment took longer on the average to treat Class I and Class II cases, but it seems to have been more efficient at treating Class II cases.

Archived cases from the Department of Orthodontics are coded to what extraction pattern (if any) was involved. For individual extraction patterns the mean time in treatment is as follows: Non-extraction, 2.25 years; 4 first premolars, 2.72 years; 4 second premolars, 2.52 years; maxillary first premolars and mandibular second premolars, 2.69 years; maxillary second premolars and mandibular first premolars, 2.59 years; and maxillary first premolars only, 2.69 years. A Tukey-Kramer HSD comparisons test showed that significant differences between treatment times existed between non-extraction and (1) four first premolar extraction $(\mathrm{P}<0.0001)$, (2) maxillary first and mandibular second premolar extraction $(\mathrm{P}=0.009)$, and (3) maxillary first premolar only extraction $(P=0.006)$, with extraction cases taking longer to treat than non-extraction cases. However, for cases with (1) all second premolars extracted, and (2) maxillary second premolars and mandibular first premolars extracted, there was no statistical difference in treatment time when compared to non-extraction or with any other extraction pattern. No extraction pattern was found to be significantly different in treatment time to any other extraction pattern. 


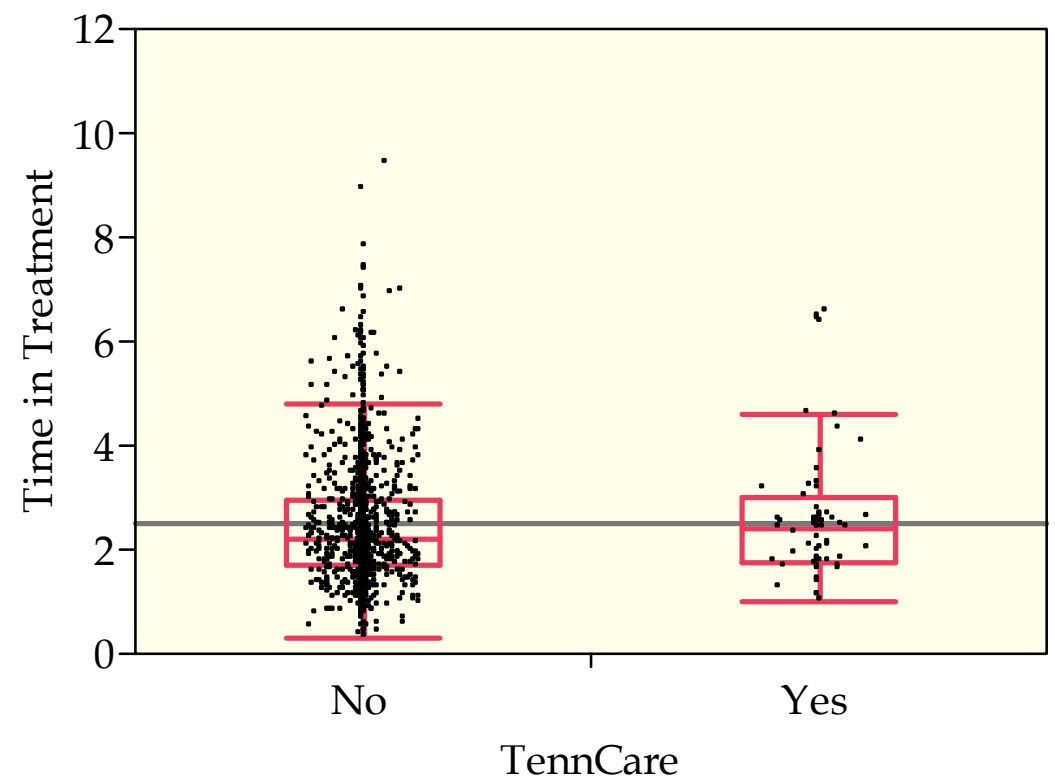

Figure 45. Plot of time in treatment by whether or not the patient had TennCare. TennCare patients did not significantly differ in time in treatment from nonTennCare patients.
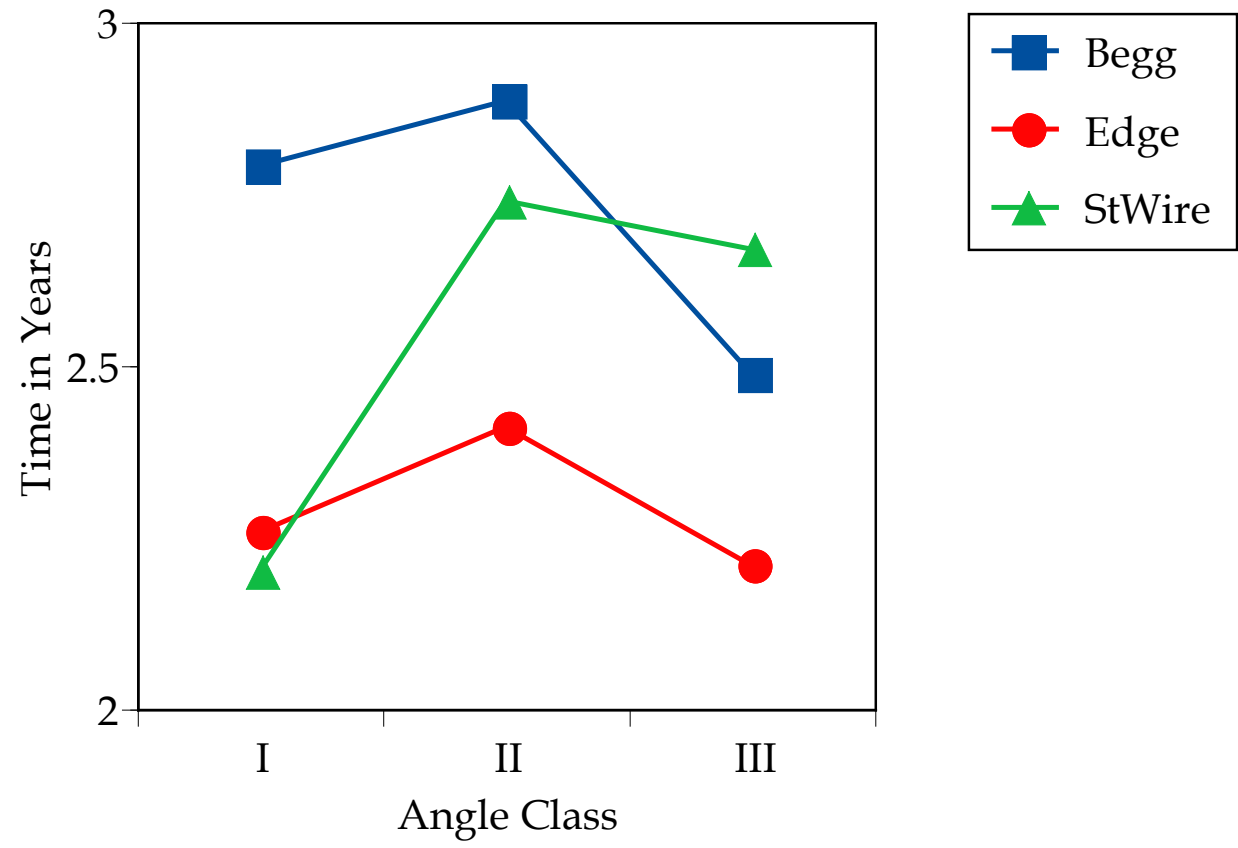

Figure 46. Mean treatment times for Begg, standard edgewise, and straight-wire edgewise mechanics by Angle class. 
The ANB angle and the FMA both showed small but significant effects on treatment time. As both the ANB angle $(P=0.0007)$ and the FMA $(P=0.02)$

increase, treatment time increases (Figure 47, Table 31 and Figure 48, Table 32). This increase treatment time is very small, only evident due to the large data set for this survey, and it has little or no clinical relevance $\left(\mathrm{r}^{2}=0.009\right.$ and $\mathrm{r}^{2}=0.004$, respectively). One might suppose that increasing ANB angle would increase treatment difficulty (as reflected in treatment time), so there would be a Ushaped line fitting the data (with the shortest time coinciding with ANB =0). In fact, cases with negative ANB angles evidently treated out rather quickly (Figure 47), whereas those with positive ANB angles (i.e., mandibular retrognathic cases) took the longest to complete.

\section{Treatment Duration and Race}

On average, Black patients took about 2 months longer to treat than White patients (Figure 49), although this difference was not significant $(\mathrm{F}=2.85 ; \mathrm{P}=$ $0.09)$. 


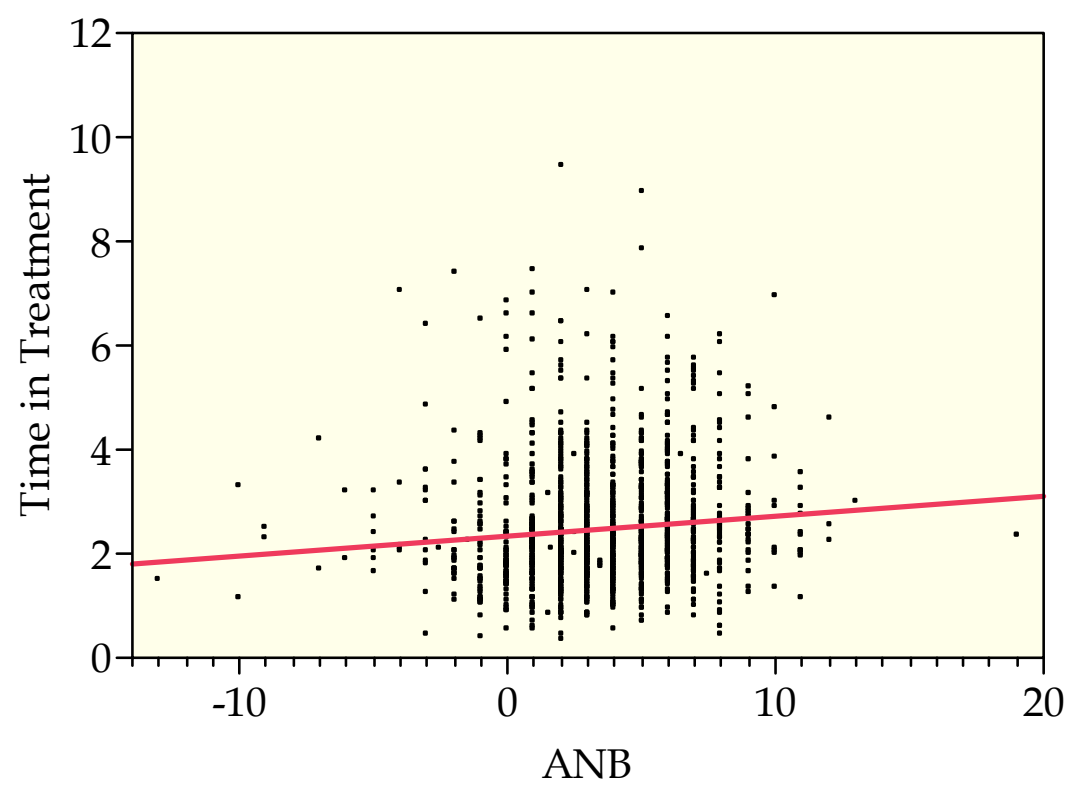

Figure 47. Plot generated by bivariate fit of time in treatment by ANB angle. As the ANB angle increases, time in treatment increases significantly: Time in $\mathrm{TX}=2.35+0.038(\mathrm{ANB})$. This equation can be read that each degree of positively increasing ANB adds an average of about $1 / 2$ month to treatment. While significant statistically, many other factors interfere with the precision of this trend.

Table 31. Results of bivariate fit testing for a significant change in time in treatment by ANB angle.

\begin{tabular}{llcrr}
\hline Term & Estimate & Std Error & t-test & P-value \\
\hline Intercept & 2.3498306 & 0.05148 & 45.65 & $<0.0001$ \\
Start Year & 0.0378335 & 0.011194 & 3.38 & 0.0007 \\
\hline
\end{tabular}




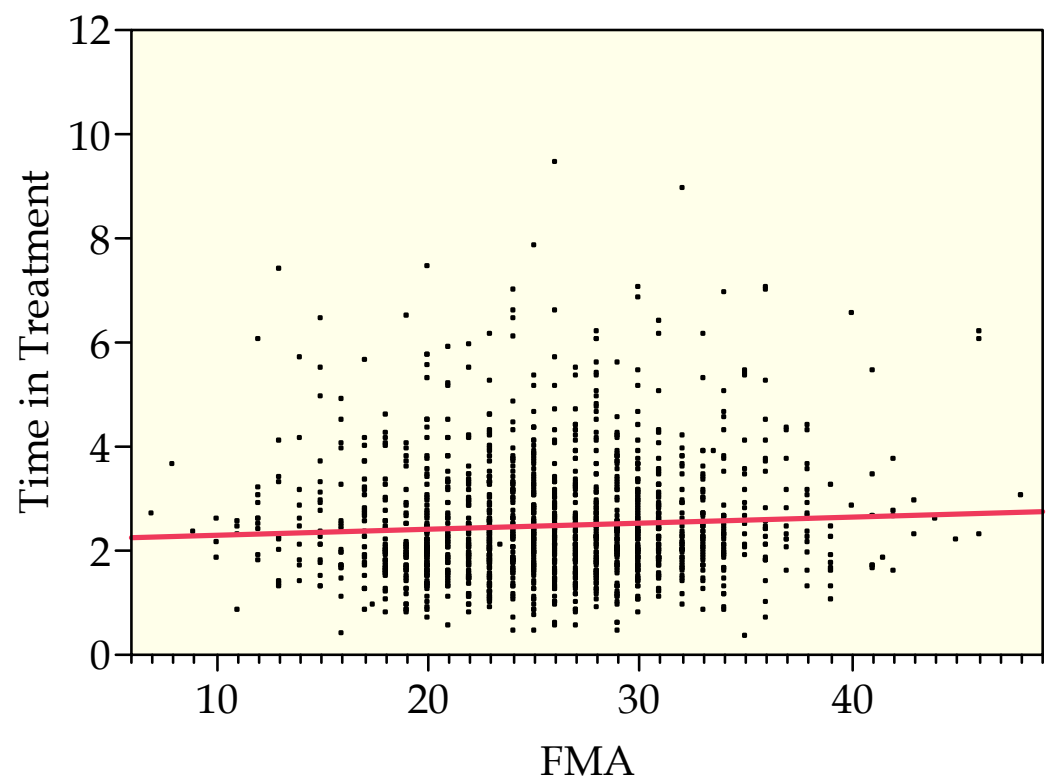

Figure 48. Plot generated by bivariate fit of time in treatment by the FMA. As the FMA increases, time in treatment increases significantly: Time in TX = $2.15+0.012$ (FMA).

Table 32. Results of bivariate fit testing for a significant change in time in treatment by the FMA.

\begin{tabular}{llrrr}
\hline Term & Estimate & Std Error & t-test & P-value \\
\hline Intercept & 2.1515567 & 0.139579 & 15.41 & $<0.0001$ \\
Start Year & 0.0124539 & 0.005245 & 2.37 & 0.0177 \\
\hline
\end{tabular}




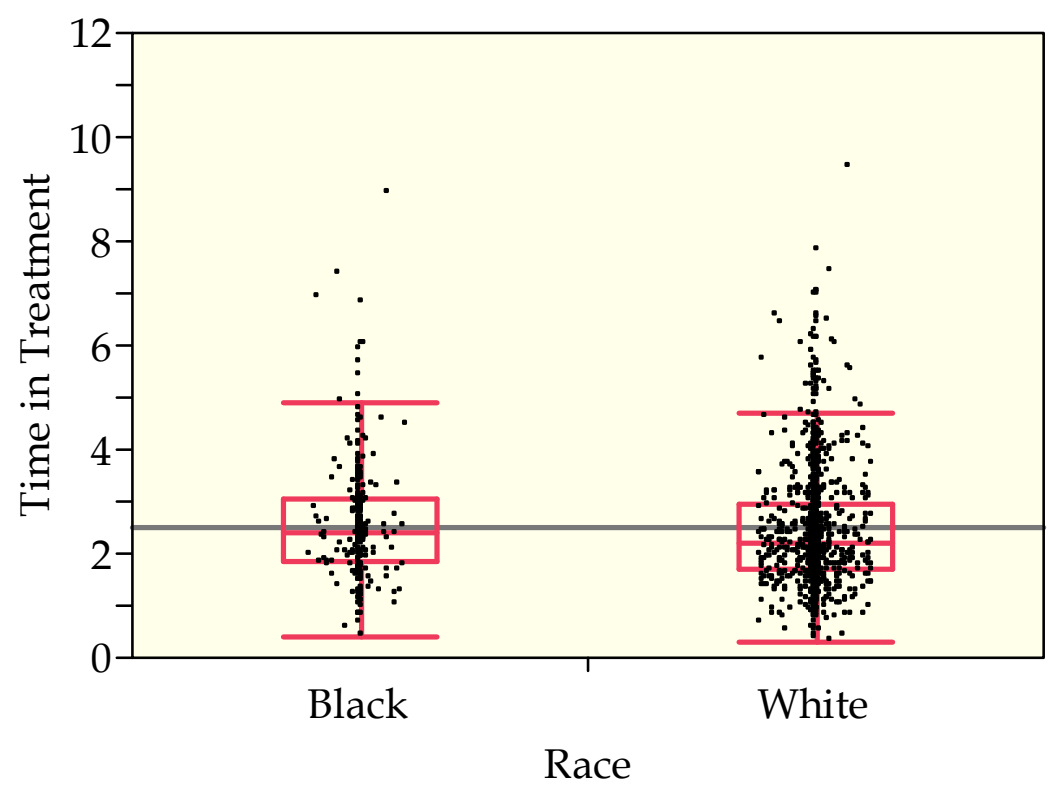

Figure 49. Plot of time in treatment by race.

Treatment time averaged 2.61 years for Black patients and 2.46 years for White patients. This difference was not significant $(P=0.09)$. 


\section{CHAPTER V: DISCUSSION}

\section{Ethnic Groups}

Although differences in malocclusion do exist among different racial and ethnic groups, there is no difference in the overall need for orthodontic treatment among groups (Kelley and Harvey 1977; Proffit et al. 1998). That being said, the racial proportions of our patient sample should mirror the proportions of the population of Memphis, but this is not the case. As shown in Table 33, Whites are over-represented in our patient sample $(75 \%)$ when compared to the population of Memphis (34\%), while Blacks are under-represented in our patient sample $(21 \%)$ compared to the population of Memphis (61\%). Other races or ethnic groups may be slightly over or under represented, but not nearly to the extents of Blacks and Whites (Table 33).

This discrepancy is consistent with reported literature showing that Whites are more likely to obtain orthodontic treatment. Okunseri et al., report that in a survey of over 14,000 households for the National Medical Expenditure Survey (MEPS 1996), of respondents claiming to have visited the orthodontist at least once in the past year, $85 \%$ were White, $4.5 \%$ were Black, $6.7 \%$ were Hispanic, 2.5\% were Asian and the rest were "other" (2007). Data from the NHANES III reveal that in the 8 to 17 age group $22.9 \%$ of Whites, $6.1 \%$ of Blacks, and $8.3 \%$ of Mexican-Americans had received orthodontic treatment (Proffit et al. 1998). The reasons for this racial discrepancy seem to be multi-factorial and include socioeconomic, educational, and cultural variables, as well as a decreased demand for orthodontics among Black parents compared to White parents. (Wheeler et al. 1994; Okunseri et al. 2007).

Table 33. Proportions of the total sample by race compared with the respective proportions in the population of the city of Memphis.

\begin{tabular}{lcrc}
\hline Race & Count & Percent & Memphis \\
\hline Asian & 29 & 1.799 & 1.5 \\
Black & 342 & 21.216 & 61.4 \\
Hispanic & 7 & 0.434 & 3.0 \\
Indian & 11 & 0.682 & 0.3 \\
Islander & 1 & 0.062 & 0.0 \\
Mideast & 5 & 0.310 & - \\
White & 1217 & 75.496 & 34.4 \\
\hline
\end{tabular}

Source: U.S. Census 2000. 
While a racial/ethnic disparity in orthodontic treatment does exist, in our sample this disparity was found to be decreasing over the time interval. From 1980 to 2005 there was a significant increase of both Black and "other" patients compared to White patients. This increase is promising and may reflect a greater demand for treatment, an increase in access to treatment, and an increase in awareness concerning orthodontic treatment among Blacks and minorities. The increase in treatment of non-White patients seen in the present sample was also found by Manski et al. who report that from 1987 to 1996 the percentage of nonWhite patients visiting an orthodontist increased significantly from $1.5 \%$ to $2.1 \%$ (2000).

TennCare, Tennessee's Medicaid program, may have something to do with greater access to care among the urban poor in Memphis. The population demographic of the city of Memphis where the University clinic is located is predominantly an inner-city Black population. In 1999, a faculty member in the department of orthodontics became a TennCare provider and since then there has been a significant increase in TennCare patients seen at the Department of Orthodontics. This increased access to care at the University Clinic may contribute to the increase in non-White patients. While only $5 \%$ of all patients in the sample were subsidized by TennCare, $22 \%$ of Black patients were.

\section{$\underline{\text { Sex Distribution }}$}

National surveys of the occlusal needs of youths in the United States show that the frequencies and severities of maloclussion are the same in boys and girls, especially after accounting for the greater uptake of orthodontic services by females (Kelly and Harvey 1977; Brunelle et al. 1996; Proffit et al. 1998). And yet, evidently because of greater esthetic concerns by girls and their parents, orthodontic practices consist of a preponderance of girls. Of note, actual data confirming this sex difference in the actual uptake of orthodontic services are rare. Although the literature agrees that girls do not have a greater need for orthodontics (Tang and So 1994; Wheeler et al. 1994; Birkeland et al. 1996; Kelley and Harvey 1997; Al Yami et al. 1998; Leipa et al. 2003; and Souames et al. 2006), significantly more girls than boys receive orthodontic treatment (Kelly and Harvey 1977; Wheeler, et al. 1994; Brunelle, et al. 1996; Al Yami et al. 1998).

Our results agree with the literature and reveal that $59 \%$ of the sample (n $=6,927$ ) is female, a highly significant difference from an expected 50:50 ratio of males to females. This 6-to-4 female-to-male ratio of orthodontic patients has also been found by other researchers. In a survey of 1,000 consecutively treated patients in Britain, and almost 1,500 patients in Belgium, this same ratio was reported (Rose 1974; Willems et al. 2001). This ratio also appears in a British 
study of patients referred for orthodontic treatment in a socialized medical system. Of those referred, $62 \%$ of the patients accepted for orthodontic treatment were female and only $38 \%$ were male ( $\mathrm{O}^{\prime}$ Brien et al. 1996). Likewise, a random assessment of 920 orthodontic patients in the Netherlands revealed that $56 \%$ of those patients treated were female. It appears that this 6 to 4 ratio of female to male patients, or a ratio close to it, may be rather universal in westernized countries.

Of note, this ratio did not change over the studied time interval. We found no literature that has specifically investigated the sex ratio of orthodontic patients through time, however, data from the NHANES III suggests that the disparity between boys and girls being treated orthodontically may have decreased. That study divided patients into adult and child/adolescent groups. While a greater percentage of both adult and child/adolescent girls had received orthodontic treatment when compared to boys, more boys and fewer girls in the younger age group are receiving treatment when compared to the older age group (Brunelle et al. 1996).

Sex role stereotyping, where parents and society place a greater emphasis on female physical beauty, is well documented in the literature (Prahl-Andersen 1978; Shaw 1991). This, combined with the fact that girls are more critical of their dental appearance and express a higher desire for orthodontic treatment (Shaw 1981; Liepa et al. 2003; O'Brien et al. 2006) explain why more girls than boys receive orthodontic treatment although there are no sex differences in malocclusion or treatment need.

\section{$\underline{\text { Angle Classification }}$}

In the present sample Angle Class II cases was the most common molar relationship encountered (50\%), followed by Class I cases at $41 \%$ and Class III cases at about $9 \%$. This is substantially different from proportions found in the general population where $53 \%$ of children are Class I, 32\% are Class II, and 14\% are Class III (Kelly and Harvey 1977). When evaluating the sample, it is important to remember that these are cases that were treated at the University Clinic and therefore are more likely than untreated or mixed treated/untreated samples to contain malocclusions, specifically Class II and Class III cases.

Reports on Angle Classification are widely varied (Table 34), but our results are somewhat similar to results found by Willems on 1,500 Belgian orthodontic patients (2001). Willems' data also revealed a preponderance of Class II cases, likely for the same reason our data did: people who have more severe malocclusion are more likely to become orthodontic patients. The only 
Table 34. Proportions of Angle Class from various studies. ${ }^{1}$

\begin{tabular}{lcccl}
\hline Study & Class I & Class II & Class III & Race/Sample \\
\hline Angle (1907) & 69.2 & 21.6 & 4.2 & White,ortho \\
Massler (1951) & 50.0 & 19.4 & 9.0 & White,mixed \\
Altemus (1957) & 66.4 & 12.0 & 5.0 & Black,mixed \\
Emrich (1965) & 85 & 14 & 1 & Mixed,mixed \\
Kelly, Mixed (1977) & 53 & 32 & 14 & Mixed,mixed \\
Kelly, Black (1977) & 62 & 18.0 & 18.6 & Black,mixed \\
Kelly, White (1977) & 52 & 33.6 & 13.0 & White,mixed \\
Willems (2001) & 31 & 62 & 6 & Mixed,ortho \\
Current Study, Mixed & 41 & 50 & 9 & Mixed,ortho \\
Current Study, Black & 51 & 31 & 17 & Black,ortho \\
Current Study, White & 42 & 51 & 7 & White,ortho \\
\hline
\end{tabular}

${ }^{1}$ Coding defines: 1) whether a study is based on a Black, White, or unspecified mixed race sample, and 2) whether the sample consisted of orthodontic patients only, or a mixed treated and untreated sample.

other non-mixed sample found was in a report by E.H. Angle in 1907 where the majority of his patients (69\%) were Class I.

The Black-White difference in Angle Classification reported in the literature (Kelley and Harvey 1977) is mirrored in the current sample. Blacks are more likely to have a Class I ( $51 \%$ vs $42 \%$ ) or Class III (17\% vs $7 \%$ ) malocclusion than Whites, while Whites are more likely to have a Class II malocclusion than Blacks (51\% vs 31\%). Altemus (1957) reported on a Black sample and found a much lower percentage of Class III Black patients (5\%) than in the current study $(17 \%)$, however, his sample was a mixed sample of treated and untreated children compared to our sample consisting of those actually being treated because of a malocclusion. Still, the percentage of Black Class III patients from the Altemus study is low compared to the mixed treated/untreated sample of Kelly and Harvey (1977).

Interestingly, over the 26 years surveyed, the ratio of Angle Classes has changed significantly. Comparatively more Class I patients are being treated compared to Class II patients and more Class III patients are being treated compared to Class II patients. Although the reasons for these changes are not clear, some hypotheses can be formed. It may be that as the University struggles to maintain a high volume of "good teaching cases" for its graduate students, the standard of difficulty for a patient to be accepted into the program has declined. If true, this may explain the increase of Class I cases compared to Class II cases, as "easier" patients are accepted for treatment. The increase of Class III cases 
compared to Class II cases could at least partially be explained by the fact that relatively more Black patients (with a higher incidence of Class III malocclusion) compared to White patients (with a higher incidence of Class II malocclusion) are being seen in the University Clinic over the surveyed time.

\section{Orthognathic Surgery}

According to Dr. Jimmy Albright, a long time faculty member of the Department of Oral Surgery at the University, the reason for the decline in orthognathic surgery case is due to the fact that the faculty of the Department of Orthodontics refers fewer patients for orthognathic procedures than they did in the past. Albright and his team perform the same number of orthognathic procedures that they always have, just with fewer of the referrals coming from the orthodontic department (Albright, pers. comm.). There are several possible reasons that the Department of Orthodontics refers fewer patients for surgical procedures. These include an increase in the use of functional appliances, such as the Herbst, the MARA, and the bionator, and an increase in early treatment in the department.

\section{$\underline{\text { Treatment Mechanics }}$}

Orthodontic treatment mechanics at the University over the time surveyed can be grouped into three types: Begg mechanics, standard edgewise mechanics (Tweed), and straight-wire edgewise mechanics. Students are assigned specific numbers of patients to certain instructors who treat in one of the above categories. Consequently, trying to compare treatment mechanics at the University to anything going on in private practice would be somewhat artificial. In 1999, the University discontinued Begg mechanics as a treatment modality. This reflected a national trend away from Begg treatment, which was once very popular, especially in the U.S. South. As Begg mechanics, once the predominant method taught at the school, was discontinued, standard edgewise and straightwire edgewise cases both increased to roughly $50 \%$ of treated cases and this 1:1 ratio has not changed significantly in the quarter-century surveyed. As stated, this ratio is artificial and does not compare to anything happening at any geographical level because each student is assigned specific cases to specific teachers by the clinic director or department chair. In fact, the majority of practitioners in the United States do not use a standard-edgewise appliance, but rather a straight-wire edgewise appliance. 


\section{Extraction Frequency}

The frequency of extractions as a part of orthodontic treatment was found to decline over the quarter-century surveyed in this study. Overall, extraction cases made up over $70 \%$ of all cases in 1980 . This percentage is much higher than reported by Peck and Peck (42\% in 1979), Ricketts (33\% in 1976), and Weintraub (39\% average in 1986), but lower than Tweed who reported extractions in $80 \%$ of patients in 1966 (Peck and Peck 1979). The incidence of extractions as part of treatment steadily declined over the time interval to roughly $40 \%$ of all cases in 2005. Furthermore, this decline in extraction treatment is evident within each of the three types of treatment mechanics taught at the university, namely Begg, standard edgewise, and straight-wire edgewise. Of note, extraction in standard edgewise treatment fell from roughly $85 \%$, a little bit higher than what was reported by Charles Tweed (1966), to about $50 \%$ of cases, the percentage of which Tweed (1945) once thought that four premolar extractions were necessary.

The decrease in orthodontic extractions over time is evident from the literature. Brian and $\mathrm{O}^{\prime}$ Connor (1993) found a $22 \%$ decline in extractions from 1984 to 1989 with more than $50 \%$ of orthodontists surveyed reporting a decrease in extraction frequency. This number may, however, be inaccurate. Weintraub reported in 1989 that orthodontists' self-estimations of extraction percentages were often inaccurate, with reported extraction rates ranging from a $20 \%$ overestimation, to a $15 \%$ underestimation. Proffit (1994), in a study similar to the present one, conducted at the University of North Carolina, found a fluctuating extraction frequency that went from $30 \%$ in 1953 , to $76 \%$ by 1968 , and slowly back down to $28 \%$ in 1993 , which is considerably lower than the extraction rate at the University of Tennessee in 1993 (over 55\%).

Reasons for the decrease in extraction frequency probably are varied. A desire for improved facial esthetics, TMJ concerns, medico-legal concerns, increased use of functional appliances and palatal expansion, and the use of bonded brackets rather than bands, have all been attributed to decreased extraction frequency (Weintrab 1989; Brian and O'Connor 1993; Proffit 1994).

\section{Treatment Duration}

Treatment Duration at the University of Tennessee averaged 30 months. This is on the higher end of the spectrum reported in the literature, which ranged from 22 to 31 months (Vig et al. 1990; Fink and Smith 1992; Alger 1998). Factors such as the student learning curve, student breaks, patient transfers, and limited appointment availability of faculty members, no doubt, increase treatment time in this university setting compared to a private practice setting. 
Factors found to have a significant influence on treatment time include type of mechanics, Angle Classification, whether or not extractions were performed, FMA, and ANB angle. On average, Begg cases (34 months) took longer to treat than straight-wire edgewise cases (30 months), which took longer to treat than standard edgewise cases (28 months). Reasons for this are not entirely clear, but can be hypothesized. Begg mechanics may take longer than the other mechanics, because of a steep learning curve, while straight-wire edgewise mechanics may take longer than standard edgewise mechanics because practitioners are more likely to employ phased treatment or use functional appliances or palatal expanders .

Extraction of (1) four first premolars (2.72 years), (2) maxillary first premolars and mandibular second premolars (2.69 years), and (3) maxillary first premolars only ( 2.69 years) were all found to significantly increase treatment time compared to non-extraction treatment (2.25 years). However, cases with the extraction patterns of (1) all second premolars and (2) maxillary second premolars and mandibular first premolars, there was no significant difference in treatment time when compared to non-extraction. No individual extraction pattern was found to be significantly different from any other extraction pattern in regards to treatment time.

Depending on the extraction pattern, the significant increase in treatment time for extraction treatment ranges from 3.2 months to 5.6 months. These increases are comparable to Fink and Smith (1992) and Alger (1998) who report that extraction increases treatment time by 3.6 months and 4.6 months, respectively.

Angle classification also had a significant effect on treatment duration. After controlling for extractions, the mean treatment time was 2.3 years for Class I patients, 2.6 years for Class II patients, and 2.5 years for Class III patients.

The cephalometric variables investigated in this study, the FMA and ANB angle, both were found to have a significant effect on treatment duration, with larger angles correlating with an increase in treatment time. Each degree increase in the ANB was associated with an increase in treatment time of almost half a month. This is consistent with the findings of Fink and Smith who found an increase in treatment time with an increasing ANB (1992). The effect of FMA on treatment time is significant, but not clinically relevant and is only evident due to the large sample in this study. Our findings, that treatment time only increased 5 days a year per degree increase in FMA, are at odds with Fink and Smith who report a 0.3 months per degree decrease in treatment time (1992). 
Throughout the quarter-century surveyed in this study, there is a decrease in the overall treatment time for standard edgewise and straight-wire edgewise cases, but no change in the Begg cases. Treatment time decreased 3.6 months per decade for standard edgewise cases, and 4.7 months per decade in straight-wire cases. Reasons for this decrease are unclear but can be hypothesized. In 1998 the orthodontic program went from a 2 year to a 3 year program, most likely decreasing treatment time by decreasing patient transfers among students. A new chairman who started in 1999 also began to implement new policies and hire more full time faculty which may have led to a decrease in treatment time. It is also probable that the patients being treated more recently have less severe malocclusions than those treated more towards the beginning of the surveyed interval. As the clinic struggles to maintain enough "good teaching cases" for each student, less severe cases are admitted as become patients. This idea is supported by findings in the current study that more Class I cases are being treated compared to Class II cases as time moves forward over the surveyed period (Figure 7). 


\section{CHAPTER VI: SUMMARY AND CONCLUSIONS}

The present study provides a unique look into orthodontic treatment at a graduate orthodontic clinic. Patient demographics, dental and skeletal relationships, and treatment variables, as well as temporal trends, reveal who is actually seeking orthodontic treatment, receiving that treatment, what type of treatment was received, and how all of these variables have changed over time. This information not only adds to the orthodontic literature, but provides a valuable "audit" of orthodontic treatment at The University of Tennessee Graduate Orthodontic Clinic from 1980 to 2005. Major findings of this research are:

1. Black patients are grossly under-represented in the patient population, but the frequency of Black patients and "other" non-White patients have significantly increased compared to White patients over the quartercentury surveyed.

2. The ratio of girls to boys treated orthodontically is 6:4. This ratio has not changed over the surveyed time interval and reflects the greater esthetic concern for girls compared to boys that is well documented in the literature.

3. Fifty percent of the cases surveyed exhibit an Angle Class II molar relationship, 41\% exhibit Class I relationship, and 9\% exhibit a Class III relationship. Over time, this ratio has changed as comparatively more Class I patients are being treated compared to Class II patients, suggesting either that more patients with less severe malocclusions are seeking treatment or that the clinic is accepting less severe malocclusions for treatment.

4. A Class III molar relationship is more common in Black patients $(17 \%)$ than White patients $(7 \%)$, while a Class II relationship is more common in Whites (51\%) than Blacks (31\%). This difference is well documented in the national epidemiological studies of occlusion.

5. Two percent of patients treated at the graduate clinic received treatment that involved orthognathic surgery. Over time the frequency of surgical procedures has decreased. This decrease is thought to occur because orthodontic treatment planning at the clinic is less likely to involve orthognathic surgery, perhaps because this treatment is expensive and it is increasingly difficult to receive insurance approval for such procedures.

6. Over the surveyed time interval, there was a significant increase in the age of patients, reflecting a greater desire for adult orthodontic treatment as time went forward.

7. Treatment with Begg mechanics, once the most common technique at the University, ceased in 1999. Discounting Begg mechanics, slightly more 
patients were treated with a straight-wire edgewise appliance (53\%) than a standard edgewise appliance (47\%), and this ratio did not change over time.

8. Extraction cases of all types decreased over time from above $70 \%$ down to below $50 \%$ of all cases. Treatment with Begg, straight-wire, and standard edgewise mechanics all showed a decrease in extraction frequency over time. The reason for this decrease is multifactorial, but involves an increased concern for patient esthetics, TMD concerns, and the use of functional appliances and palatal expansion.

9. Over the surveyed time $52 \%$ of Class I patients, $60 \%$ of Class II patients, and $46 \%$ of Class III patients were treated with extraction.

10. Approximately $5 \%$ of all cases and $9 \%$ of cases treated from 2000 to 2005 were subsidized for treatment by TennCare. The number of these cases increased over the surveyed time interval.

11. Non-extraction treatment was only found to be of shorter duration when compared to three extraction patterns (4-4/4-4, 4-4/5-5, and 4-4/0-0); no other extraction pattern involving premolars was found to be of longer duration than non-extraction, and treatment duration difference between all extraction patterns were not significant. After controlling for Angle Class, non extraction treatment averaged 2.2 years, while extraction treatment averaged 2.7 years.

12. The average duration of treatment is 2.5 years for all cases, 2.8 years for Begg cases, 2.3 years for standard edgewise cases, and 2.5 years for straight-wire edgewise cases. Treatment duration decreased over time possibly due to many factors, but most likely because of an increase in the number of patients with less severe malocclusions.

13. After excluding the effects of extraction on treatment time, the mean treatment time was 2.3 years for Class I patients, 2.6 years for Class II patients, and 2.5 years for Class III patients.

14. Treatment time increased as the ANB angle increased and the FMA increased. Although the treatment time increase is significant, it is so small that it is clinically imperceptible.

The present study, because of its size and scope, encountered certain limitations. Future studies, more likely on a smaller scale, could look more closely at factors affecting treatment time. The number of broken appointments and phased treatment were not examined in this study and both have a significant effect on treatment duration. The number of patient visits, rather than calendar time may be a better indicator of treatment duration. This study also fails to account for how the outcome of orthodontic treatment affects treatment duration and any future studies may want to account for this factor. 


\section{LIST OF REFERENCES}

Albino JE. Psychosocial factors in orthodontic treatment. NYS Dental J 1984:4869.

Al Yami EA, Kuijpers-Jagtman AM, van't Hof MA. Orthodontic treatment need prior to treatment and 5 years post retention. Community Dent Oral Epidemiol 1996;26:421-7.

Alger DW. Appointment frequency versus treatment time. Am J Orthod Dentofacial Orthop 1988;94:436-9.

Angle EH. Malocclusion of the teeth. 7th ed. Philadelphia: S.S. White Mfg. Co., 1907.

Arya BS, Savara BS, Thomas D, Clarkson Q. Relation of sex and occlusion to mesiodistal tooth size. Am J Orthod 1974;66:479-86.

Beckwith FR, Ackerman RJ, Cobb CM, Tira DE. An evaluation of factors affecting duration of orthodontic treatment. Am J Orthod Dentofacial Orthop 1999;115:439-47.

Begg PR. Stone age man's dentition. Am J Orthod 1954;40:289-312.

Birkeland K, Boe OE, Wisth PJ. Orthodontic concern among 11-year-old children and their parents compared with orthodontic treatment need assessed by index of orthodontic treatment need. Am J Orthod Dentofacial Orthop 1996;110:197-205.

Brunelle JA, Bhat M, Lipton JA. Prevalence and distribution of selected occlusal characteristics in the US population, 1988-1991. J Dent Res 1996;75:706-13.

Buttke TM, Proffit WR. Referring adult patients for orthodontic treatment. J Am Dent Assoc 1999;130:73-9.

Ciuffolo F, Manzoli L, D'Attilio M, Tecco S, Muratore F, Festa F, Romano F. Prevalence and distribution by gender of occlusal characteristics in a sample of Italian secondary school students: a cross sectional study. Eur J Orthod 2005;27:601-6.

Edgar HJ, Hunley KL. Race reconciled? How biological anthropologists view human variation. Am J Phys Anthropol 2009;139:1-4.

Emrich RE, Brodie AG, Blayney JR. Prevalence of Class I, Class II, and Class III malocclusions (Angle) in an urban population: an epidemiological study. J Dent Res 1965;44:947-53.

Fink DF, Smith RJ. The duration of orthodontic treatment. Am J Orthod Dentofacial Orthop 1992;102:45-51.

Freund RJ, Littell RC. SAS system for regression. 2nd ed. SAS Institute Incorporated, Gary, NC., 1991.

Guay AH, Brown LJ, Wall T. Orthodontic dental patients and expenditures2004. Am J Orthod Dentofacial Orthop 2008;134:337-43. 
Huang GJ, Marston BE, del Aguila MA. Orthodontic care in an insured population in Washington: demographic factors. Am J Orthod Dentofacial Orthop 2004; 125:741- 6.

Jenny J. A social perspective on need and demand for orthodontic treatment. Int Dent J 1975;25:248-53.

Keim RG, Gottleib EL, Nelson AH, Vogels DS 3rd. 2005 JCO Orthodontic Practice Study. Part 1: trends. J Clin Orthod 2005;39:641-50.

Kelly JE, Harvey CR. An assessment of the occlusion of the teeth of youths 12-17 years, United States. Rockville, MD: Health Resources Administration, National Center for Health Statistics 1977.

Leipa A, Urtane I, Richmond S, Dunstan F. Orthodontic treatment need in Latvia. Eur J Orthod 2003;25:279-84.

Manski RJ, Davidson WM, Moeller JF. Orthodontic dental visits during 1987 and 1996. Am J Orthod Dentofacial Orthop 2000;118:10-3.

Massler M, Frankel JM. Prevalence of malocclusion in children aged 14 to 18 years. Am J Orthod 1951;37:751-68.

Montagu A. The concept of race. New York: Free Press, 1964.

O'Brien K, McComb JL, Fox N, Wright J. Factors influencing the uptake of orthodontic treatment. Br J Orthod 1996;23:331-4.

O'Brien K, Wright JL, Conboy F, Macfarlane T, Mandall N. The child perception questionnaire is valid for malocclusions in the United Kingdom. Am J Orthod Dentofacial Orthop 2006;129:536-40.

O'Connor BMP. Contemporary trends in orthodontic practice: a national survey. Am J Orthod Dentofacial Orthop 1993;103:163-70.

Okunseri C, Pajewski NM, McGinley EL, Hoffmann RG. Racial/ethnic disparities in self-reported pediatric orthodontic visits in the united states. J Public Health Dent 2007;67:217-23.

Peck S, Peck H. Frequency of tooth extraction in orthodontic treatment. Am J Orthod 1979;76:491-6.

Prahl-Andersen B. The need for orthodontic treatment. Angle Orthod 1978;48:19.

Proffit WR. Forty year review of extraction frequencies at a university orthodontic clinic. Angle Orthod 1994;64:407-14.

Proffit WR, Fields HW, Moray LJ. Prevalence of malocclusion and orthodontic treatment need in the United States: estimates from the NHANES III survey. Int J Adult Orthod Orthognath Surg 1998;13:97-106.

Riedel RA. The relation of maxillary structures to cranium in malocclusion and normal occlusion. Angle Orthod 1952;22:142-5.

Rose JS. A thousand consecutive treated orthodontic cases - a survey. Br J Orthod 1974;1:45-54.

Salzmann JA. Handicapping malocclusion assessment to establish treatment priority. Am J Orthod 1968;54:749-65. 
Shaw WC. Factors influencing the desire for orthodontic treatment. Eur J Orthod 1981;3:151-62.

Shaw WC, O'Brien KD, Richmond S. Quality control in orthodontics: factors influencing the receipt of orthodontic treatment. British Dental J 1991;170:66-8.

Souames M, Bassigny F, Zenati N, Riordan PJ, Boy-Lefevere ML. Orthodontic treatment need in French schoolchildren: an epidemiological study using the index of orthodontic treatment need. Eur J Orthod 2006;28:605-9.

Steiner CC. Cephalometrics for you and me. Am J Orthod and Oral Surg 1953;39:729-54.

Tang ENK, So LLY. Correlation of orthodontic treatment demand with treatment need assessed using two indices. Angle Orthod 1995; 65:443-50.

Tweed CH. A philosophy of othodontic treatment. Am J Orthod 1945;31:74-85.

Tweed $\mathrm{CH}$. The frankfort mandibular plane angle in orthodontic diagnosis, classification, treatment planning, and prognosis. Am J Orthod Oral Surg 1946;32:175-230.

Vig PS, Weintraub JA, Brown C, Kowalski CJ. The duration of orthodontic treatment with and without extractions: a pilot study of five selected practices. Am J Orthod Dentofacial Orthop 1990;97:45-51.

Wheeler TT, McGorray SP, Yurkiewicz L, Keeling SD, King GJ. Orthodontic treatment demand and need in third and fourth grade schoolchildren. Am J Orthod Dentofacial Orthop 1994;106:22-33.

Weintraub JA, Vig PS, Brown C, Kowalski CJ. The prevalence of orthodontic extractions. Am J Orthod Dentofacial Orthop 1989;96:462-6.

Whitesides J, Pajewski NM, Bradley TG, Iacopino AM, Okunseri C. Sociodemographics of adult orthodontic visits in the United States. Am J Orthod Dentofacial Orthop 2007;133:489e9-e14.

Willems G, De Bruyne I, Verdonk A, Fieuws S, Carels C. Prevalence of dentofacial characteristics in a Belgian orthodontic population. Clin Oral Invest 2001;5:220-6.

Zhang M, McGrath C, Hägg U. The impact of malocclusion and its treatment on quality of life: a literature review. Int J Paediatr Dent 2006;16:381-7. 


\section{VITA}

Allen Brian Anderson, the son of Dr. and Mrs. Allen F. Anderson, was born on April 18, 1977 and is a native of Nashville, Tennessee. Brian graduated from Montgomery Bell Academy in 1995 and attended Rhodes College, where he received a Bachelor of Arts degree in History in 1999. He received his Doctor of Dental Surgery degree from The University of Tennessee College of Dentistry in 2006, where he graduated with highest honors and as a member of the Omicron Kappa Upsilon honor dental society. Following dental school, he entered the University of Tennessee Health Science Center as a graduate student in the Department of Orthodontics and is expected to receive his Master of Dental Science degree in May 2010. 